\title{
Directed blasts and blast-generated pyroclastic density currents: a comparison of the Bezymianny 1956, Mount St Helens 1980, and Soufrière Hills, Montserrat 1997 eruptions and deposits
}

\author{
Alexander Belousov • Barry Voight • Marina Belousova
}

Received: 4 August 2004 / Accepted: 13 October 2006

(C) Springer-Verlag 2007

\begin{abstract}
We compare eruptive dynamics, effects and deposits of the Bezymianny 1956 (BZ), Mount St Helens 1980 (MSH), and Soufrière Hills volcano, Montserrat 1997 (SHV) eruptions, the key events of which included powerful directed blasts. Each blast subsequently generated a high-energy stratified pyroclastic density current (PDC) with a high speed at onset. The blasts were triggered by rapid unloading of an extruding or intruding shallow magma body (lava dome and/or cryptodome) of andesitic or dacitic composition. The unloading was caused by sector failures of the volcanic edifices, with respective volumes for BZ, MSH, and SHV c. $0.5,2.5$, and $0.05 \mathrm{~km}^{3}$. The blasts devastated approximately elliptical areas, axial directions of which coincided with the directions of sector failures. We separate the transient directed blast phenomenon into three main parts, the burst phase, the collapse phase, and the PDC phase. In the burst phase the pressurized mixture is driven by initial kinetic energy and
\end{abstract}

Editorial responsibility: J Stix

A. Belousov $\cdot$ M. Belousova

Institute of Marine Geology and Geochemistry,

Nauki str, 1,

Yuzhno-Sakhalinsk 693022, Russia

M. Belousova

e-mail: belousov@mail.ru

A. Belousov $\cdot$ M. Belousova

Institute of Volcanology and Seismology,

Piipa boulevard, 9,

Petropavlovsk-Kamchatsky 683006, Russia

B. Voight $(\square)$

Department of Geosciences, Deike Building,

Penn State University,

University Park PA 16802, USA

e-mail: voight@ems.psu.edu expands rapidly into the atmosphere, with much of the expansion having an initially lateral component. The erupted material fails to mix with sufficient air to form a buoyant column, but in the collapse phase, falls beyond the source as an inclined fountain, and thereafter generates a PDC moving parallel to the ground surface. It is possible for the burst phase to comprise an overpressured jet, which requires injection of momentum from an orifice; however some exploding sources may have different geometry and a jet is not necessarily formed. A major unresolved question is whether the preponderance of strong damage observed in the volcanic blasts should be attributed to shock waves within an overpressured jet, or alternatively to dynamic pressures and shocks within the energetic collapse and PDC phases. Internal shock structures related to unsteady flow and compressibility effects can occur in each phase. We withhold judgment about published shock models as a primary explanation for the damage sustained at MSH until modern 3D numerical modeling is accomplished, but argue that much of the damage observed in directed blasts can be reasonably interpreted to have been caused by high dynamic pressures and clast impact loading by an inclined collapsing fountain and stratified PDC. This view is reinforced by recent modeling cited for SHV. In distal and peripheral regions, solids concentration, maximum particle size, current speed, and dynamic pressure are diminished, resulting in lesser damage and enhanced influence by local topography on the PDC. Despite the different scales of the blasts (devastated areas were respectively 500, 600, and $>10 \mathrm{~km}^{2}$ for BZ, MSH, and SHV), and some complexity involving retrogressive slide blocks and clusters of explosions, their pyroclastic deposits demonstrate strong similarity. Juvenile material composes $>50 \%$ of the deposits, implying for the blasts a dominantly magmatic mechanism although hydrothermal explosions also occurred. The 
character of the magma fragmented by explosions (highly viscous, phenocryst-rich, variable microlite content) determined the bimodal distributions of juvenile clast density and vesicularity. Thickness of the deposits fluctuates in proximal areas but in general decreases with distance from the crater, and laterally from the axial region. The proximal stratigraphy of the blast deposits comprises four layers named A, B, C, D from bottom to top. Layer A is represented by very poorly sorted debris with admixtures of vegetation and soil, with a strongly erosive ground contact; its appearance varies at different sites due to different ground conditions at the time of the blasts. The layer reflects intense turbulent boundary shear between the basal part of the energetic head of the PDC and the substrate. Layer B exhibits relatively well-sorted finesdepleted debris with some charred plant fragments; its deposition occurred by rapid suspension sedimentation in rapidly waning, high-concentration conditions. Layer $\mathrm{C}$ is mainly a poorly sorted massive layer enriched by fines with its uppermost part laminated, created by rapid sedimentation under moderate-concentration, weakly tractive conditions, with the uppermost laminated part reflecting a dilute depositional regime with grain-by-grain traction deposition. By analogy to laboratory experiments, mixing at the flow head of the PDC created a turbulent dilute wake above the body of a gravity current, with layer B deposited by the flow body and layer $\mathrm{C}$ by the wake. The uppermost layer D of fines and accretionary lapilli is an ash fallout deposit of the finest particles from the high-rising buoyant thermal plume derived from the sediment-depleted pyroclastic density current. The strong similarity among these eruptions and their deposits suggests that these cases represent similar source, transport and depositional phenomena.

Keywords Directed blast - Lateral blast . Pyroclastic surge . Pyroclastic density current - Shock wave - Stratified flow .

Fountain collapse $\cdot$ Dynamic pressure $\cdot$ Overpressured jet .

Debris avalanche $\cdot$ Bezymianny $\cdot$ Mount St Helens .

Soufrière Hills Montserrat

\section{Introduction}

Directed volcanic blasts are powerful explosions with a significant laterally-directed component, which can generate devastating, high energy pyroclastic density currents. Understanding the nature of directed blasts is very important for volcanic hazard assessments due to the extreme violence of these events; despite their relatively small volumes of erupted magma (commonly a small fraction of a cubic kilometer), areas of severe to complete devastation can reach hundreds of square kilometers. The term "directed volcanic blast" was suggested for the first time by Gorshkov (1959), who studied the eruption of Bezymianny volcano (BZ) in Kamchatka in 1956. This directed blast eruption was observed only from large distances, and thus the main conclusions about mechanisms of the event were based on the effects and deposits of the eruption. The peculiar consequences of this eruption characterized then as a directed blast (or Bezymianny type eruption; Gorshkov 1962, 1963) - include the formation of a large horseshoe-shaped crater and an extensive, strongly eccentric zone of devastation, with a spectacular directional tree blow-down pointed away from the crater breach. In the devastation zone, two types of blast-related deposits were described:

(1) A thick, hummocky, coarse breccia, occupying the axial zone of devastation and representing mainly the displaced and fragmented material of the destroyed volcanic edifice. Originally this was called 'directed blast agglomerate' and was interpreted as exploded ejecta of the destroyed volcano (Gorshkov 1959, 1963; Bogoyavlenskaya 1962; Gorshkov and Bogoyavlenskaya 1965); more recently, this was reinterpreted as the deposit of a debris avalanche (Belousov and Bogoyavlenskaya 1988; Belousov and Belousova 1996, 1998).

(2) A comparatively fine-grained and thin layer of mainly juvenile pyroclasts, covering the whole area of the tree blow-down (the directed blast deposit, sensu stricto). The stratigraphy of the blast deposits was studied by Belousov (1996).

The strikingly similar explosive eruption of Mount St. Helens (MSH) in 1980 (Lipman and Mullineaux 1981; Crandell and Hoblitt 1986) reactivated an interest in directed blasts for volcanologists around the world. The large quantity of observations and photo-documentation of the Mount St. Helens blast, as well as detailed studies of stratigraphy of the deposits, enabled a detailed understanding of the eruptive succession and the basic causative mechanisms. It was observed that the large-scale collapse of the volcanic edifice, which transformed into a debris avalanche, was the event that triggered a directed explosion (Voight 1981; Voight et al. 1981, 1983; Glicken 1998). This explosion generated a pyroclastic density current which spread over a large area of complex topography, where it knocked down trees and left deposits closely resembling those of Bezymianny. The stratigraphy and textures of the blast deposits were studied by numerous scientists (Hoblitt et al. 1981; Moore and Sisson 1981; Waitt 1981; Walker and McBroome 1983; Brantley and Waitt 1988; Fisher et al. 1987; Fisher 1990; Druitt 1992; Sisson 1995; Bursik et al. 1998). Some difficulties were raised in the interpretation of the nature of the pyroclastic current, as the deposits 
appeared to combine features of both pyroclastic flow and pyroclastic surge deposits (Hoblitt et al. 1981; Walker and McBroome 1983, 1984; Hoblitt and Miller 1984; Waitt 1984).

While the Bezymianny and Mount St. Helens directed blast eruptions were of similar magnitude, with devastated areas of 500 and $600 \mathrm{~km}^{2}$ respectively, the blast of the Soufriere Hills volcano (SHV) on Montserrat, at night on 26 December 1997, was over an order of magnitude smaller; only $10 \mathrm{~km}^{2}$ of devastation was recorded on land, before the blast-generated current entered the sea (Sparks et al. 2002; Hart et al. 2004). Despite this smaller size, many of the known features of directed blasts (a triggering slope failure with debris avalanche, directional tree blowdown, and peculiar deposits) were found in this case also. The slope failure and debris avalanche was studied by Voight et al. (2002), and the stratigraphy and textures of the blast deposits were studied by Ritchie et al. (2002), and also by $\mathrm{AB}$ and $\mathrm{BV}$ (unpublished data). The blast eruption at SHV recalls in many respects the classic descriptions of Alfred Lacroix (1904) involving Montagne Pelée, Martinique, although important aspects of the 1902 eruption remain controversial (Bourdier et al. 1989; Boudon and Lajoie 1989).

Catastrophic but conventional explosive eruptions in general are relatively infrequent and dangerous events, and much data about their mechanisms have been obtained not only from direct observations of some recent events, but also by studying prehistoric pyroclastic deposits. This is not the case for directed blasts, for until very recently, very few ancient deposits were suspected to be of directed blast origin. Perhaps the problem is connected with the fact that, although the classic deposits of BZ, MSH and SHV have been extensively studied, no comparative study has been done, and the characteristic features of these deposits have not been clearly defined. Since the Mount St. Helens eruption there have been some attempts to recognize blastrelated deposits in ancient and modern sequences (Sparks 1983; Boudon et al. 1984; Siebe et al. 1992, 1995; Siebert et al. 1995; Cantagrel et al. 1999; Clavero et al. 2002), but there is also the risk of misinterpretation because of the lack of reliable criteria, and some deposits interpreted as the products of directed blasts have been likely generated by other eruptive mechanisms (e.g., pyroclastic density currents from lava-dome collapse).

Other, different types of deposit have also been sometimes described as caused by directed blasts, such as the $\sim 1,150$ BP Sugar Bowl deposit at MSH (Mullineaux and Crandell 1981) and the September 1996 explosion on Montserrat (Robertson et al. 1998). These deposits have been caused by inclined explosions focused toward a given azimuth, yielding a narrowly distributed depositional field of ballistics and lapilli fallout. The term directed blast is really not misplaced here, as these are indeed highly directed, inclined vulcanian, explosions, but this transport process is different from that emphasized in this paper in relation to pyroclastic density currents. Thus it may be recognized that there may be several types of directed blasts or explosions, namely, those which primarily produce fallout and ballistic deposits, and those which primarily produce violent pyroclastic density currents. Emphasis in this paper is placed on the latter type. However we recognize that these phenomena can be gradational, e.g., ballistic clasts are found within blast-generated pyroclastic density currents.

This paper aims at a comparative study of the classic directed blasts and their deposits, to attempt to understand which characteristics are common for directed blast eruptions and deposits, and to discern the reasons responsible for some observed differences in deposit characteristics. We analyze the sequences of events that occurred during the blast-generating eruptions and present a model for directed blast generation and the development of transportation and deposition systems. The principal questions to answer are:

(1) What explodes, and why do blasts occur?

(2) What focuses the directed blasts?

(3) What dynamic processes cause damage?

(4) What was deposited, and how?

(5) Which criteria enable recognition of old directed blasts?

(6) Which volcanoes are potentially blast-dangerous?

To make this comparative study, the authors have analyzed all the available data (published material, and their own unpublished information), have visited all the principal volcanoes considered, and have examined numerous key stratigraphic sections of the blast deposits. We answer the questions stated above in the conclusions of this paper.

We use the following abbreviations: Bezymianny (BZ), Mount St. Helens (MSH), Soufrière Hills volcano (SHV). As regards terminology, it has been suggested that there are almost as many labels for this complex and violent phenomenon that swept over the terrain about these volcanoes as there have been volcanologists who have studied it (Hoblitt 2000). Kieffer (1981) used the expression blast flow. The term blast surge was preferred by Fisher (1990) and Belousov (1996), which however implies the dominance of low-particle concentration conditions. Hoblitt (2000) used pyroclastic density flow (PDF) as a nonspecific term for pyroclastic flow or pyroclastic surge in representing the 'blast' at MSH. For SHV, the term pyroclastic density current was adopted for Geological Society of London Memoir 21 (Druitt and Kokelaar 2002), because significant lateral and vertical gradients in particle size and concentration were inferred to have been present in 
the moving current so that neither pyroclastic surge nor pyroclastic flow seemed appropriate.

We accept the view that volcanology has suffered from an excess of names for types of pyroclastic currents and their deposits, resulting in an overly complex terminology that can confuse non-specialists and experts alike. We prefer plain English and do not introduce complex terms. We use directed blast here to denote the explosion, with a significant lateral component, caused by decompression of a cryptodome or lava dome. This is the mechanism of eruption. A principal product of the eruption is a pyroclastic density current or PDC, which evolves by transformation in a gravitational field. We refer to a PDC of this origin as a blast-generated $P D C$, or, as a simplification, a blast PDC.

We separate the transient directed blast phenomenon into three main parts, the burst phase, the collapse phase, and the $P D C$ phase. In the burst phase the pressurized mixture is driven by initial kinetic energy and expands rapidly into the atmosphere, with much of the expansion having an initial lateral component. The erupted material fails to mix with sufficient air to form a buoyant column and thus, in the collapse phase, falls beyond the source as an inclined fountain. The material then moves parallel to the ground surface in the PDC phase.

Some authors have imagined the blast as a transient overpressured jet, accompanied by the propagation of atmospheric shocks, and internal shock structures related to unsteady flow and compressibility effects (Kieffer 1981, 1984; Kieffer and Sturtevant 1984, 1988; Wohletz and Valentine 1990). (Similar "blast" phenomena may also occur with vertical eruptions; see Wohletz et al. 1984; Valentine and Wohletz 1989; Valentine 1998b). We accept this possibility but note that a jet requires injection of momentum from a rigid orifice, and we suggest that some exploding sources may have different geometry or breakable enclosure media, so that a jet is not necessarily assured. A major unresolved question is whether the preponderance of strong damage observed in the volcanic blasts should be attributed to air shock (Wohletz et al. 1984; Wohletz 1998), internal shock waves within an overpressured jet (Kieffer 1981, 1984), or to dynamic pressures and shocks within the energetic collapse and PDC phases (Esposti Ongaro et al. in press). We note here that internal shock structures can occur in each phase of a directed blast, and that exploring these issues is a goal of our paper.

\section{Volcanic edifices and summary of past eruptive activities}

The volcanoes BZ, MSH and SHV are 11,000, 40,000 and $>30,000$ years old, respectively, and commonly erupt magmas of mostly andesite or dacite calc-alkaline composi- tions typical for convergent plate margin settings (Braitseva et al. 1991; Bogoyavlenskaya et al. 1991; Hoblitt et al. 1980; Carey et al. 1995; Roobol and Smith 1998). Before the directed-blast eruptions, the edifices of these volcanoes were rather steep-sided cones, with moderate relative cone heights of 1,300, 1,700, and 1,000 m, respectively (Fig. 1). Each edifice was composed of a complex assemblage of highly crystalline domes (both summit and flank) and thick lava flows, with associated aprons of volcanic breccias. Multiple plug domes in the structures of these volcanoes indicate previous eruptions of viscous siliceous magmas, which were able to degas and crystallize in the upper parts of conduits while slowly ascending toward the ground surface. Open conduit eruptions of the plinian type, although they occurred also (especially frequently on MSH; Mullineaux 1986), were relatively rare in the late histories of these volcanoes (Mullineaux and Crandell 1981; Crandell 1987; Braitseva et al. 1991; Wadge and Isaacs 1988; Roobol and Smith 1998; Druitt and Kokelaar 2002).

Despite their moderate heights, the edifices of BZ, MSH and SHV were marginally stable. Additionally to the large-scale failures that occurred during all the three directed-blast eruptions, evidence of ancient failures were found on MSH and SHV (Voight et al. 1981; Hausback and Swanson 1990; Robertson et al. 2000) (Table 1). A prehistoric debris avalanche occurred on Montserrat in 4000 BP (Wadge and Isaacs 1988), resulting in the formation of English's Crater, and an ancient southern deposit has been recognized from submarine investigations (Deplus et al. 2001). The absence of pre-historic avalanches on $\mathrm{BZ}$ can be connected with the comparatively young age of its edifice. Instability of BZ, MSH and SHV could be intimately associated with the high magma viscosity and strength that results in much disturbance of a volcanic edifice during magma ascent, intrusion or extrusion, and thus frequently triggers large-scale sector collapses (Belousov et al. 1999; Voight 2000). At the same time BZ, MSH and perhaps even SHV were apparently less unstable than Augustine, Egmont, Bandai, Shiveluch, and Harimkotan volcanoes, which throughout their histories generated numerous debris avalanches that were provoked by minor intrusions of viscous magmas, but produced no confirmed directed blasts (Beget and Kienle 1992; Palmer et al. 1991; Yamamoto and Suto 1996; Belousov et al. 1999; Belousov and Belousova 1996). However, a blast deposit was reported for Augustine by Siebert et al. (1995), and a phreatic blast occurred at Bandai-san (Sekiya and Kikuchi 1889; Glicken and Nakamura 1988). Nevertheless, a generalized rationale for this circumstance is that if a volcano edifice is extremely sensitive to minor perturbations, it may fail before a significant mass of magma can be injected in it. Thus in such a case no magmatic directed blast occurs. 
Fig. 1 Mount St. Helens and Bezymianny volcanoes before $(\mathbf{a}, \mathbf{c})$ and after $(\mathbf{b}, \mathbf{d})$ the directed blast-generating eruptions. The images of Soufrière Hills volcano show the situation (c) in December 1996 before dome growth extended southward over the crater rim, and (f) in December 1997, a few days before collapse of the dome complex and south flank triggered the blast. Views opposite to the directions of the blasts, which were southeast, north, and southwest, respectively for Bezymianny, Mount St Helens, and Soufrière Hills. The dates of photographs are indicated. Following the blasts, the craters were partially filled by lava domes. Photo b-courtesy of Cascade Volcano Observatory, e and f-courtesy of Montserrat Volcano Observatory
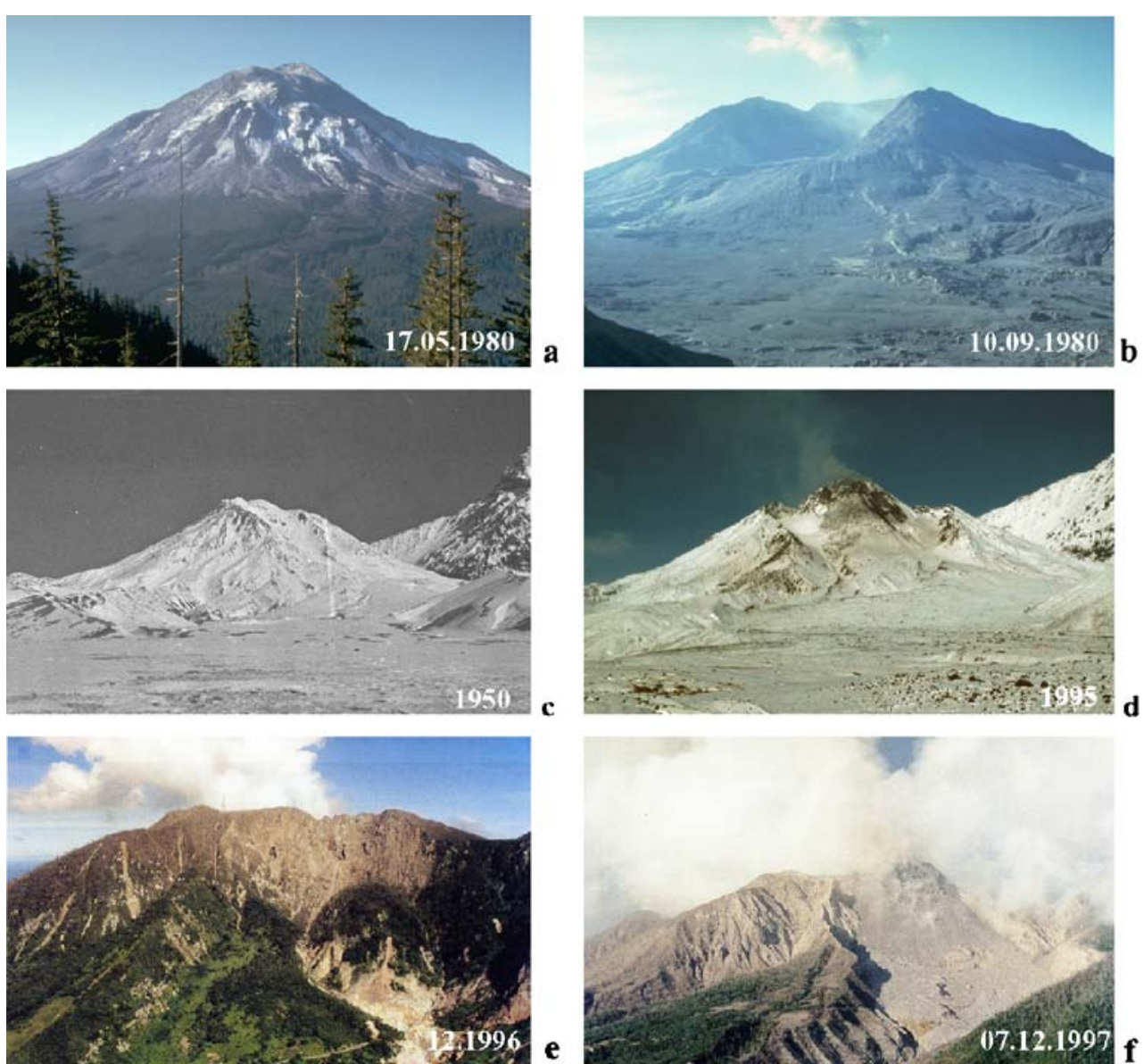

On a very unstable volcano, during seismogenic ascent of a new batch of viscous magma, sector collapse can occur by augmented seismic loading before a magma body is emplaced at a shallow superficial level as a cryptodome or dome, or by disturbances of the edifice by the gas-depleted vanguard of rising magma (Voight and Elsworth 1997, 2000). In such cases, lacking the necessary 'gas/magma charge,' no directed blast is generated.

There is no evidence that genuine directed blasts comparable in scale with the blasts of the 20th century occurred on these three volcanoes in the past. Repose periods before the major blast-generating eruptions of $\mathrm{BZ}$, MSH and SHV were accordingly about 1,000, 123, and 400 years. These repose periods seem of ordinary duration for these volcanoes, as well as for volcanoes of this type in general. There is nothing particularly anomalous about the repose intervals.

Based on the above data, we conclude that any volcano erupting viscous, siliceous, water-bearing magmas, especially in the form of lava domes, is potentially blastdangerous. Signs of moderate structural instability of a volcanic edifice increase the probability of a directed blast, although instances of extreme instability (e.g., multiple ancient debris avalanches), may not necessarily favor major directed blasts; in such cases instability can occur before a large magma mass can be injected into the edifice. However, multiple failures of lava domes (in contrast to edifice failures) may favor the possibility of minor blasts or energetic conventional surges involving smaller volumes of decompression-sensitive magma. Absence of recognized significant blast deposits, as well as debris avalanches, in the past history of a volcano does not guarantee their absence in the future, as indicated by the experience at BZ and MSH. Length of repose period has no apparent influence on blast probability. Volcanoes with the above characteristics are very common in volcanic arcs.

\section{Analysis of chronologies of the blast-generating eruptions}

Each of the directed blasts studied occurred as one episode of a long and complex eruption, which consisted of several periods of volcanic activity involving different styles and magnitudes (Table 1). These eruptions can be logically subdivided into a pre-climactic stage (preparations and precursors for a directed blast), a climactic stage (triggering events, the directed blast itself, and immediate reactions of the volcanic system), and a post-climactic stage (long-term reactions of the volcanic system to the directed blast). 
Table 1 Comparative data

\begin{tabular}{|c|c|c|c|}
\hline & Bezymianny & Mount St. Helens & SHV, Montserrat \\
\hline \multicolumn{4}{|l|}{ Characteristics of volcanic edifices } \\
\hline Age of volcano, years & 11,000 & 40,000 & $>30,000$ \\
\hline Ancient failures: number/age & 0 & $1 / 20,000$ & $1 / 4,000$ \\
\hline Ancient blasts: number/age & 0 & $1 / 1200$ & 0 \\
\hline Repose period before the blast, years & 1,000 & 123 & 400 \\
\hline Composition & andesite & dacite & andesite \\
\hline Edifice height above base, $\mathrm{m}$ & 1,300 & 1,700 & 1,000 \\
\hline Height before/after, $\mathrm{m}$ & $3,085 / 2,886$ & $2,951 / 2,549$ & $1,030 / 650$ \\
\hline Height reduction over vent, $\mathrm{m}$ & 750 & $500-900$ & 300 \\
\hline Crater after eruption, $\mathrm{km}$ & $1.7 \times 2.8$ & $2.8 \times 3.5$ & $0.4 \times 0.5$ \\
\hline \multicolumn{4}{|l|}{ Pre-climactic stage of eruption } \\
\hline Dome/cryptodome volume, $\mathrm{km}^{3}$ & $0.15-0.2$ & 0.11 & 0.035 \\
\hline Deformations, months & $2-6$ & 2 & 1.5 \\
\hline meters & 100 & 150 & not known \\
\hline Volcanic activity & Phreatomagmatic-magmatic & phreatic-phreatomagmatic & magmatic \\
\hline \multicolumn{4}{|l|}{ Climactic stage of eruption } \\
\hline \multicolumn{4}{|l|}{ Debris avalanche } \\
\hline Drop height $\mathrm{H}, \mathrm{km}$ & 2.4 & 2.25 & 1 \\
\hline Travel distance $\mathrm{L}, \mathrm{km}$ & 22 & 25 & 4.5 \\
\hline Coefficient $\mathrm{H} / \mathrm{L}$ & 0.12 & 0.09 & 0.22 \\
\hline Area, $\mathrm{km}^{2}$ & 36 & 64 & 1.7 \\
\hline Volume, $\mathrm{km}^{3}$ & 0.5 & 2.5 & 0.05 \\
\hline Landslide volume/ edifice volume & 0.1 & 0.1 & 0.2 \\
\hline Velocity, $\mathrm{m} \mathrm{s}^{-1}$ & $<60$ & $50-70 \max$ & $>27$ avg \\
\hline \multicolumn{4}{|l|}{ Directed blast } \\
\hline Opening angle of devastation zones (degree) & 110 & 180 & 70 \\
\hline Travel distance, $\mathrm{km}$ & 30 & 27 & $>7$ \\
\hline Area, $\mathrm{km}^{2}$ & 500 & 600 & $>10$ \\
\hline Maximum thickness (m) unchanneled & 2.5 & $2-2.5$ & 3 \\
\hline Volume, $\mathrm{km}^{3}$ & 0.2 & 0.11 & 0.03 \\
\hline Velocity, $\mathrm{m} \mathrm{s}^{-1}$ & $>100$ & $100-235$ & $>100$ initial \\
\hline Boundary proximal/distal zone on axis $(\mathrm{km})$ & 19 & 15 & $>4$ \\
\hline Temperature, ${ }^{\circ} \mathrm{C}$ & $<250$ & $100-350$ & $\sim 300$ \\
\hline Average clast density $\left(\mathrm{kg} \mathrm{m}^{-3}\right)$ & 2,100 & 1,660 & 2,200 \\
\hline Average vesicularity (\%) & 20 & 30 & 15 \\
\hline Amount of juvenile material, vol.\% & 84 & 62 & 87 \\
\hline \multicolumn{4}{|l|}{ Post-blast eruption } \\
\hline General characteristics & open-conduit & open-conduit & Semi-open-conduit \\
\hline Type of eruption & pumiceous pyroclastic flows & plinian eruption pyroclastic flows & Vulcanian explosions \\
\hline \multicolumn{4}{|l|}{ Post-climactic stage } \\
\hline \multicolumn{4}{|l|}{ Growth of lava dome: } \\
\hline duration, years & $>47$ & 6 ; resumed after 24 & $>11$ \\
\hline volume, $\mathrm{m}^{3}$ & $>0.4$ & 0.07 in 6 years & $>0.3$ \\
\hline
\end{tabular}

Pre-climactic stage

Understanding the processes of the pre-climactic stages is important for potential forecasts of directed blast probability. In all three cases considered here, two important interrelated processes were observed:

(1) Ascent and accumulation of some volume of magma in the upper part of the volcanic edifice (volumes for BZ, MSH, SHV: $0.15-0.2 \mathrm{~km}^{3}, 0.11 \mathrm{~km}^{3}, 0.035 \mathrm{~km}^{3}$ );
(2) Important quasi-steady deformations or "bulging" of the volcanic edifice (in two cases $>100 \mathrm{~m}$ displacement).

Accumulation of magma occurred in the form of a very shallow intrusive body (cryptodome) completely surrounded by host rocks on MSH, a mostly-exposed extrusive body (lava lobe) on SHV, or a combination of both on BZ (Fig. 2). The magma bodies formed 'charges' for the explosive blasts (see below). Emplacement of these bodies 

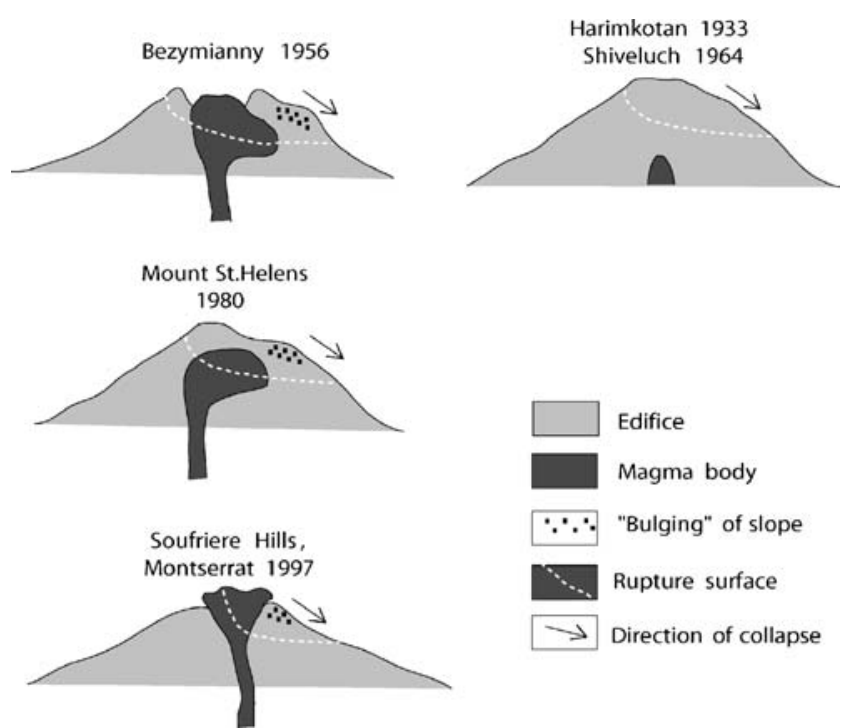

Fig. 2 Sketches illustrating positions of shallow magma bodies inside volcanic edifices before the blasts: Bezymianny-combination of dome and cryptodome; Mount St Helens-cryptodome; Soufrière Hills, Montserrat - dome. Positions of bulged slopes and rupture surfaces of large-scale landslides are shown relative to the magma bodies. At Harimkotan (1933) and Shiveluch (1964), magma was deeper at the moment of landsliding, and thus lateral blasts did not occur

was a process requiring approximately $2-6,2$, and 1.5 months, for BZ, MSH and SHV, thus a similar time scale was followed for each case. The calculated magma discharge rate was $\sim 8 \mathrm{~m}^{3} \mathrm{~s}^{-1}$ at SHV (Voight et al. 2002; Woods et al. 2002), a relatively high value for this eruption. At MSH the average magma flux was about $20 \mathrm{~m}^{3} \mathrm{~s}^{-1}$. At MSH and perhaps BZ, the deformation evidence suggests that the initial rate of emplacement was most rapid (Voight et al. 1981, Fig. 209).

The emplacement process in all cases was accompanied by intense seismicity, and by weak to moderate vulcanian, or explosive phreatic activity. Some pre-climactic volcanic activity was connected with heating up of groundwater, and its related interactions with degassing of the emplacing shallow magma bodies. The character of the precursory tephra-producing activity was phreatomagmatic to magmatic at BZ (Gorshkov 1963), phreatic to phreatomagmatic at MSH (Cashman and Hoblitt 2004), and magmatic at SHV, in accordance with position of the explosion source to the magma body in the edifice; the more exposed the magma, the more magmatic were the explosions (Table 1).

Large deformations of volcanic edifices were an important process of the pre-climactic stages because they increased the structural instability of the edifices by oversteepening and destruction of rock mass strength (Voight 2000; Donnadieu and Merle 1998), thus contributing to their lateral collapses. Collapse is crucial because it produces the rapid laterally-directed decompression of a shallow magma body that triggers a directed explosion (Alidibirov 1994; Alidibirov and Dingwell 1996). The deformations (intrusive wedging of volcanic edifices) were caused by the emplacement of magma bodies in the upper parts of volcanic cones, and started simultaneously with emplacement (Gorshkov 1959; Voight et al. 1981; Moore and Albee 1981; Donnadieu and Merle 1998, 2001). At MSH the bulge comprised an elliptical area about $1.5 \times$ $2 \mathrm{~km}$, with measurements indicating subhorizontal displacements as much as $1.5-2.5 \mathrm{~m} /$ day (Lipman et al. 1981). The scale of deformations was large $(\sim 100,150 \mathrm{~m}$ at $\mathrm{BZ}$ and $\mathrm{MSH}$ ), but the volcanic edifices were able to accommodate them for a time, allowing considerable volumes of magma to be accumulated in the edifices. Although the system was moving toward catastrophic eruption at MSH (Voight 2000), the timing of collapse could have been different without a seismic trigger.

The situation at SHV in December 1997 was more complicated, as the volcano had been erupting magma since November 1995 (Watts et al. 2002). Exogenous lava dome growth ceased temporarily in November 1996, and was followed by endogenous swelling $(\sim 100 \mathrm{~m})$ of an elongate area $800 \times 300 \mathrm{~m}$ near the southern crater rim. Swelling ceased with a switch to exogenous dome growth in other sectors, but degradation of the outer parts of the south wall was observed, with radial cracks crossing the wall and discrete slab avalanches dislodged from it. Deformations were monitored by crack-meters and tiltmeters, with displacements about $1 \mathrm{~m}$ (Young et al. 2002), and thus the area at risk was evacuated. After a hiatus, dome growth resumed in the southern sector in November 1997, with dome and talus loading of weak hydrothermally-altered substrate leading to a condition that became increasingly unstable (Voight et al. 2002).

\section{Climactic stage}

Climactic stages of the eruptions consisted of three key events in rapid succession:

(1) Large-scale collapse of the volcanic edifice;

(2) Directed blast eruption;

(3) Open-conduit (BZ, MSH) or semi-open-conduit (SHV) eruptive activity.

On MSH, a rapid uninterrupted transition was directly observed and photographed, from a complex slope failure to explosions that began even as the slope failure evolved, leading to subsequent joint travel of the resulting flows (debris avalanche, explosion, and blast PDC) (Voight 1981; Foxworthy and Hill 1982). Slope failures at MSH and probably also at BZ occurred retrogressively in several slices, with outer slices failing first because of highest shear stress (Voight and Elsworth 1997). The difference in 
velocities of the flows (debris avalanche $50-70 \mathrm{~m} \mathrm{~s}^{-1}$; blast-generated PDC 100-110 $\mathrm{m} \mathrm{s}^{-1}$ initially (Voight 1981) and $>90 \mathrm{~m} \mathrm{~s}^{-1}$ for the PDC front over the first several minutes (Moore and Rice 1984)), led to the front of the PDC overtaking the debris avalanche (which had a $3-\mathrm{km}$ headstart) in about 90-100 s. Thereafter they were in motion simultaneously, although the blast-generated dispersal was more or less radial from the vent, whereas the avalanche bent westward in the main river valley after first moving northward. On BZ, MSH and SHV very similar event sequences were reconstructed from pyroclastic stratigraphy, as well as from deposit structures formed by interactions between the moving avalanche and the superposed, depositing PDC (Belousov 1996; Voight et al. 2002; Ritchie et al. 2002). At SHV the avalanche deposit was probably emplaced to $3.7 \mathrm{~km}$ in $\sim 138 \mathrm{~s}$, suggesting an average speed of $27 \mathrm{~m} \mathrm{~s}^{-1}$ (Voight et al. 2002). It was then overtopped by a blast-generated PDC moving at speeds ranging from $>100 \mathrm{~m} \mathrm{~s}^{-1}$ initially to $\sim 40 \mathrm{~m} \mathrm{~s}^{-1}$ downslope (Sparks et al. 2002; Esposti Ongaro in press). These relationships show that in all cases the blasts were provoked by edifice collapse and not vice versa. This is a strong argument that the cause of the blasts was the rapid lateral decompression associated with the slope failures.

The post-blast, open-conduit eruptions were triggered also by rapid unloading of the conduit, and progression of the fragmentation wave towards the magma reservoir. In contrast to the blasts, which involved explosive fragmentation of highly-crystallized, extensively degassed magma which had accumulated in the upper parts of volcanic edifices, the immediate post-blast explosive activities were the result of decompression and fragmentation of less degassed, less crystallized, and less viscous magmas from progressively deeper levels of the feeding systems, including conduits and magma reservoirs. Distinctiveness of the local magma properties and geometries of the conduits were responsible for differences in post-blast explosive activities. At BZ, the post-collapse (and post-blast) eruption was dominated by voluminous expulsion of pumiceous pyroclastic flows, whereas at MSH the post-collapse eruption was dominated by formation of a plinian column with some transitional behavior involving generation of pumiceous pyroclastic flows.

The contrast is reminiscent of the numerical explosion models of Clarke et al. (2002a,b), who showed for a vent of given size how instantaneous collapse of a low fountain could occur with low (or reduced) volatile fraction. In general the stable convective columns are favored by low mass fluxes and high eruption velocities, whereas collapsing fountains are favored by high fluxes and low velocities (Sparks et al. 1997). In turn, eruption velocity depends on magma volatile content and vent geometry, while mass flux depends mostly on conduit cross-section dimensions. Thus the differences between BZ and MSH post-collapse eruptions might relate fundamentally to differences in initial and exsolved magma volatile content and conduit cross-section area. Similarly, the regime diagrams of Wilson et al. 1980 (cf. Carey et al. 1990; Sparks et al. 1997) show that an eruption beginning in the plume convection field can make a transition to fountain collapse by decrease in volatile content or increase in conduit diameter, and the results fit the MSH case. The sequence at MSH was established from tephra stratigraphy and careful analysis of timed eyewitness photos (Criswell 1987). The eruption occurred over a $9 \mathrm{~h}$ period, and included two phases of stable plinian columns that rose with time and were followed by plume instability and pumice flow production; the second plinian phase, at $\sim 8 \mathrm{~h}$ from the eruption onset, produced the maximum plume height of $19 \mathrm{~km}$. The column parameters lie close to the regime boundary, accounting for the ease of switching from one regime to another. Similar transitions were observed at BZ during the 1997 eruption, when gradients in properties of magma in the conduit (degree of crystallization, exsolved volatile content) led to progressive changes in eruptive styles: base surge $\rightarrow$ block and ash pyroclastic flows $\rightarrow$ pumiceous pyroclastic flows $\rightarrow$ subplinian eruption column (Belousov et al. 2002).

At SHV no plinian event occurred, but the main explosive collapse was sustained for $15.2 \mathrm{~min}$ and was concluded by three high-amplitude seismic signals interpreted as registering small, short-lived vulcanian explosions (Sparks et al. 2002). At SHV the relatively small unloading (small volume of the landslide and removed portion of lava dome), and its off-center position in relation to the conduit, may have been partly responsible for comparatively weak explosive activity immediately after the blast, since only a limited mass of magma stored in the upper part of conduit of the volcano was involved. However, previous explosions at SHV, even at times of enhanced magma flux, generally ceased when the conduit drawdown reached an inferred depth 1 or $2 \mathrm{~km}$ below the crater floor (based on assumed conduit area; Druitt et al. 2002a; Formenti and Druitt 2003), to a level in which the magma pressure was not able to drive fragmentation. The critical factors may have been the exsolved volatile content distribution with depth, gas permeability of the conduit system, bubble nucleation and growth kinetics, and conduit geometry (probably a dike at depth).

\section{Post-climactic stage}

Post-climactic stages in all the cases consisted of long periods of intermittent growth of lava domes (accordingly for BZ, MSH, SHV: $>47,>26$ and $>11$ years with volumes $0.4 \mathrm{~km}^{3}, 0.07 \mathrm{~km}^{3}$ (plus $0.06 \mathrm{~km}^{3}$ since 2004) and 
$\sim 0.6 \mathrm{~km}^{3}$ ). The eruptions at BZ and SHV continue, whereas at MSH, extrusion stopped in 1986 but resumed in 2004 (Dzurisin et al. 2005). Obviously, notable reduction of heights of the volcanic edifices occurred as a result of the blast-generating eruptions (vent height reductions of 750, 900 and $\sim 300 \mathrm{~m}$ at BZ, MSH, SHV), and should have reduced back-pressure and increased pressure gradients driving magma flow to the surface. However there is no linear dependence between the removed heights of edifices and the durations of post-climactic dome-forming stages, as well as cumulative volumes of the erupted magma. Indeed the largest unloading, on $\mathrm{MSH}$, corresponded to only 6 years of immediate dome growth (through 1986), and the smallest volume of erupted post-climactic magma. Thus, although lowering of the edifices due to failure-blast events might have influenced the post-climactic stages, the deep geometry of feeding systems and the processes of magma generation and re-vitalization (through replenishment of mafic magmas, magma mixing and hybridization) were more important.

\section{Erupted magmas}

The magmas involved in these three eruptions are broadly similar. Juvenile material from the blast at BZ is a moderately vesicular andesite (58-60 wt.\% SiO2), with approximately $35 \%$ phenocrysts of plagioclase, hornblende and orthopyroxene in a microcrystalline rich groundmass (Bogoyavlenskaya and Kirsanov 1981). Magma at depth contained about $5 \mathrm{wt} . \%$ water, temperature before the eruption was $900-930^{\circ} \mathrm{C}$, and estimated reservoir depth was 10-20 km (Kadik et al. 1986). Similarly, juvenile material from the blast deposit at MSH is a moderately vesicular, silica-poor dacite $\left(63\right.$ wt.\% $\left.\mathrm{SiO}_{2}\right)$, with approximately $30 \%$ phenocrysts of plagioclase, hypersthene and hornblende in a microcrystalline-rich groundmass (Cashman 1992). Material erupted in the succeeding plinian phase has been divided into two categories, a phenocryst poor $(20-24 \%)$ silicic $\left(63-64 \% \mathrm{SiO}_{2}\right)$ pumice and a less abundant, higher density, phenocryst rich (29-35\%) silicic andesite $\left(61-63 \% \mathrm{SiO}_{2}\right)$ with augite. Initial melt water content has been estimate at $4.6 \mathrm{wt} . \%$ by phase equilibria (Merzbacher and Eggler 1984; Rutherford and Devine 1988). Mineralogy suggests a temperature about $920^{\circ} \mathrm{C}$ and pressure of $220 \mathrm{MPa}$ (Rutherford et al. 1985), consistent with seismic evidence of reservoir depth of 7 $12 \mathrm{~km}$ (Scandone and Malone 1985). The andesite (5861 wt.\% $\mathrm{SiO}_{2}$ ) at $\mathrm{SHV}$ contains $35-45 \%$ phenocrysts (plagioclase, hornblende, orthopyroxene, titanomagnetite and minor quartz) and 15-20\% microphenocrysts, plus microlites set in hi-Si rhyolite glass. Phase equilibria and melt inclusions indicate that the magma at depth contained
4-5 wt. $\% \mathrm{H}_{2} \mathrm{O}$ in the rhyolitic melt phase (Barclay et al. 1998). Temperature and water pressure conditions are estimated at $830-860^{\circ} \mathrm{C}$ and about $120-140 \mathrm{MPa}$ (Murphy et al. 2000), consistent with the seismic estimate to top of magma reservoir at $>5 \mathrm{~km}$ (Aspinall et al. 1998).

\section{Directed blast effects}

Orientation of blasts, shapes and areas of blast-affected zones

The general directions of the blasts coincided with the directions of the preceding edifice failures, which, in turn, occurred in the directions of dominant pre-climactic deformations of the volcanic edifices (Fig. 3a). Blasts were generated where the steep rear part of the failure surfaces (in some cases, multiple retrogressive failure surfaces) intersected the pressurized magma bodies, and this influenced considerably the orientation of initial explosions. Thus, the explosions at MSH were mainly directed laterally or at least had large lateral initial velocity components with initial trajectories mainly from $-10^{\circ}$ to $+70^{\circ}$, measured from the horizontal (see Rosenquist photographs in Voight 1981). Some nearly-vertical explosions occurred also (Voight 1981, Fig. 43), but the explosive boil-over (low collapsing fountain) of pyroclastic currents was largely redirected toward the freshly open amphitheatre of the collapse scar (cf. Belousov et al. 2002).

Opening angles of devastation zones, as measured from their source (BZ, MSH, SHV: $110^{\circ}, 180^{\circ}, 70^{\circ}$ ), and the general shapes of devastation zones suggest that blast and PDC may have been strongly influenced by accelerations on the initial down-slope descent, and by large scale topography (Fig. 3b). The shape of the sector at SHV was replicated closely in models by Esposti Ongaro et al. (2005a,b, in press).

The broad shape of the MSH blast zone $\left(180^{\circ}\right.$ wide near crater, $140^{\circ}$ at $>8 \mathrm{~km}$ ) has been interpreted to reflect overpressured flow (pressure of expanding multiphase fluid $\gg$ atmospheric pressure) (Kieffer 1981; Wohletz 1998). BZ and SHV show lesser opening angles $\left(<110^{\circ}\right)$. The topography of the blast-affected area at MSH has a broad open valley to the west and high transverse ridges, while topographies of affected areas of BZ and SHV have more or less longitudinal or radial orientations. An additional factor is that MSH is an isolated edifice, and its blast-generated PDC could spread relatively freely about the foot of the volcano, while the edifices of BZ and SHV are parts of clusters of volcanoes, and their PDCs were partly confined by the nearby volcanic edifices.

The outer boundary of MSH devastation zone is quite irregular with main lobes to the NW and NE, whereas the 
Fig. 3 Distributions of deposits at Bezymianny 1956, Mount St Helens 1980, Soufrière Hills, Montserrat 1997. a Deposits of debris avalanches and directed blasts; b deposits of directed blasts. North is upward. Dots mark location of craters. Distal boundary of the blast deposit at SHV is undetermined (submarine) and is approximated as dashed line. Data from Belousov (1996), Mullineaux and Crandell (1981), Ritchie et al. (2002)

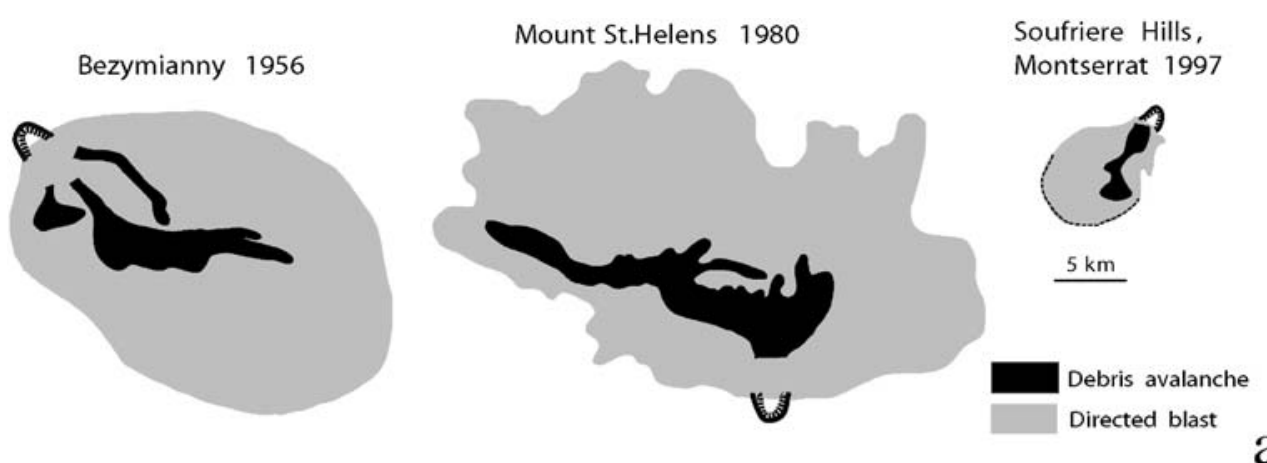

a boundary of BZ is drawn more smoothly. This is partly an artifact of the investigative technologies available, because the blast zone of BZ was not accurately mapped nor systematically photographed from the air. Another factor could be the much less dissected, less irregular topography beyond the foot of BZ. The outer boundary of the SHV blast zone was in the sea and so its overall shape at termination of the blast current is undefined.

Zones of devastation produced by the blasts and associated PDCs coincide approximately with the regions covered by their deposits, excluding the fallout from the thermal plume rising above the blast-affected area (Sparks et al. 1986; Sisson 1995). For BZ and MSH they have similar areas, 500 and $600 \mathrm{~km}^{2}$, respectively (Gorshkov 1959; Lipman and Mullineaux 1981); the total area of the SHV blast zone, excluding an unknown part in the sea, has been estimated as $\sim 10 \mathrm{~km}^{2}$ (Sparks et al. 2002).

Temperatures and thermal effects of the blast-generated currents

Temperature of the blast-generated currents can be estimated from direct measurements in deposits, and from thermal effects on vegetation and plastics. The effects in general were similar for the three eruptions. In the proximal zones of the blasts, the temperature was not high enough to carbonize large standing trees (those not incorporated into deposits) during passage of the blast currents. On MSH and SHV in proximal zones, only thin standing trees and the edges of 'war-bonnet style' splintered tree stumps were scorched (Waitt 1981; Banks and Hoblitt 1981; our personal observations), while on BZ they were not charred. This suggests the temperature at BZ was lower. At MSH most fragments of plants incorporated into blast deposits in the proximal zone (with the exception of basal layer) were charred due to prolonged exposure to heat, since the deposits remained hot for days to weeks. The thermal effects on buried wood correlate with the proportion of juvenile blast lava in the deposit (Banks and Hoblitt 1981). In the lowermost layer of the blast deposit in the proximal zone, the temperature was lower, and in this case, the incorporated plant material was only partly charred or uncharred. In distal zones, the temperatures were lower, and standing thin trees as well as plants incorporated in the blast deposits appeared desiccated but not charred. Based on direct measurements on ponded deposits in topographic lows and thermal effects, the temperatures of the MSH blast-generated $\mathrm{PDC}$ was estimated as $100-325^{\circ} \mathrm{C}$ and varied with azimuth (hottest in east sector) (Banks and Hoblitt 1981, Figs. 178c, 180; 1996). The temperature peak passed within 1-10 $\mathrm{min}$, with the temperature dropping rapidly below $150^{\circ} \mathrm{C}$, consistent with the survival of paints, polystyrene, and color film. Along the narrow lateral margin of downed timber, many trees were bent outward 
but not downed, and their needles were yellowed but not scorched brown or black (Waitt 1981; Winner and Casadevall 1981).

Temperatures at BZ may have been similar initially, but the blast PDC was affected by incorporation of colder air and eroded snow, since the eruption occurred in winter conditions in Kamchatka, and snow mantled the landscape.

At SHV, temperatures were similar, with variable temperatures measured in blast deposits, up to a maximum of $293^{\circ} \mathrm{C}$ (Sparks et al. 2002), suggesting current temperatures $>300^{\circ} \mathrm{C}$. Fire damage included ignition of wood in structures by hot ash, melted bitumen shingles and PVC gutters (Baxter et al. 2005). A remarkable feature observed locally at SHV was a pervasive black tar under the blast deposit. The area was affected by a turbulent erosive current that grooved the surface and burnt all vegetation, thus creating a combustion cloud charged with organic substances that rapidly condensed to form a plastic tar layer 1-4 mm thick. This was followed by a second energetic current pulse with basal clasts that formed parallel skid marks before hardening of the tar, and shaved off all trees to ground level (Sparks et al. 2002).

On BZ, probably because of the severe winter conditions and snow and cold air entrainment, the temperature of the blast PDC was not high enough to produce a tar. On MSH, although thermal effects on vegetation were generally similar to SHV, no tar was formed. Possibly the local properties of soil (e.g. density, moisture content, percentage of organic material, local snow cover), vegetation type, as well as thermal structure of the blast current were factors influencing the tar-generation processes.

\section{Velocity of the blast-generated currents}

Direct estimations of velocity of propagation (based on photographic and satellite observations) exist only for MSH: the blast front moved at $100-110 \mathrm{~m} \mathrm{~s}^{-1}$ initially (Voight 1981), and $>90 \mathrm{~m} \mathrm{~s}^{-1}$ over the first several minutes, with local speeds to $\sim 130 \mathrm{~m} \mathrm{~s}^{-1}$ or more (Moore and Rice 1984) (Fig. 4a, b). Since the frontal speeds of turbulent gravity currents may be only $60-70 \%$ of internal speeds (Simpson 1987), the latter could have been $\sim 130-210 \mathrm{~m} \mathrm{~s}^{-1}$. The supersonic velocities $\left(\sim 325 \mathrm{~m} \mathrm{~s}^{-1}\right)$ calculated by Kieffer (1981) for MSH are based on a theoretical model and seem unrealistically high in comparison to calculations based on image analyses. Kieffer and Sturtevant (1988), for one area near Spirit Lake about $9 \mathrm{~km}$ from source, reported a Mach number $\mathrm{M} \sim 2.5$, and for a sound speed of $94 \mathrm{~m} \mathrm{~s}^{-1}$, an internal current velocity of $235 \mathrm{~m} \mathrm{~s}^{-1}$ and flow Reynolds number of $\sim 2 \times 10^{9}$. The apparent precision on these estimates however veils large uncertainties.

Dynamic effects on trees and other features are similar for all three cases. Taking into account similar concen- trations of particles (see below), velocities of the explosion plume and blast-generated PDC on BZ may have been roughly similar to MSH. Timing from destruction of a seismic station at $\mathrm{SHV}$ at $3.4 \mathrm{~km}$ from the blast, and interpretation of seismic records as indicating the initiation of the blast, yields a minimum average frontal speed around $38-57 \mathrm{~m} \mathrm{~s}^{-1}$ (faster speeds were reported by Sparks et al. (2002), but the travel distance they assumed in the calculation was too large). Noting that the head of a turbulent gravity current travels at roughly two-thirds the speed of the following current (Simpson 1987), minimum internal speeds were about 54-79 $\mathrm{m} \mathrm{s}^{-1}$. Models using the Bursik and Woods (1996) approach predict speeds of 80$120 \mathrm{~m} \mathrm{~s}^{-1}$ (Sparks et al. 2002), but multiphase numerical models in 2D and 3D yielded variable speeds, $>100 \mathrm{~m} \mathrm{~s}^{-1}$ for the burst phase and parts of the collapse phase, and about $70-30 \mathrm{~m} \mathrm{~s}^{-1}$ for the PDC phase, depending on distance from source and model details (Esposti Ongaro et al. 2005a,b, in press). The blast PDCs at SHV developed in several pulses of short (minutes) duration, and peak current speeds were likely attained in a post-initial pulse (Sparks et al. 2002). Seismic data suggest unsteady fragmentation of the dome over 10-15 min, in six pulses, with the second pulse being the strongest.

Solids concentration of the blast-generated currents

Significant vertical, lateral and temporal gradients in particle size and concentration are inferred to have been present in the moving current, and indeed are indicated by the variations noted in the deposits. Concentration of pyroclasts can be qualitatively estimated, based on various models involving explosive expansion of the magma body (Kieffer 1981; Woods 2000; Woods et al. 2002; Wohletz 1998), sedimentological characteristics of the blast deposits (Bursik et al. 1998), and observed damage to poles, trees and structures (Clarke and Voight 2000).

Using the former approach, Kieffer modeled the MSH blast as an exploding disc-shaped reservoir on the north side of the mountain, yielding a choked velocity at steady state of $104 \mathrm{~m} \mathrm{~s}^{-1}$ and a density of $600 \mathrm{~kg} \mathrm{~m}^{-3}$. Similarly, in the Woods et al. (2002) model for SHV, a pyroclast and gas mixture expands from a fragmenting magma body at about $60 \mathrm{~m} \mathrm{~s}^{-1}$, yielding an initial current density of the order of $100-500 \mathrm{~kg} \mathrm{~m}^{-3}$ (Woods et al. 2002).

Mobile mixtures with these densities are negatively buoyant, but the capability of sustaining such mixture densities must be short lived. The ability of a current to maintain particles in turbulent suspension depends on the Rouse number, $R_{n}$, defined as the ratio of particle fall speed $w$ to the frictional or shear velocity of the current:

$$
\mathrm{R}_{n}=w / \beta v^{*}
$$




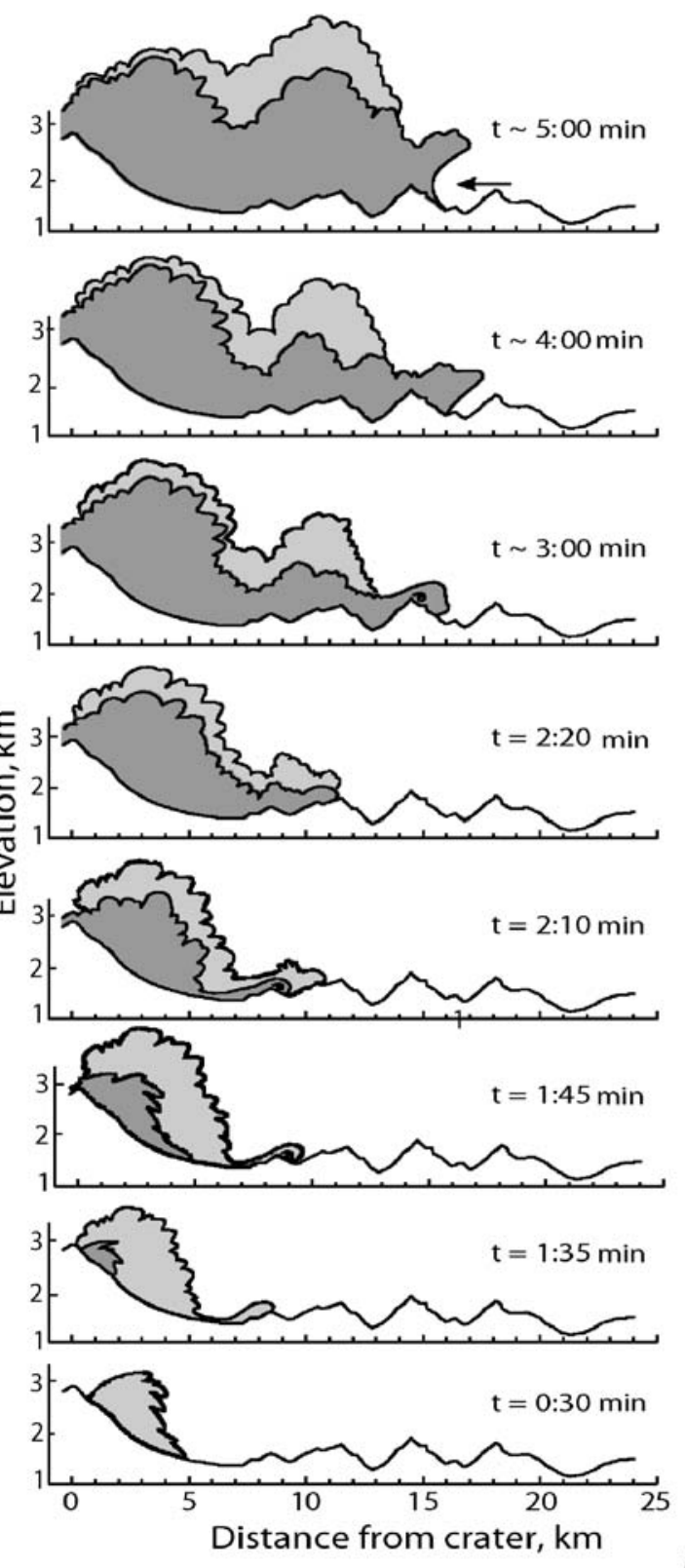

a

Fig. 4 a Cartoon showing the development and movement of two explosions during Mount St. Helens blast (after Hoblitt 2000). Time is in seconds after 8:32:11 PDT. First and second explosions shown by pale grey and dark grey patterns, respectively. b Blast current front

where $\beta=0.4$, and $v^{*}$ is related to mean current speed $v$ by the relation $v^{*} \sim \beta v / \ln (30 \mathrm{~B} / \mathrm{k})$ where $B / k$ is the ratio of boundary layer thickness of the current and the surface roughness length, speculated to have a value about 5 (Valentine 1987). The fall speed for a pyroclast $\gg 1 \mathrm{~mm}$ falling in a turbulent regime is:

$\mathrm{w}=\left(\rho \mathrm{g} \mathrm{d} / \mathrm{c} \rho_{\mathrm{bc}}\right)^{1 / 2}$

where $\rho$ is particle density, $g$ is gravity acceleration, $d$ is clast diameter, $c$ is particle drag coefficient, and $\rho_{b c}$ is bulk density of the current (Druitt 1998).

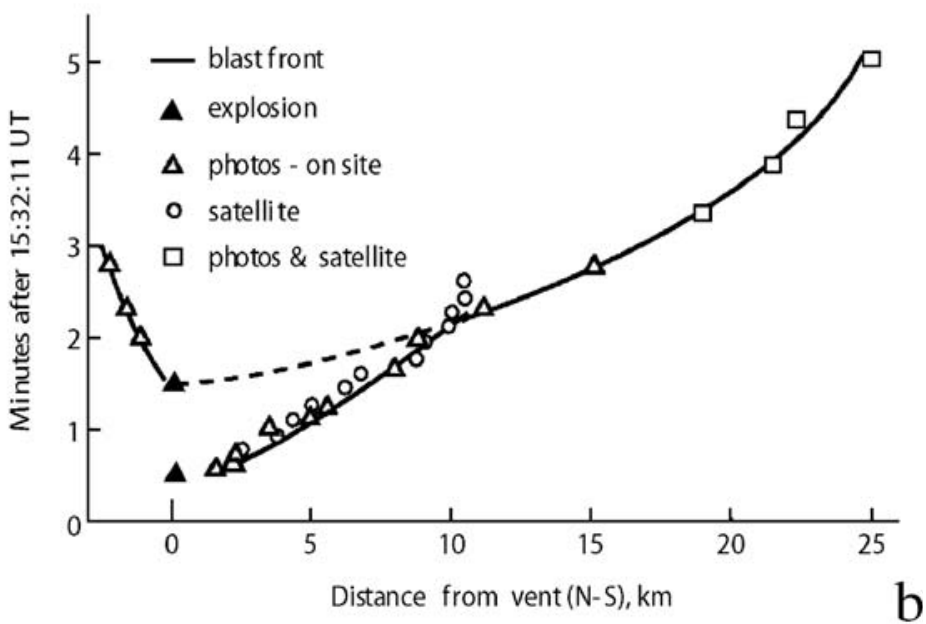

position versus time for Mount St Helens blast. The lower black triangle shows the start time of the first explosion cluster, and the upper black triangle, the second explosion cluster (after Hoblitt 2000)

It may be assumed that all finer-grained particles that are suspended in the current contribute to the drag experienced by particles that are 'just suspended' (Woods et al. 2002). If, for a given particle size $R_{n}>2.5$, then such particles cannot be suspended in the flow. For $1<R_{n}<2.5$, particles are barely suspended but tend to be concentrated near the base of the current. Only much smaller particles for which $R_{n}<1$ become fully suspended and well mixed in the current. Figure 5 (solid lines) illustrates the variation of $R_{n}$ with free stream velocity in a current of density $\sim 100 \mathrm{~kg} \mathrm{~m}^{-3}$, for particles of density $2500 \mathrm{~kg} \mathrm{~m}^{-3}$ and sizes of $0.1,1$, and 


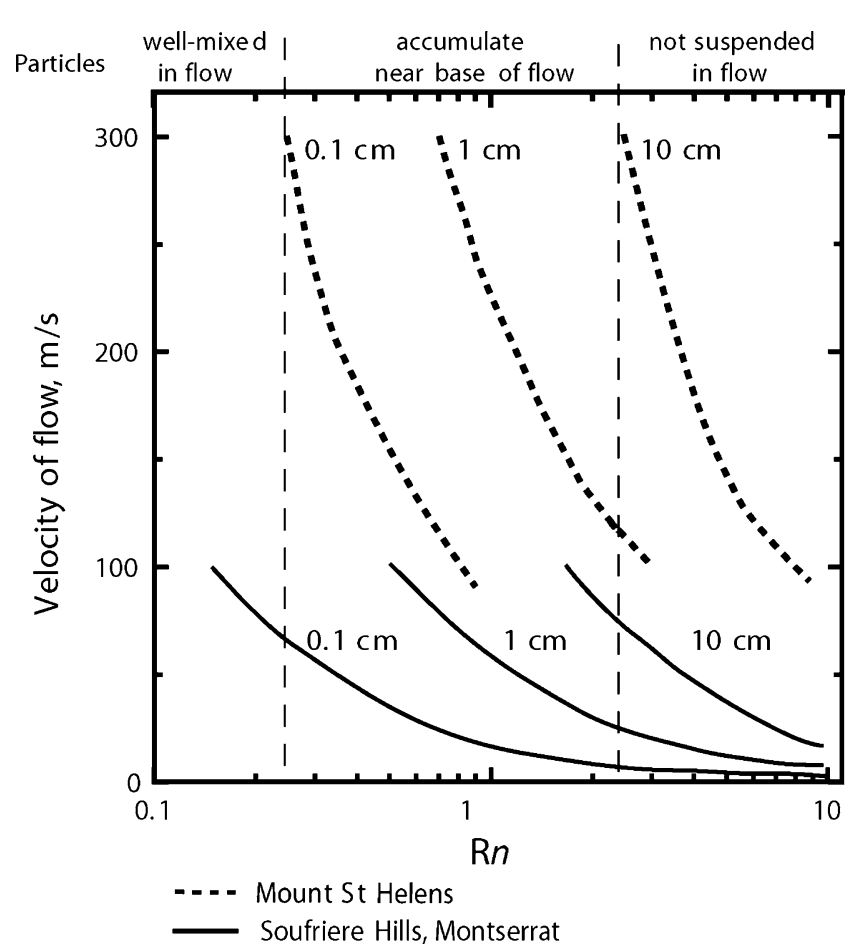

Fig. 5 Rouse number $\left(R_{n}\right)$ as a function of the free-stream flow velocity of dusty gas (steam) and particle sizes $(0.1,1$ and $10 \mathrm{~cm})$ for the Mount St Helens blast (dashed lines, after Valentine 1987), and the Soufrière Hills volcano blast (solid lines, after Woods et al. 2002). For MSH, parameters include roughness height of $1 \mathrm{~m}$, boundary layer thickness of $5 \mathrm{~m}$, clast density of $2000 \mathrm{~kg} \mathrm{~m}^{-3}$. For SHV, parameters include a flow of bulk density $100 \mathrm{~kg} \mathrm{~m}^{-3}$, and clast density $2500 \mathrm{~kg} \mathrm{~m}^{-3}$. For particles with $\mathrm{Rn}>2.5$, turbulent suspension is ineffective

$10 \mathrm{~cm}$. For internal current speeds about $80-120 \mathrm{~m} \mathrm{~s}^{-1}$ (suitable for the burst phase at SHV), particles with size much in excess of $10 \mathrm{~cm}$ cannot be kept in suspension and will be transported in traction or deposited, whereas particles in the range $1-10 \mathrm{~cm}$ will be barely suspended and will concentrate near the base of the current. Only particles that are of 1-2 mm diameter or finer will be wellmixed in the current. The internal current speeds at $\mathrm{MSH}$ may have been greater $\left(\sim 200 \mathrm{~m} \mathrm{~s}^{-1}\right)$ and therefore $10 \mathrm{~cm}$ clasts could be supported (dashed lines, clast density $2000 \mathrm{~kg} \mathrm{~m}^{-3}$ ). These results seem qualitatively consistent with the deposits at both MSH and SHV (Waitt 1981; Ritchie et al. 2002).

The implication is that vertical stratification of the current in both density and particle size, which results from the concentration of intermediate sized particles near the base of the current, is likely to develop very early, within the burst and collapse phases, and as the blast PDC spreads rapidly from the collapsing explosive fountain (Woods et al. 2002). This stratification can lead to segregation of the current and vertical stratification of the deposits.

Thus in very proximal zones, the blast currents have transitional characteristics, involving a dense lower part grading up into a more dilute part, with the denser lower part of the current moving independently of the upper part and being more influenced by topography and localized blocking (Valentine 1987; Fisher 1990). This dichotomy partly explains some of the controversies that developed in the literature for $\mathrm{MSH}$, on whether or not the blast phenomenon corresponded more closely to a pyroclastic flow or a pyroclastic surge.

At greater distances from the source, the density of the blast PDC rapidly waned as a result of loss of mass in the current to deposits or a traction layer. Thus blast deposits in distal zones (which may constitute the majority of the area of the blast) can resemble those of typical surge deposits, with grain sizes dominantly $1-2 \mathrm{~mm}$ or finer, implying that the concentration of particles in the moving distal current was relatively low.

Using observations of tree damage from the blast PDC at about $8 \mathrm{~km} \mathrm{NW}$ from the source at MSH, Clarke and Voight (2000) estimated upper-bound current density averaged over the height of destroyed trees as $5-8 \mathrm{~kg} \mathrm{~m}^{-3}$. Overall current height was taken as $\sim 200-400 \mathrm{~m}$, and the bulk density increases substantially with depth, reaching a maximum value near the base of the current that is many times greater than its average value (Valentine 1987). Kieffer and Sturtevant (1988) assumed $10 \mathrm{~kg} \mathrm{~m}^{-3}$ for flow density at MSH for a boundary layer $14 \mathrm{~m}$ thick at $\sim 9 \mathrm{~km}$ from source, but in contrast for a region $15-18 \mathrm{~km}$ from source at MSH, Bursik et al. (1998) calculated a bulk current density of $1.5 \mathrm{~kg} \mathrm{~m}^{-3}$, only $36 \%$ greater than atmospheric density at a similar altitude $\left(1.1 \mathrm{~kg} \mathrm{~m}^{-3}\right)$. The latter value is consistent with the buoyant lift-off that occurred about $5 \mathrm{~min}$ after blast initiation, generating a giant plume that carried about $30 \%$ by mass of the PDC (Sparks et al. 1986). The lift-off was enabled by progressive loss from the PDC of particles by sedimentation, and by airentrainment and heating, thus reducing current density to less than atmospheric density.

For SHV, Sparks et al. (2002) suggest that an approximate expression for density of the current mixture $\left(\rho_{b c}\right)$ is:

$\rho_{\mathrm{bc}}=\mathrm{p} / \mathrm{nRT}$

where $p$ is impact pressure (as judged from structural damage; Valentine 1998a), $n=0.1-0.2, R=265 \mathrm{~J} \mathrm{~kg}^{-1} \mathrm{~K}^{-1}$, and temperature $=500 \mathrm{~K}$, yielding an estimate of $6 \mathrm{~kg} \mathrm{~m}^{-3}$. These values are similar to those reported for ordinary pyroclastic surges elsewhere, e.g., $3-5 \mathrm{~kg} \mathrm{~m}^{-3}$ for distal surges at Unzen (1991), Merapi (1994), and Lamington (1951) (Clarke and Voight 2000). Note that these are crude average measures, given the stratified nature of the currents.

In contrast, Esposti Ongaro et al. (in press) on the basis of multiphase models report for SHV higher current densities, ranging from 116 to $17 \mathrm{~kg} \mathrm{~m}^{-3}$, at $10 \mathrm{~m}$ above ground level and 2-4 km from source, and decreasing with 
distance from source. These higher density values are significant in that higher dynamic pressures may be generated at moderate speeds.

Devastation in the blast-affected zones and destructive mechanisms

The explosions and blast-generated PDCs affected vegetation and soils both mechanically and thermally in the course of their movement. The effects were similar in general for the three eruptions.

At $\mathrm{BZ}$ all vegetation was carried away within a radial distance of $10 \mathrm{~km}$ from the volcano. At distances 10-20 km a small number of bushes remained, but were knocked over in the direction of blast current. On the upper limit of birch forest (20 km from the volcano), all trees were knocked down or broken off at a height $1-1.5 \mathrm{~m}$ above the ground. With increasing distance from the source, the average height at which trees were broken off gradually increased. At the narrow outer margin of the blast-affected zone, the majority of trees had lost only their tops (Belousov 1996).

Destruction at MSH was nearly complete within a radial distance of $13 \mathrm{~km}$ from the source, with all vegetation and most of soil removed from slopes facing the volcano; beyond this zone, in an area extending $18 \mathrm{~km}$ ENE and $24 \mathrm{~km} \mathrm{NW}$, old-growth timber was blown down and lesser vegetation was killed. Most of the damaged trees were delimbed before or during blow down, based on the observation that most felled trees were limbless (Waitt 1981; Moore and Sisson 1981). Also in most situations at MSH the forest was toppled en masse, such that there was a 'group effect' to the destruction (Clarke and Voight 2000). At the outer limits, younger trees were flexed, but older thicker-trunked trees tended to break off near the top.

Kieffer (1981) described two zones, an inner 'direct blast zone' in which the current was more or less radial and relatively undeflected by even large topographic features, and an outer 'channelized blast zone' in which the current followed or was deflected by local topography. These observations were interpreted in light of a $2 \mathrm{D}$ 'rocketexhaust' blast model, in which intercepting shock waves connected across the blast front to form a Mach disc shock, about $11 \mathrm{~km}$ north of the vent (Kieffer 1981; JANNAF 1975). The current upstream of this disc would be supersonic and at sub-atmospheric pressure, and the current downstream, subsonic and near-atmospheric pressure. Kieffer proposed that the boundary between the direct blast zone and the channelized blast zone north of the vent marked the position of the Mach disk shock, and that possibly the boundaries on the east and west represent positions of much weaker intercepting shocks. A subsequent solution using a Lockheed plume code was thought preferable but the discrepancy between the disc position and the field zone boundary was increased (Kieffer 1984). The temperature increases dramatically on passing through the disc shock (Kieffer 1984). Wohletz and Valentine (1990, Fig. 12) briefly presented some results from a numerical model with gravity effects, using input data similar to Kieffer (1981), and suggested that their results generally supported her model; however the Mach disc interpreted by Wohletz and Valentine occurred at only $3.5 \mathrm{~km}$ from the source.

In a further study, Kieffer and Sturtevant (1988) described furrows from ridge tops in the region $3.5-9 \mathrm{~km}$ from the blast source, and interpreted them as caused by scour from longitudinal vortices resulting from flow instabilities induced by complex topography. The erosion under the furrows was about an order of magnitude greater than predicted for a vortex-free boundary layer, with a scour rate $\sim 0.7 \mathrm{~cm} / \mathrm{s}$ and vertical mass flux of eroded soil $\sim 9 \mathrm{~kg} \mathrm{~m}^{-2} \mathrm{~s}^{-1}$.

While not disputing that shocks can occur with some types of eruptions (e.g., Wohletz et al. 1984), and notwithstanding the relative sophistication (for the 1980s) of the models presented, we are suspending judgment about the shock model as a primary explanation for the damage sustained at MSH. There are some problems. The assumptions of a fixed vent and a blast duration of 10-20 s are at variance with observations of multiple explosions from moving slide blocks over a period of several minutes, creating an unsteady PDC (Voight 1981; Sousa and Voight 1995; Hoblitt 2000). Stratified flow, boundary friction, and flow in a vertical plane are not considered. A standing Mach disc shock is mainly a steady-state flow phenomenon, whereas the MSH blast was highly transient, and any such shock was likely very short lived (few seconds). The Wohletz and Valentine (1990) result of an interpreted shock at $3.5 \mathrm{~km}$ does not match the result of Kieffer (1981) nor does it explain the severe damage observed at MSH to $\sim 13 \mathrm{~km}$ radius from the blast source. Likewise, Brodsky et al. (1999) reported on the basis of seismic data that a significant proportion of the jet thrusts during the blast were steeply inclined (quasi-vertical rather than quasi-horizontal), and although this does not preclude lateral shock effects, it does argue against quasi-steady flow and a disc shock at fixed position. Finally there is no evidence from blast deposits of any temperature increase beyond the postulated position of the disc shock (Banks and Hoblitt 1981), although this may not be a strong argument.

As an alternative explanation, we suggest that the boundary between the 'direct blast zone' and 'channelized blast zone' could instead be interpreted in light of sediment concentration gradients and dynamic pressure thresholds within a stratified current. In the axial and proximal region the current possessed the greatest solids concentration, carried the coarsest sediment and entrained objects (e.g., 
boulders and trunks of trees) capable of inducing impact damage, and had the greatest lateral dynamic pressure, defined as half the product of the fluid mixture density and the velocity squared (Valentine 1998a; Clarke et al. 1997; Clarke and Voight 2000). Thus erosion and damage from a PDC, and from the inclined collapsing fountain that precedes PDC generation, would have been more severe in the proximal region, and here the currents might not have been strongly influenced by local topography. In distal and peripheral regions, solids concentration, maximum particle size, current speed, and dynamic pressure were much diminished, thus causing lesser damage and localized blocking of the stratified current. Also, in these regions topography could exert more influence on current orientations, especially on the lower parts of the PDC. We think that such a model is plausible and can explain most of the observed damage without recourse to bow-shocks propagating ahead of the current (Wohletz 1998), which we believe did not occur at MSH because speed of the current front was less than atmospheric sound speed, or strong shocks standing within the current (Kieffer 1981, 1984). We do not preclude the existence of some shock effects in either the burst or collapse phases at relatively close range, or even in the PDC phase at farther distances, because sound speeds of dense mixtures are low (Wallis 1969). But we suspect that such $M>1$ (Mach number) effects may be localized to near-source areas and to dense mixtures near the base interior parts of the PDC. Further, in the latter case, severe damage at any given location could be generated by high dynamic pressure in frontal parts of the PDC with $\mathrm{M}<$ 1 , before the interior $M>1$ region arrived. The adequacy of these competing hypotheses needs to be tested further by 3D multiparticle thermofluid modeling on a high-resolution DEM (e.g., Esposti Ongaro et al. 2005a,b, in press); such modeling research is now under consideration for MSH and BZ by several research groups.

At SHV, seismic data suggest six pulses (Sparks et al. 2002) that might have involved specific erosional and depositional events, although stratigraphy suggests clearly only two depositional events and at least two erosional events (Ritchie et al. 2002). The discrepancy has not been resolved. The individual events were likely short lived, lasting but a few minutes. The destruction was complete in the axial area of the blast near the village of St Patrick's, where in general only the foundations of houses remain, with most loose debris (including building walls) having been flattened to the ground or carried to the sea. Buildings swept away include stone-built structures and those with poured reinforced concrete walls, and trees with trunks up to $1 \mathrm{~m}$ diameter were removed entirely leaving only abraded stumps and roots (Sparks et al. 2002). Entrained boulders and pieces of destroyed buildings added to the destructive capability of the PDCs in addition to dynamic pressure (Baxter et al. 2005). East of this axis, the blast zone is dominated by erosional features across the shoulder of an older volcanic edifice, thus creating an asymmetric blast zone. The severity of damage decreases systematically, but with local variability, from the axis of the PDC towards the lateral periphery. One kilometer west of the axial zone, the top floors of houses were blown down and scattered $50 \mathrm{~m}$ downslope, impact marks from saltating boulders occur on house walls facing the volcano, and trucks and a bulldozer were flung over a cliff onto the beach (Sparks et al. 2002; Baxter et al. 2005). Although trees up to $50 \mathrm{~cm}$ diameter were broken a few meters above ground, smaller trees $(<10 \mathrm{~cm}$ trunks $)$ and shrubs were merely bent over with branches stripped and the trunk tip sharpened by abrasion. Still farther from the axis, house walls were damaged, roofs were partially or entirely removed, and crumpled cars were displaced tens of meters. At the lateral limit of damage in a 200-m marginal zone, damage was limited to in-blown windows and displaced roof tiles and blown-down wooden sheds (Sparks et al. 2002). Lateral dynamic pressures estimated from the damage ranged from $>25 \mathrm{kPa}$ in axial regions to $1-3 \mathrm{kPa}$ near the periphery, with local fluctuations of about $\sim 1-$ $5 \mathrm{kPa}$ associated with localized sheltering and topographic effects (Baxter et al. 2005).

The SHV blast was simulated by Esposti Ongaro et al. (2005a,b, in press) using 2D and 3D multiparticle thermofluid dynamic flow codes and realistic topography. This study includes the first truly 3D modeling of a directed blast. The source was taken as a decompressed dome on a sloping flank, using the Woods et al. (2002) model of preblast pressure profile. The simulations used three particle sizes $(5,000 \mu \mathrm{m}, 500 \mu \mathrm{m}, 50 \mu \mathrm{m})$, representative of the range of observed size classes, and the influence of several different source volumes was tested over a $20-\mathrm{m}$ grid. The modeling demonstrated the important influences on mass and inertia on blast dynamics, and enabled time-sequential maps of particle concentration, velocities, and dynamic pressures. The $3 \mathrm{D}$ model run representative of a highervolume destructional pulse generated a blast-affected sector of $\sim 70^{\circ}$, comparing well with the mapped blast area. Velocities ranged from $>100 \mathrm{~m} \mathrm{~s}^{-1}$ in the proximal blast and collapse phases to $30-40 \mathrm{~m} \mathrm{~s}^{-1}$ on the lower flank. The dynamic pressures were $20-60 \mathrm{kPa}$ for the region of complete destruction, matching well the estimates based on field observations (Sparks et al. 2002; Baxter et al. 2005). Peripheral areas show $<10 \mathrm{kPa}$, also compatible with observations of damage. The dynamic pressures built up over tens of seconds.

Esposti Ongaro et al. (in press) also calculated the distribution of mixture velocities within the blast plume, and by comparison with local sound speeds, generated the distributions of Mach number for the same simulations. In 
one model run with high gas pressure, by $10 \mathrm{~s}$ the blast collapse phase exhibited a stem region with $\mathrm{M}>1.4$, enveloped by a region of $\mathrm{M} \ll 1$, both upstream and downstream. Such a Mach number distribution, influenced by high speed generated by the gravitationally collapsing mixture, involves a quite different mechanism than the blast phase Mach disc postulated by Kieffer (1981) for MSH using the assumption of steady blast flow. After $20 \mathrm{~s}$, the region for $\mathrm{M}>1$ was limited to a thin continuous basal PDC zone to $\sim 2 \mathrm{~km}$ from source, and by the time the PDC arrived at St. Patricks (where observed devastation was complete), the basal zone indicated $\mathrm{M}<0.6$ although dynamic pressures were very high. Thus even if one were to infer that a PDC region of $\mathrm{M}>1$ were to spread downslope to encompass an area of potential damage, that area would already have been subjected to a dynamic pressure pulse $>20 \mathrm{kPa}$, sufficient to cause heavy damage.

Considering the several volcanoes generally, the orientations of tree destruction and blow-down, fence posts, and other damaged features in the blast zones show that although moderate-to-small scale topographic obstacles were not able to influence significantly the gross propagation of the blast current in proximal regions, they generated vortices and shaped local sub-currents, orientations of which could deviate considerably from general directions of the blast currents (Belousov 1996; Lipman and Mullineaux 1981; Ritchie et al. 2002; Sparks et al. 2002; Baxter et al. 2005). All the blast-generated currents strongly eroded substrate in proximal areas, and eroded material was incorporated in the blast current and subsequently deposited. On BZ a layer of frozen pre-climactic ash $>1 \mathrm{~m}$ thick, as well as a layer of snow of unknown thickness (but $\gg 1 \mathrm{~m}$ ), was completely eroded away. On MSH and SHV thick soil was locally stripped off and bedrock exposed.

\section{Directed blast deposits}

Components of the deposits

There are two types of clasts in the blast deposits, juvenile and accidental. In general, the juvenile material comprises more than $50 \mathrm{vol} \%$ of the deposits, and at BZ, MSH and SHV is represented by highly crystalline andesite, dacite, and andesite, respectively, with significant ranges in vesicularity (Fig. 6, Table 1). The average density of juvenile clasts is high and vesicularity is low. The clasts originated from magma that had ascended into or onto the edifices during the pre-climactic stages of the eruptions; the earliest emplaced magmas were then stored and evolved texturally, for months.

The density distributions of the juvenile clasts of $\mathrm{BZ}$ and MSH have a clear bimodality, while the SHV clasts appear

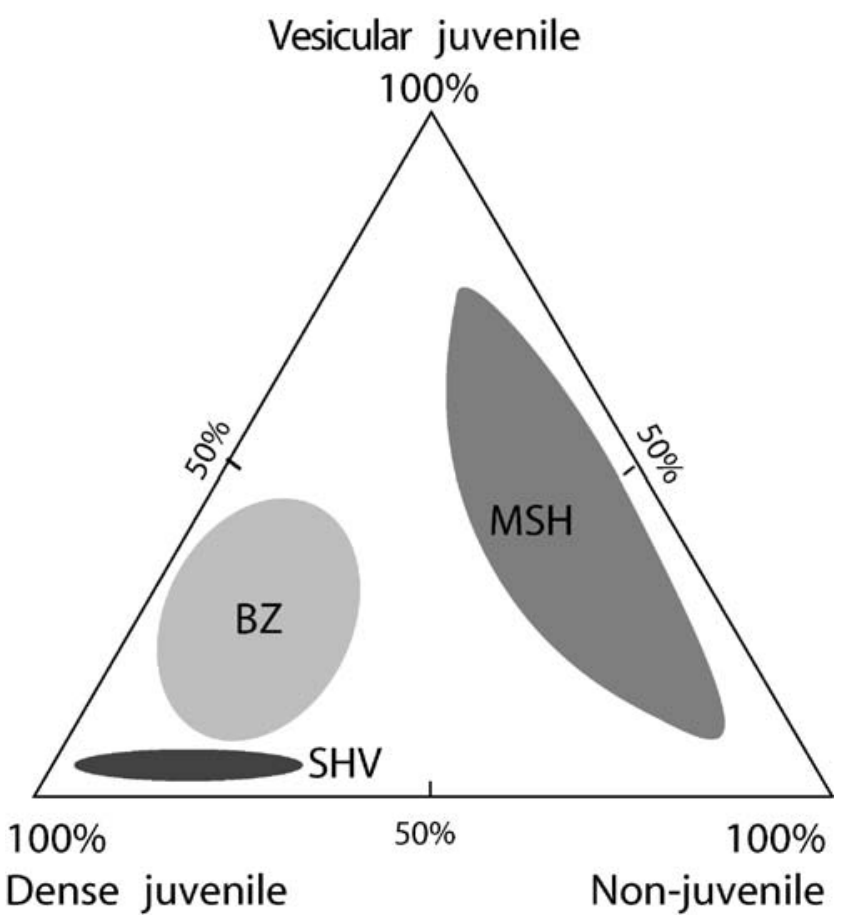

Fig. 6 Percentage of vesicular juvenile, dense juvenile and accidental fragments in the directed blast deposits of Bezymianny 1956 (BZ), Mount St. Helens 1980 (MSH), Soufrière Hills volcano 1997 (SHV). Sources: Belousov (1996), Hoblitt and Harmon (1993), and unpublished data of authors

unimodal, with a peak that corresponds to the dense mode of BZ and MSH (Fig. 7). Highly vesicular material has a light-gray color, and dense material is typically dark-gray, with the densest clasts having a very dark-gray to almost black color.

A comparison of parameters for the pre-blast shallow magma bodies (residence time or 'age,' volume, and degree of exposure to ground surface), leads to the conclusion that the dense mode represents the most-cooled (in some cases chilled) and degassed material of the outer parts of the intruded magma bodies. The low-density mode represents internal parts of the magma body, with pre-explosion formation of gas-filled vesicles that had formed as a result of melt degassing in association with ascent and shallow arrest, decompression, and microlite crystallization of anhydrous minerals. Finely crystalline cryptodome dacite clasts at MSH have high number densities of small acicular plagioclase microlites and glass compositions that indicate equilibration at shallow levels $(10-30 \mathrm{MPa}$, resulting in undercooling $>100^{\circ} \mathrm{C}$ ) (Rutherford et al. 1985; Cashman and Blundy 2000). During and after the blast explosion, much of this fragmented cryptodome magma was able to actively expand, generating the coarse bread-crust bombs that are common in the blast deposits of both $\mathrm{BZ}$ and MSH. The material from the expanded internal parts of these bombs is virtually identical with the material of the low- 

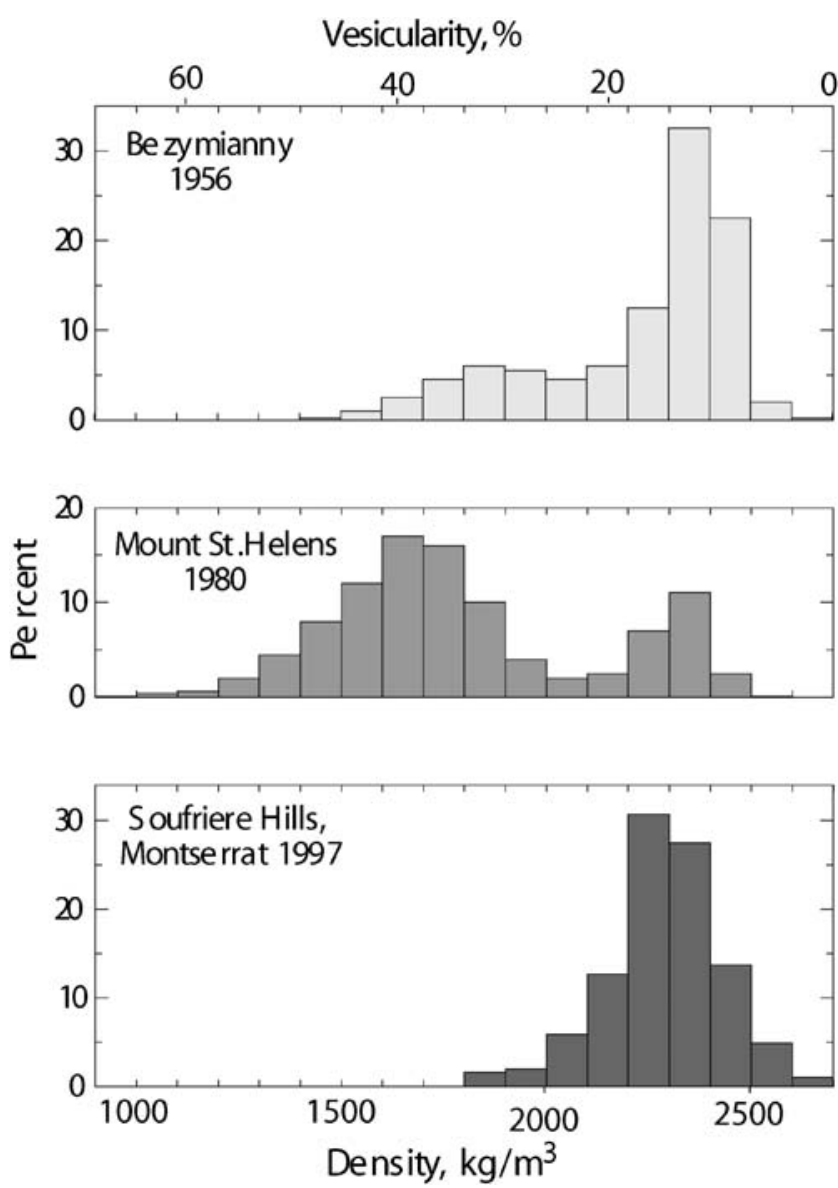

Fig. 7 Clast density and vesicularity distributions for juvenile material of directed blast deposits of Bezymianny 1956, Mount St Helens 1980 and Soufrière Hills volcano 1997. Measured clasts were $1-2 \mathrm{~cm}$ across. Vesicularity was calculated using a dense rock value of $2,700 \mathrm{~kg} \mathrm{~m}^{-3}$. Data from authors and R.P. Hoblitt

density clasts from the blast deposits. The outer dense crust of the bombs represents the chilled material of the internal, partly molten parts of the magma bodies; the initial vesiculation of the outer parts of the bombs was arrested by rapid cooling when the bombs were hurled through the air.

In contrast, practically the whole volume of magma involved in the SHV blast was already too crystalline and degassed to vesiculate further once the blast initiated, thus material of the blast deposit is represented primarily by the dense mode. Crystallinity in the SHV dome was developed primarily by degassing, not cooling (Sparks et al. 2000). Bread-crust bombs, oblate spheroidal in shape, are rare in SHV blast deposit; the several we found were probably ejected by late-blast vulcanian explosions involving small amounts of magma from parts of the conduit passing through the dome.

The shapes of juvenile gravel-boulder-size clasts in the blast deposits can be characterized as subangular for most dense clasts to subrounded for most vesicular clasts. The relatively angular character of the clasts indicates a brittle fragmentation of the blast charge from a shallow magma body that was already mostly crystallized at the moment of the blast. Rounded edges were obtained as a result of abrasion (multiple collisions) of clasts during transportation in the blast PDC, and the more-rounded shape of vesicular clasts is due to their weaker resistance to abrasion. Some very angular clasts of vesiculated material, with sharp edges, represent the result of disintegration of larger clasts (bombs) along prismatic cooling joints, which occurred just before, or even after, deposition.

Accidental (non-juvenile) clasts are represented by old rocks of different lithologies, as well as different degrees of oxidation and alteration, having different colors, densities, and compositions (chemical and mineral). The proportion of accidental clasts in the blast deposits widely fluctuates (Fig. 6); in general it is less than $50 \mathrm{vol} \%$. A portion of the accidental clasts originated from the edifices of the volcanoes, and a portion was derived by incorporation of erosion products into the blast current, such as from underlying debris avalanche deposits. Due to similarities in some lithologies, these parts cannot always be precisely partitioned. A comparison of substrate material, and accidental clasts in blast deposits directly above, shows that the material eroded from the substrate was generally not transported far from the source since the erosion and subsequent deposition of this material seem closely spaced in time and position. Topographic obstacles (volcano-facing slopes of ridges, uprooted trees, buildings) where blastinduced erosion was especially high, often served as local sources of accidental material.

The blast deposits also contain pieces of vegetation, soil (clots and/or dispersed), and - where available at MSH, SHV - fragments of different artificial material such as broken wood, metal, or plastics. These materials were entrained from the substrate by the blast PDC. They are variously affected thermally and are usually concentrated in the lower layer of the deposits (Belousov 1996; Fisher 1990).

\section{Thickness}

The thickness of the blast deposits widely fluctuates on short distances but on a kilometer-scale the maximum value shows a clear tendency to decrease with distance from the volcano (Fig. 8a). In the proximal zone thickness fluctuations are especially large, from a few $\mathrm{cm}$ to a few meters on interfluves, and tens of meters in river valleys. The fluctuations of thickness over interfluves are caused by very unsteady deposition from the blast currents, which resulted in a typically patch-like distribution of blast deposits (Belousov 1996) (Fig. 8b). Patches decimeters to several meters thick are tens to hundreds of meters wide at 


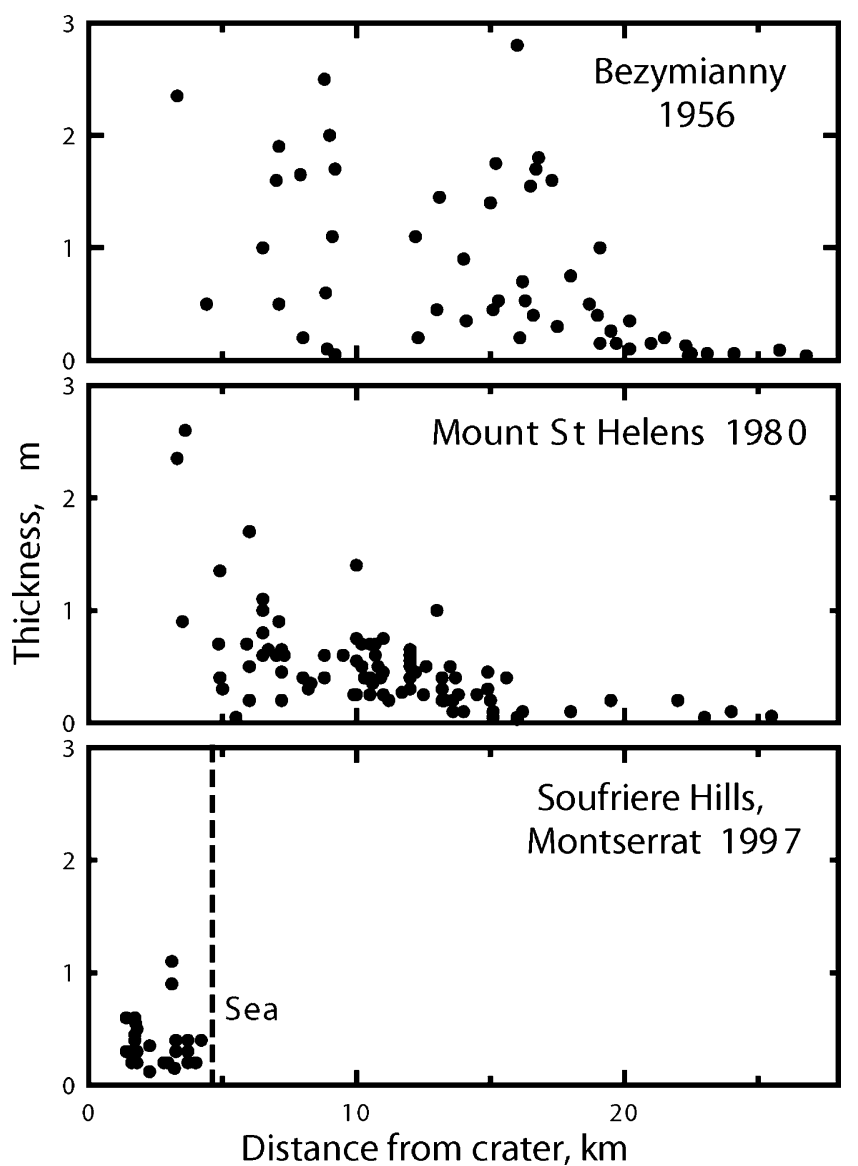

Fig. 8 Thicknesses of directed blast deposits of Bezymianny 1956, Mount St Helens 1980, Soufrière Hills 1997, versus distances from the craters along axial zones of blasts. Thickness data from valleys are excluded. Sharp thinning at Bezymianny and Mount St Helens indicates transition from proximal zone to distal zone stratigraphies. This transition occurred offshore at Soufrière Hills. Data from Belousov (1996), Hoblitt et al. (1981), Druitt (1992) and unpublished data of authors

$\mathrm{BZ}$ and $\mathrm{MSH}$, and are separated by areas of similar or larger sizes where the thickness of the blast deposit decreases to almost zero. The layered deposits thin toward the margin of patches, so that the distribution of patches cannot be explained simply by erosion, although erosion could modify the bedforms.

The maximum thicknesses of blast deposits on interfluves in the proximal zones of $\mathrm{BZ}$ and $\mathrm{MSH}$ are approximately equal, around $2.5 \mathrm{~m}$, and this is consistent with the similar scales and energies of the blasts and durations of sedimentation (Belousov 1996; Hoblitt et al. 1981). Although the SHV blast volume is about four to six times smaller, the maximum thickness of the interfluve blast deposit there is only two times smaller, around $1 \mathrm{~m}$ (Ritchie et al. 2002).

In distal zones, the fluctuations of thickness are much smaller (few $\mathrm{mm}$ to $10 \mathrm{~cm}$ ). The patchy character of the distribution of blast current deposits is absent or not so profound here, and thickness fluctuations seem to reflect the presence of dune-like structures. For BZ and MSH, within the proximal zone, or within the distal zone, the deposit thickness decreases rather slowly with distance from the volcano; however a sharp decrease of thickness occurs at the transition from proximal to distal zones. At $\mathrm{BZ}$ and MSH (NW sector), the change occurs in axial regions of the blasts at distances of about 19 and $15 \mathrm{~km}$, respectively (Belousov 1996; Hoblitt et al. 1981), about $0.5-0.6$ of the total runout distance, with some variations with azimuth. For the ENE sector at MSH, the boundary occurs at $\sim 8 \mathrm{~km}$ (Druitt 1992), corresponding to the proximal-medial boundary of Fisher (1990). In the axial zone of SHV, the transition to the distal zone cannot be observed and probably occurred over the sea. In all the three cases, the proximal/distal boundary is located at the farthest distance from the volcano in the axial part of the devastated zones, and is progressively closer to the source with increasing angle off-axis.

Large thicknesses of blast deposits occur in valleys, and are the result of localized pyroclastic flow-like behavior of the PDC (see 'valley facies' below).

\section{Deposit stratigraphy}

Proximal zone

The stratigraphy in the proximal zone is complex and dependent upon local conditions. A critical factor appears to be local relief on a moderate to large scale. Two major depositional environments are distinguished for blast deposit facies, namely interfluves, and large valleys.

Interfluve facies

The interfluve facies for the deposits of the blast current consists basically of three layers, A, B, C, listed from bottom to top (Figs. 9, 10). This nomenclature was first applied to the Bezymianny deposit (Belousov 1996), while for MSH it corresponds respectively to layers A0, A1, A2 of Fisher (1990). For SHV, the layer A - due its poor development - was not distinguished by Ritchie et al. (2002), but instead was described together with the well-developed layer B as part of Layer 1, while their Layer 2 corresponds to our layer C. A principal difference at SHV in comparison to the other sites is that the interfluves (and valleys) slope seaward at $\sim 10^{\circ}$, and generally complex topography did not lie athwart the main blast current direction. The result was that the event at SHV was largely erosional with very little deposition on land; only $2-3 \times 10^{6} \mathrm{~m}^{3}$ was deposited, and about ten times this much either entered the sea or was convected into a 
Fig. 9 a Composite

stratigraphic sections of directed blast deposits. b Generalized stratigraphic sections for Bezymianny 1956, Mount St Helens 1980, Soufrière Hills 1997

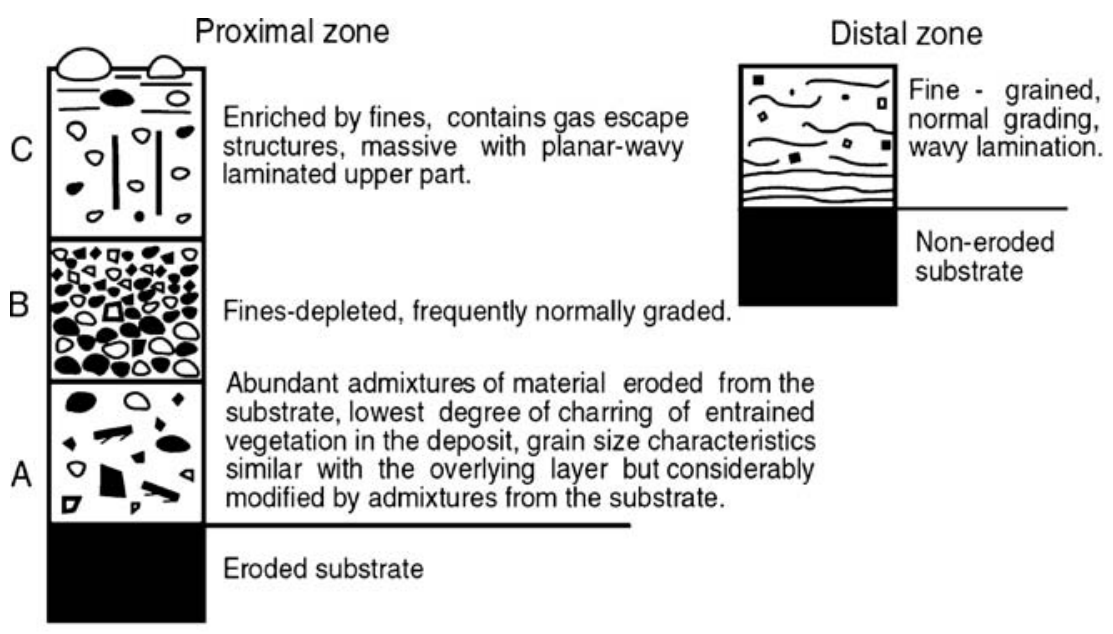

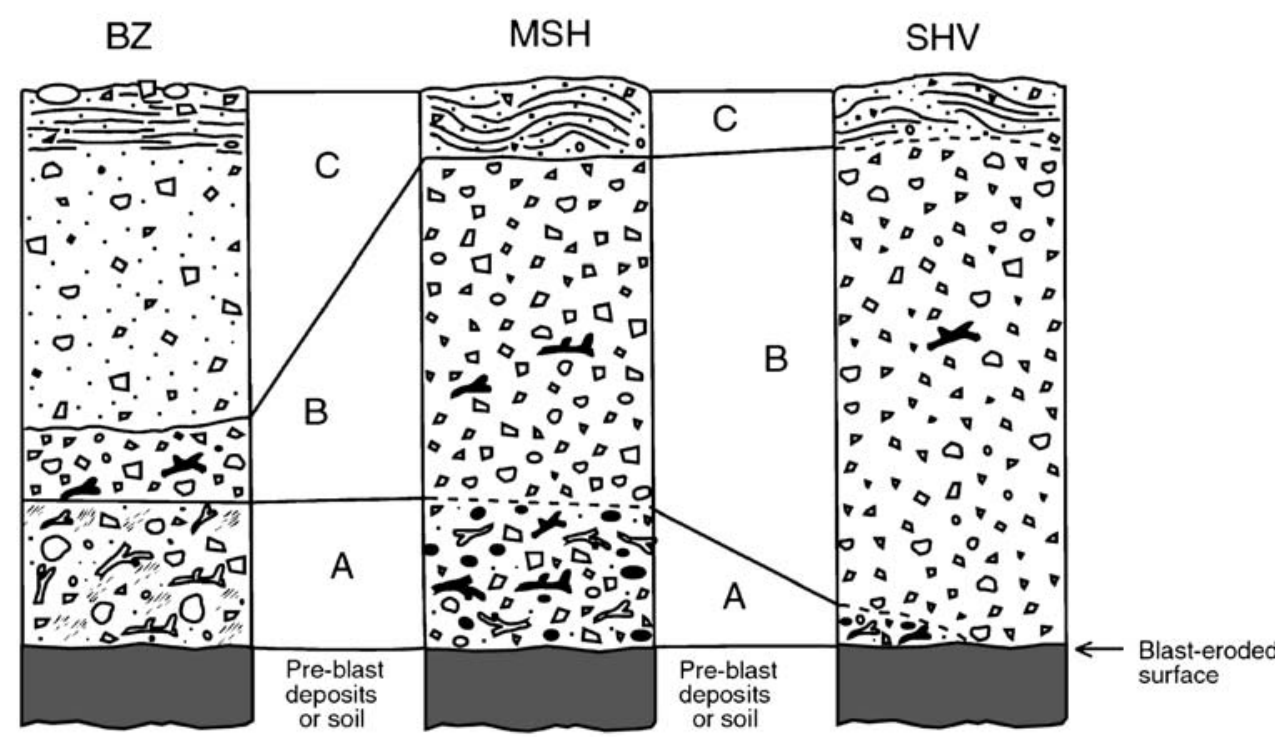

$\left.\begin{array}{l}\text { Gravel-sized clasts } \\ \text { Sand-sized clasts }\end{array}\right\} \begin{aligned} & \text { Mixed dense and vesiculated } \\ & \text { juvenile and accidental }\end{aligned}$
Fragments of plants (charred and uncharred)
Sispersed soil
Schlieren of soil lofting plume of ash and steam (Sparks et al. 2002; Mayberry et al. 2002).

The deposit is veneered at all locations by an uppermost layer D of fines and accretionary lapilli (layer A3 of Fisher 1990; blast ashfall of Sisson 1995; Unit 3 of Ritchie et al. 2002), which is an ash fallout deposit of the finest particles from the high-rising thermal plume associated with the blast PDC (Sparks et al. 1986; Mayberry et al. 2002). This layer is dispersed over a wider region than that affected directly by the PDC and represents about $30 \%$ of the mass carried by the PDC (Sparks et al. 1986).

In most cases, the contacts between the $\mathrm{A}, \mathrm{B}, \mathrm{C}$ layers are sharp and well defined, but they are gradual in some locations. The thickness of each layer is commonly of the order of a few $\mathrm{cm}$ to a few tens of centimeters (occasionally to $\sim 1 \mathrm{~m}$ for layer $\mathrm{A}$, and $\sim 2 \mathrm{~m}$ for $\mathrm{C}$, at $\mathrm{BZ}$ and $\mathrm{MSH}$ ), and 
Fig. 10 Typical outcrops of the classic directed blasts deposits. $(\mathbf{a}, \mathbf{b}, \mathbf{c})$ Interfluve facies, and $(\mathbf{d}, \mathbf{e}, \mathbf{f})$ valley facies, of proximal zones of Bezymianny (a, d), Mount St Helens (b, e), and Soufrière Hills (c, f). Stratigraphic layers A, B, C, and layer boundaries, are indicated. (g) Sandy deposit of the distal zone of Bezymianny blast (fine grained ash layers above and below are deposits of the preand post-climactic stages of the eruption, respectively).

$\mathrm{DA}=$ debris avalanche deposit; $\mathrm{BRD}=$ block-rich blast deposit; $\mathrm{PA}=$ pre-climactic ash
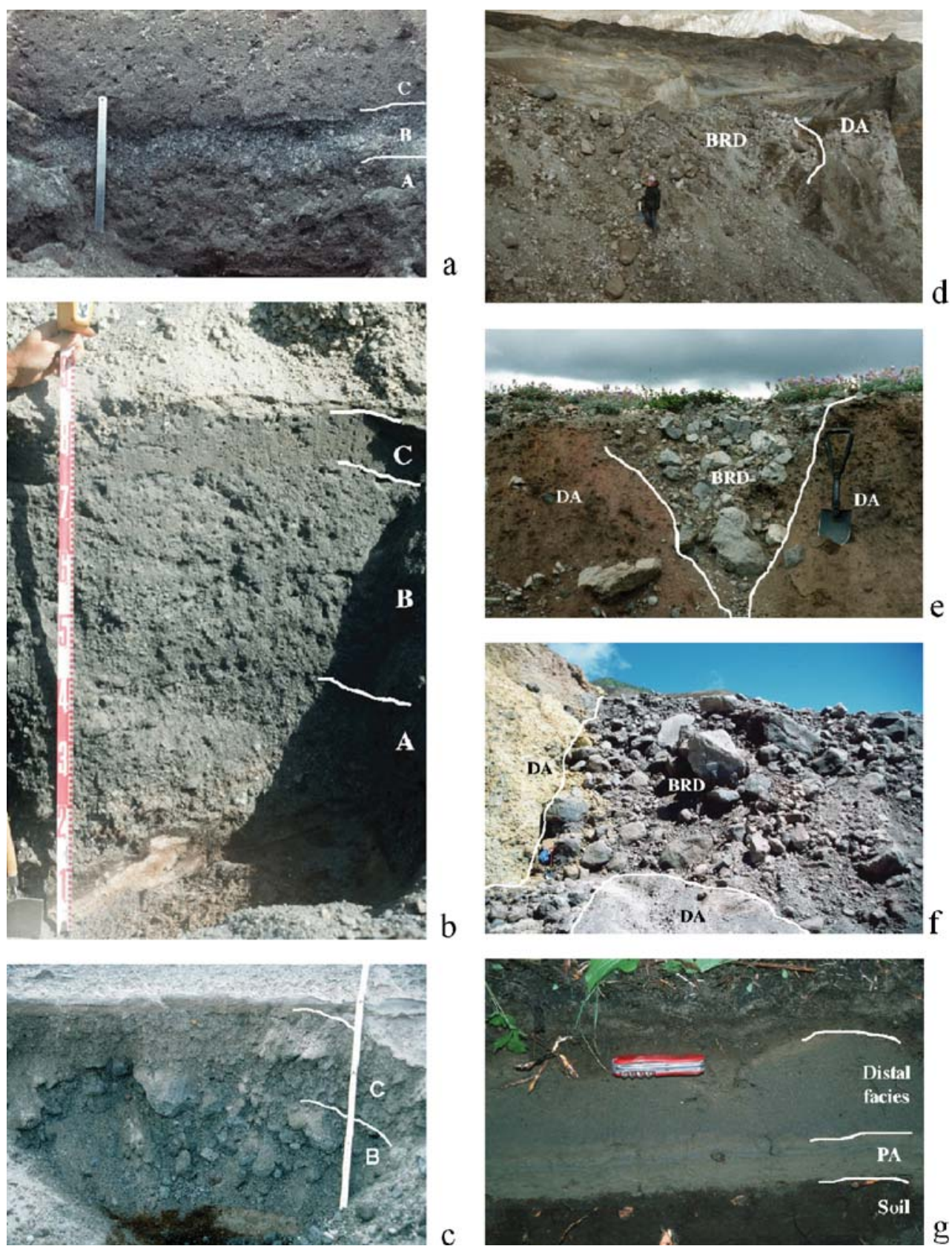

rapidly fluctuates over distances of tens of meters. These fluctuations have no clear relations with the thickness of other neighboring layers above or below, and are not proportional to the total thickness of the blast deposit in a particular location.

Several features, including occasional transitional contacts between the layers, suggest that the layered sequence at $\mathrm{BZ}$ and MSH was rapidly deposited, one layer after another, as a result of passage of a single blast-generated PDC (Druitt 1992; Belousov 1996). Differences in lithological characteristics of the three layers are the results of rapid evolution of sedimentation regimes in a blast current. Although one generalized blast current is envisaged, such a current can include pulsatory internal unsteadiness as a consequence of its generation from multiple explosions in the source area. Thus for MSH, at least two clusters of explosions are recognized as contributing to the blast current, and these were caused by the complex edifice collapse. The first cluster originated from a portion of the cryptodome inside slide block II as slide block I of the debris avalanche pulled away from it, and the second more intense explosion cluster began about one minute later from the remaining part of the cryptodome exposed behind the falling block II (Sousa and Voight 1995; Hoblitt 2000). Another interpretation involving a more northerly second explosion was given by Moore and Rice (1984), but this seems unconvincing to us. At 
SHV the situation is less clear. Six seismic pulses have been identified, intermittently pulsed for about 12 min (Sparks et al. 2002); these seismic pulses have been interpreted as explosive pulses, but only a few depositional units and erosional events have been recognized (Ritchie et al. 2002).

Layer $A$ is composed generally of poorly sorted sandy gravel (Figs. 9, 10). The layer rests on a PDC-eroded surface, and is always notably enriched (in some locations $>90 \mathrm{vol} \%$ ) in material of the substrate. If the substrate is soil, it could be either finely dispersed (BZ), or comprise sheared clots up to $10 \mathrm{~cm}$ across (MSH). This difference is the result of different ground conditions: on BZ the soil at the moment of deposition was partly cemented (frozen capillary moisture), while on MSH it was mostly thawed and soft. In several places on MSH, where the soil was still frozen at the moment of the blast (the eruption occurred in May and there were several places that were snow covered), layer A contains dispersed soil similar to BZ. Another reason for the abundant soil clots on MSH is the massive blast-induced tree blowdown, particularly in the proximal zone. Many of the trees were uprooted and the root balls served as local sources of clots of soil. At BZ there were no trees in the proximal zone (only small bushes, which were mostly broken and bent, but not uprooted) and thus there were few root balls to provide soil clots to the current. Layer A on SHV (part of Unit 1 of Ritchie et al. 2002) does not contain much soil, possibly due to a strong erosive pulse that preceded deposition. The dispersed soil makes layer A cohesive and homogeneous at BZ whereas clots of sheared soil and fragments of plants in layer A at MSH and SHV are incorporated in a fines-depleted, sandy gravel, layer A matrix, similar to layer B material (see below), that makes the layer friable. At some places A can be formed almost entirely of sheared soil, forest duff, and shreds of wood and vegetation, lacking juvenile clasts (Fisher et al. 1987). At others, sheared lenses of juvenile material are present. Thus layer A can have a different character, depending on what materials are eroded and entrained.

In places where substrate is represented by other than soil, e.g. an erodible material such as tephra, this material is also abundantly admixed in layer A. On BZ the substrate (besides snow) was mostly ash from the pre-blast vulcanian activity, and locally as much as $1 \mathrm{~m}$ of ash was eroded and incorporated in the blast deposit. In such places the admixture of this ash gives a yellowish cast to the whole layer A. Similarly, at MSH, layer A commonly contains white or yellow gravel-size pumice from pre-1980 MSH plinian deposits.

The strong erosion of the substrate that is characteristic for blast-generated PDCs provides the evidence for violent turbulence, in comparison with less powerful surges from different eruptive mechanisms, which usually do not have the capacity for such intense erosion. Thus at SHV the layer A (part of Unit 1 of Ritchie et al. 2002) was interpreted as localized accumulations and bedforms in a mainly erosional environment, later draped by layer B in the waning phase of the current. A similar interpretation obtains for BZ and MSH (Belousov 1996; Fisher et al. 1987; Druitt 1992).

Pieces of plants are abundant in layer $\mathrm{A}$ in all three cases. Plant fragments in layer A could be uncharred (BZ, $\mathrm{MSH}$ ) or partly charred (MSH, SHV), reflecting the temperature near the base of the frontal part of the PDC from which layer A was deposited. In the case of BZ the temperature was lower than at MSH because of colder ambient air entrained in the PDC head, and the erosion and ingestion of a thick snow pack.

The layer typically has no grading or poor normal grading (BZ), or reverse or multiple grading (MSH). Fisher (1990) reported as many as five beds in layer A, with some containing pre-1980 pumice, others with reworked soil or Tertiary rocks. In proximal sections layer A can contain lenticular layers of fines-poor dacite mixed with noncharred wood and overlain by organic-rich layers, or ground surface material mixed with a small amount of blast dacite, usually $<5$ vol. $\%$.

Whereas at BZ and MSH layer A is well developed and thins with distance; at SHV layer A is frequently thin (a few $\mathrm{cm}$ ) or entirely absent. At SHV, layer A is similar to that of MSH in places that were heavily vegetated before the blast. The reason for the degraded character of layer A on SHV is unclear but possibly reflects the close proximity of the deposits to the source of the blast, the dominantly erosive aspect of the current on a downslope topographic gradient, and the higher mean temperature of the current. As mentioned previously, at SHV layer A is replaced locally by a veneer of a peculiar tar-like substance sublimated from organic soil and grass by heat from the PDC. This phenomenon did not occur at BZ and MSH.

Among the three layers in any particular outcrop, layer A commonly has the poorest sorting and, where not composed simply of sheared soil, may contain the largest rock clasts. We interpret layer A to represent intense turbulent boundary shear between the basal part of the energetic head of the PDC, and the substrate. The layer is obviously derived from the head of the PDC because it occurs at the base of the deposit. Erosion is dominant in the front part of the head, and deposition starts at the rear part of the head and contiguous parts of the current body. Shearing under the PDC body continued after the onset of deposition, which accounts for schlieren textures (Fisher 1990) and occasional lenses of layer B material.

Layer $B$ is quite similar for the three studied cases and has an easily recognizable appearance (Figs. 9, 10). The gravelly layer is strongly depleted by fines and thus has a clast-supported fabric with open voids between clasts, 
similar to some proximal lithic-rich airfall deposits. The virtual absence of fines makes layer B the best sorted and most friable amongst the layered blast deposit sequence. There is generally little admixture of substrate material in this layer, with the local exceptions of pieces of charred vegetation. Mainly such vegetation is found in the basal third of layer B, commonly aligned in the direction of transport. Reworked older pumice is abundant, especially east of Spirit Lake at MSH (Waitt 1981).

Layer B displays various types of grading. For BZ and $\mathrm{SHV}$, normal grading is most common, while at MSH it is massive and mostly ungraded to faintly normal graded (Hoblitt et al. 1981), although reverse grading is also observed, especially near the base (Fisher 1990; Druitt 1992). Characteristics of this layer suggested that its deposition may have occurred by rapid suspension sedimentation in rapidly waning, high-concentration conditions (Druitt 1992; Belousov 1996). Fisher (1990) suggested it represented a sediment gravity flow. Although Valentine (1987) interpreted layers A and B as representing deposition from a high-energy waxing phase of the current, there is room for caution here as the processes are really poorly understood. We suggest deposition of layer B occurred because the largest and densest particles could not be supported by turbulence, and thus very rapidly settled out, in the region just rearward of the PDC head. We have previously discussed how the Rouse number $R_{n}$ can control the ability of a current to maintain clasts in turbulent suspension, and for current speeds of the order $100 \mathrm{~m} \mathrm{~s}^{-1}$, clasts in the range $1-10 \mathrm{~cm}$ will concentrate near the base of the current, being barely suspended. In such a hinderedsettling zone the main clast support mechanism is the upward escape of interstitial fluid, rather than turbulence (Druitt 1992). The hindered-settling zone has a gradational upper boundary fed by a rain of sedimentation, and accretes at the base to form a deposit (Druitt 1992; Choux and Druitt 2002; Middleton and Neal 1990). A small reduction in threshold conditions due to waning flow and interstitial fluid escape can then trigger the rapid fallout of such concentrated coarse clasts, resulting in this peculiar finesdepleted deposit. The open-work texture reflects the rapid settling, as clasts do not have time to organize themselves into dense packing configurations (Druitt 1992). Layer B thickens and coarsens into topographic lows, and thins and fines over highs (Hoblitt et al. 1981; Druitt 1992; Belousov 1996). These features suggest stratified flow blocking of the transport system (Valentine 1987; Fisher 1990).

Layer $C$ is a poorly sorted, matrix-supported, massive sandy gravel or gravelly sand, with a significant amount of fines (Figs. 9, 10). We may also refer to a lower part, layer $\mathrm{Ca}$, and an upper part, layer $\mathrm{Cb}$, corresponding to layers $A 2 a$ and $A 2 b$, respectively, of Fisher (1990). The upper part (layer $\mathrm{Cb}$ ) displays, in many cases, a fine internal lamination that becomes better developed with radial distance. Thin degassing pipes have been found at several locations in layer C on BZ and MSH (Belousov 1996; Hoblitt et al. 1981), where they commonly root onto buried vegetation and contain clasts coated with distilled carbon (Druitt 1992). Layer C on BZ is well developed with a thick, massive, lower part, while on MSH and SHV, the lower massive part of the layer is commonly thin, and in a few locations the whole layer exhibits crude sandwaves or has a fine internal lamination. Where it is massive, layer $\mathrm{C}$ can be similar in appearance to thin, fine-grained conventional pyroclastic flows. At SHV well-developed stratification occurs adjacent to small breaks in slope or depressions a few centimeters deep, and becomes better developed at greater distance from the source (Ritchie et al. 2002). Layer $\mathrm{C}$ thickens in lows and against obstacles, and thins over highs, but thickness variations are less pronounced than in Layer B.

Valentine (1987) suggested the deposition was from a waning phase current, and Fisher (1990) regarded it as a sediment gravity flow moving independently of the sediment gravity flow that deposited layer B. Druitt (1992) suggested an origin for the lower part of the layer by rapid sedimentation under moderate-concentration, weakly tractive conditions. Bursik et al. (1998) noted evidence at MSH for a dilute PDC density at distances $15-18 \mathrm{~km}$ from the vent, with layer $\mathrm{C}$ the main deposit.

Ritchie et al. (2002) noted that laboratory studies show that mixing at the flow head creates a turbulent and dilute wake above the body of a gravity current (Kneller et al. 1999), and suggested that layer B (SHV layer 1) was deposited by the flow body, and layer C (SHV layer 2) by the wake. The experiments of Choux and Druitt (2002) and Choux et al. (2004) lend support to this idea. In a blast PDC the division between these flow regions should be accentuated by heating entrained air, producing a thicker expanded wake with segregated fines, and by initial stratification generated by source dynamics (Ritchie et al. 2002; Woods et al. 2002).

We postulate that the upper (laminated) layer $\mathrm{Cb}$ denotes the transition to a dilute depositional regime with grain-bygrain traction deposition (Druitt 1992). At MSH, the upper layer $\mathrm{Cb}$ is mostly wavy, although laminated beds are reported (Waitt 1981), and at BZ and SHV, planar lamination is more common. Druitt (1992) noted for MSH that on stoss sides, sandwaves are well developed with downstream crest migration dominant, but on lee sides, sandwaves have lower amplitudes and mixed migration sense. The hydrodynamic explanations for these differences are poorly understood. Factors may include the particle concentration, current speed (Wohletz and Sheridan 1979; Wohletz 1998), and roughness of local small-scale relief. The blast PDC at MSH produced a sediment blanket across 
a toppled forest, and deposition of the last portions of the PDC commonly occurred amongst large roots, stumps and logs. Such roughness elements likely created small-scale eddies in the blast cloud that affected the processes of deposition and under some conditions could have aided the formation of wavy lamination. Druitt (1992) has documented sandwaves that nucleated upstream or downstream from fallen logs, and both Druitt (1992) and Waitt (1981) have reported on other influences of microtopography on blast sedimentation.

The three layers A, B, C are not always present in each outcrop of a blast deposit. On BZ, layer A covers the largest areas, layer B forms patches on the surface of layer A, and layer $C$ (if present) forms even smaller patches on the surface of layer B. Patches with layers B and C, which are typically tens to hundreds meters across, form areas with the largest thickness of blast deposit recorded for each particular map location. Our impression is that such patches occur also at MSH, but this may be less pronounced and has not been emphasized by other workers apart from Fisher (1990) who noted islands of non-deposition. The situation there is affected also by strong topographic influences. At SHV, deposition was patchy in axial areas, but was more continuous towards peripheral areas (Ritchie et al. 2002). At BZ and MSH, all three layers are fairly well developed in most areas; at SHV, layer A is less well developed. Layer B is the most characteristic unit of the blast deposit; it is well developed in deposits at all three blast locations and can be found in most outcrops within the proximal zonesof the blasts.

Besides the non-uniform distribution of the layers, they can have unusual characteristics or altered appearances in some outcrops. There are variations of stratigraphy, some of which are dependent on regional conditions (variable from volcano to volcano), and others which depend on local conditions (variations from site to site at a given volcano). Layer A is strongly sensitive to local conditions such as properties of substrate and character of vegetation; layer $\mathrm{C}$ is moderately sensitive to local changes, with the main factors the local relief and topographic alignment with respect to the current. Layer B is least sensitive to local and regional conditions (although its grading is sensitive to topography), and thus in most cases displays a similar appearance. Complications due to settling and collapses into openworks of downed logs are reported from MSH (Waitt 1981).

There are also complications of stratigraphy connected with repetitions of some layers, which in some cases can be explained by deposition from individual internal currents or external lobes within a complex PDC that cross paths, with some minor delay in the passage of one relative to another. These internal currents may have been influenced in some cases by different discrete explosions, contributing to pulsatory currents within the PDC, but perhaps more often the crossed paths reflect complex interactions of an evolving PDC with topography, such as converging lobes deflected around a topographic high.. At MSH, this explanation accounts for a marked superposition of overlapping tree blowdown patterns in some locations, and locally repeated stratigraphic layers (Fisher 1990). Similarly, Waitt (1981) has described patterns of tree abrasion indicating PDC flowage from two directions at different times, and Hoblitt (2000) has reported overlap of several coarse basal layers in protected environments (he does not exclude the possibility of a pulsatory current). Pronounced repetition of layers was described on SHV (e.g., Units 1 and 2 of Ritchie et al. 2002), and we have observed this also, which seems to record pulsatory flow of the blast current.

\section{Valley facies}

Blast deposits in valleys of the proximal zone are in general thick (meters to tens of meters), massive (they can contain sublayers), and can resemble superficially the deposits of lithic-rich pyroclastic flows. The clast components of the valley facies are the same as in blast deposits on interfluves. In most instances the valley deposits appear to be simply thickened and coarsened equivalents of the interfluve facies, having otherwise similar, normal blast stratigraphy, with complexities observed in deposits close to source. Another end-member type of valley facies are secondary pyroclastic flow deposits. At BZ these facies were described as, respectively, 'blast deposits in valleys that begin directly on the east slopes of the volcano,' and 'blast deposits in valleys separated from the volcano by topographic barriers' (Belousov 1996). At MSH pronounced thickening of coarse layer B in valleys has been described, attributed to stratified-flow blocking of the transport system (Valentine 1987; Fisher 1990; Druitt 1992). Also at MSH, secondary pyroclastic flow deposits were described as the 'blast pyroclastic-flow unit' and attributed to re-mobilization of unstable blast deposits on adjacent slopes (Hoblitt et al. 1981; layer A2* of Fisher 1990). On SHV these facies were described respectively as block-rich and block-poor valley-confined deposits (Ritchie et al. 2002). Submarine valleys at SHV contain deposits tens of meters thick (Hart et al. 2004).

Proximal deposits in valleys can be quite block-rich, composed of very coarse bouldery material with fines almost absent, and any matrix represented by coarse gravel (Fig. 10). Large boulders in this facies are notably subrounded, indicating intense abrasion during transport. Such deposits are found only in valleys which were sourced directly from the volcanic edifices. At SHV for example, such materials formed at the base of density- and size- 
stratified flows generated by the source explosions at the head of the White River valley, and were blocked by valley walls from access to the adjacent interfluves.

Such deposits are composed of the coarsest material of the blast current, with high Rouse numbers and too heavy to be transported far by the PDC. In many cases these deposits rest directly above deposits of the debris avalanches which immediately preceded the blasts (Belousov 1996; Belousov and Belousova 1998; Voight et al. 2002). Contacts with underlying debris avalanches are very irregular, in some places with undulating clastic dikes, veins of blast material penetrating down into tension cracks in the avalanche deposit. The character of the contacts indicates that in places this blast facies was deposited on the surface of the moving debris avalanche, and that both continued to move simultaneously for a short time before final deposition. Such contacts between pyroclastic material and a debris avalanche deposit indicates that the explosive event which generated the pyroclasts occurred semicontemporaneously with the slope failure, and very probably was triggered by it.

Secondary blast pyroclastic flows occupy isolated valleys, i.e., valleys separated from the source of the blast by topographic barriers (Fig. 11). Grain-sizes of this deposit are akin to the typical grain sizes of adjacent blast deposits in the proximal zone, containing blocks and lapilli plus a notable amount of fines. Characteristics of the deposit indicate an origin by remobilization of freshly deposited or semi-deposited blast material from steep valley slopes into the valley floors (Hoblitt et al. 1981; Belousov 1996; Druitt et al. 2002b), where it rests on layers B and C (Fisher 1990). The steep slopes $\left(>20^{\circ}\right)$ of the valleys, or closed depressions, that contain deposits of secondary pyroclastic flows are generally free of blast deposits. On such slopes, the material initially deposited from the blast current soon drained enmasse as liquefied material into the valley floors, developing a typical valley-filling morphology with a flat upper surface. Locally these flowage deposits are wood rich, and some contain enormous log jams that resemble those deposited by water (Hoblitt et al. 1981). In general such flows were not able to move far downvalley on the low thalweg gradients, as shear stresses driving flow were small, and gas was lost during draining of the material into the valleys. At MSH such deposits contain openwork pipes of lapilli and coarse ash that extend to the surface of the deposit, where they are surrounded by cones of fine ejecta (Hoblitt et al. 1981); these degassing pipes developed rapidly, within say tens of minutes, as they are covered by accretionary lapilli (layer D) and pumiceous ash also erupted on May 18, 1980. Deposition of layer D occurred within an hour or so after deposition of the blast PDC deposits. Such secondary pyroclastic flows were found generally in the proximal zones of the directed blasts at BZ, MSH, and SHV.

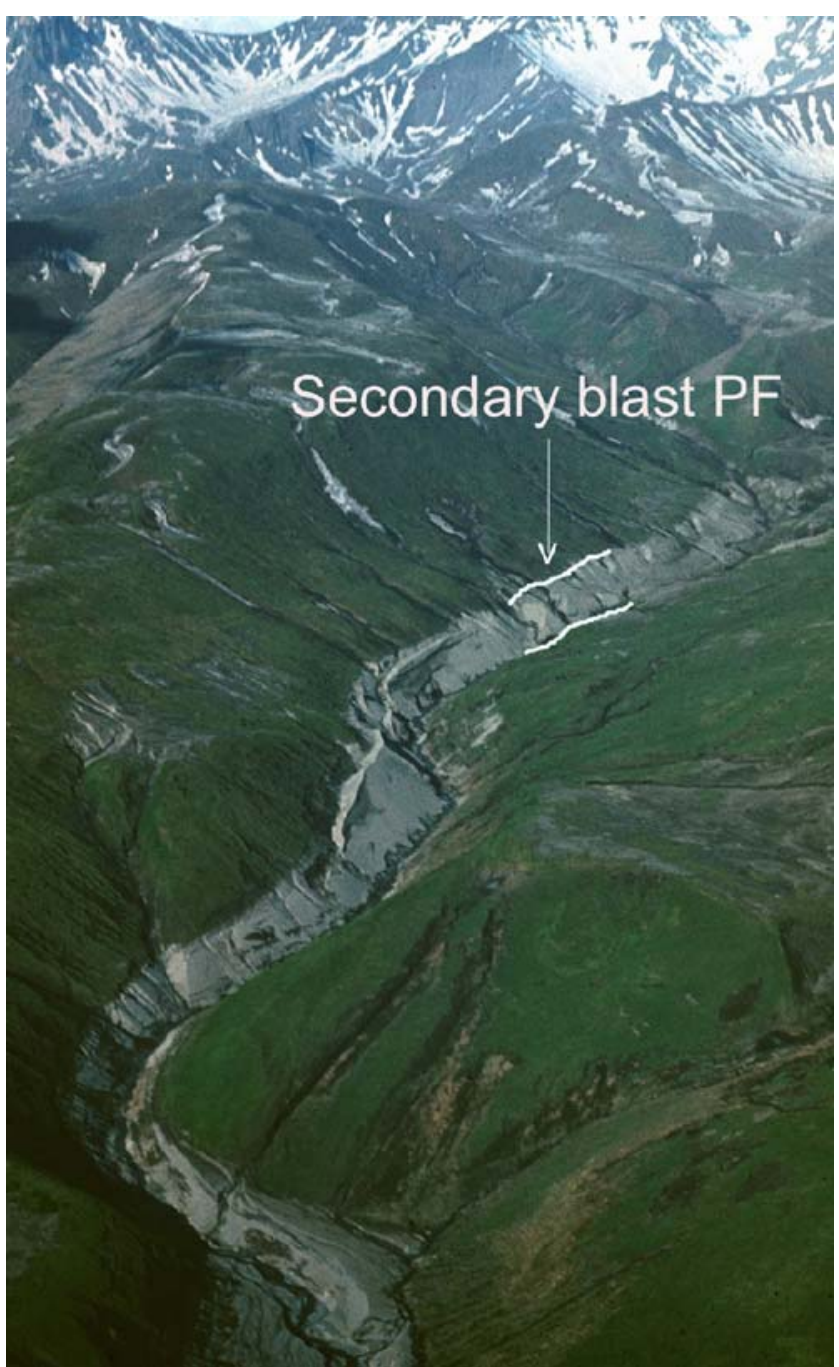

Fig. 11 Secondary blast pyroclastic flow deposit in the proximal zone of Bezymianny 1956 deposits, filling the narrow valley of the Zimina river. Volcano is far to the right, beyond the frame

Another variation of such secondary flows was found at SHV, where mobile block-poor flow deposits were found in several valleys, derived by sedimentation from a lowconcentration part of the blast current (Druitt et al. 2002b). These have been modeled by Esposti Ongaro (2005a,b, in press). A similar deposit was found at SHV also in relation to an ash-cloud surge during the lava dome collapse of 25 June 251997 (Druitt et al. 2002b).

\section{Distal zone}

At BZ at $\sim 19 \mathrm{~km}$ the three-layered interfluve facies rather abruptly disappears (Belousov 1996). Over a narrow transitional zone leading to the distal facies, the layers A, $\mathrm{B}, \mathrm{C}$ become harder to distinguish with certainty due to finer grain-size and gradational contacts. Further from the volcano they transform into a distal facies (Figs. 9, 10) 
represented by a single normally graded sandy layer, with little gravel, having a poorly developed wavy lamination. The degree of erosion of the substrate in the transitional zone becomes smaller, and the distal deposits rest on noneroded soil. Simultaneously, the amount of admixed substrate material (soil and soil clots) in the deposit became smaller, and then disappears, and incorporated plant remnants are uncharred. Likewise, in the distal zone the blast deposits are more uniform than in the proximal zone, as there are no sharp fluctuations of thickness and or grainsizes over short distances. Thus the depositional processes in the BZ distal zone appear to have been more steady. Characteristics of the deposit in the distal zone indicate traction sedimentation, common for weak pyroclastic surges. The blast PDC was already strongly diluted here, and indeed resembled a weak surge. Secondary blast pyroclastic flows did not form in the distal zone, due to a strongly diluted blast cloud, which left thin, poorly fluidized deposits.

At MSH there have been attempts to recognize, in regions far from the source, the same layers which occur in the proximal zone. In the distal zone, forest duff and soil has not been significantly eroded, and deposits are thinner and finer grained although the three main layers are still identified (Fisher 1990; Hoblitt et al. 1981). For the ENE sector, Druitt (1992) observed decreased suspended-load fallout as the blast PDC traveled across the landscape. With increased distance from source, the grain size differences between layers $\mathrm{B}$ and $\mathrm{C}$ decrease, and the erosional interface between them becomes less marked. Thus the grain size layering characteristics of the layers becomes indistinct and at many locations the individual layers are not recognizable. Ignoring local variations, the thickness of $\mathrm{B}$ diminishes rapidly with distance, whereas layers $\mathrm{Ca}$ and $\mathrm{Cb}$ maintain nearly constant thickness before thinning rapidly near the margin (Druitt 1992, Fig. 4).

At SHV any distal facies developing along the axial zone passed out to sea, to $>4 \mathrm{~km}$ offshore (Hart et al. 2004), although deposits near lateral margins of the deposit may bear some affinity to distal facies (Ritchie et al. 2002).

\section{Granulometry}

Granulometric characteristics of the deposits have been extensively studied (Hoblitt et al. 1981; Moore and Sisson 1981; Waitt 1981; Fisher 1990; Druitt 1992; Belousov 1996; Ritchie et al. 2002). Different approaches to the stratigraphy of the deposits, different stratigraphic sampling techniques, as well as different analyzing procedures, have been used by different researchers. Thus a direct detailed comparison of the published data is not straightforward. On Figs. 12, 13 and 14, grain size data taken from different sources (our published and unpublished data, and Hoblitt et

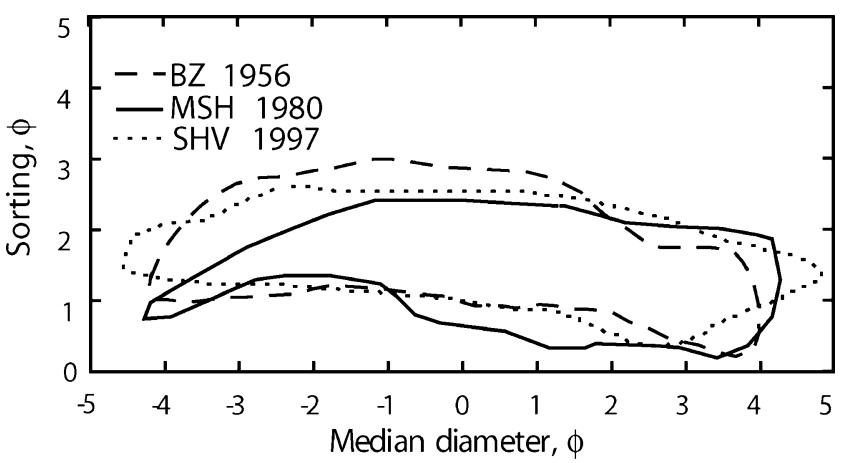

Fig. 12 Relationship between sorting and median diameter (Inman coefficients) for directed blast deposits of Bezymianny 1956, Mount St Helens 1980, Soufrière Hills 1997. Data from Belousov (1996), Hoblitt et al. (1981), Druitt (1992), Ritchie et al. (2002) and unpublished data of authors

al. 1981; Druitt 1992; Ritchie et al. 2002) are plotted without indication of stratigraphic position. On the plot of median diameter versus sorting (Fig. 12), deposits of the three blast deposits occupy almost identical clusters. Perhaps surprising is that the much smaller scale of the SHV blast did not, apparently, much influence the granulometry of deposits. This overall similarity is consistent with the idea that the mechanisms of magma fragmentation, and of transportation and deposition from the blast PDCs, were similar for all the three cases.

The grain-size characteristics of the interfluve facies of blast deposits fluctuate strongly over short distances. Thus, the grain size distributions of layers of the proximal facies were compared only for locations where layers A, B, C were sampled in one outcrop (preferably), or at least, at nearby locations (Fig. 13). The grain-size distributions of layer A commonly have several poorly defined modes that result in a very poor sorting overall for the facies. Grainsize characteristics of this layer are consistent with deposition from a very energetic turbulent flow, with entrainment of material eroded from the substrate. Obviously, the grain-size characteristics of layer A strongly depend on the grain-size characteristics of the eroded substrate near the location of the depositional site.

Grain-size distributions of layer B commonly have one well-defined mode (Fig. 13), and in comparison with layer A, are depleted by both very coarse and fine fractions, resulting in relatively good sorting for the layer. The grainsize characteristics of this layer are consistent with deposition from rapid suspension sedimentation in highconcentration conditions (Druitt 1992). In some cases before final deposition, the material of the layer experienced small to moderate traction and movement as a traction carpet.

Grain-size distributions of layer $\mathrm{C}$ also have a single well-defined mode (Fig. 13), but in comparison with layer $\mathrm{B}$ are depleted by coarse fractions, and are also notably 
Fig. 13 Grain-size distributions for proximal and distal zones of Bezymianny 1956, Mount St Helens 1980, Soufrière Hills 1997. Data from Belousov (1996) and unpublished data of authors
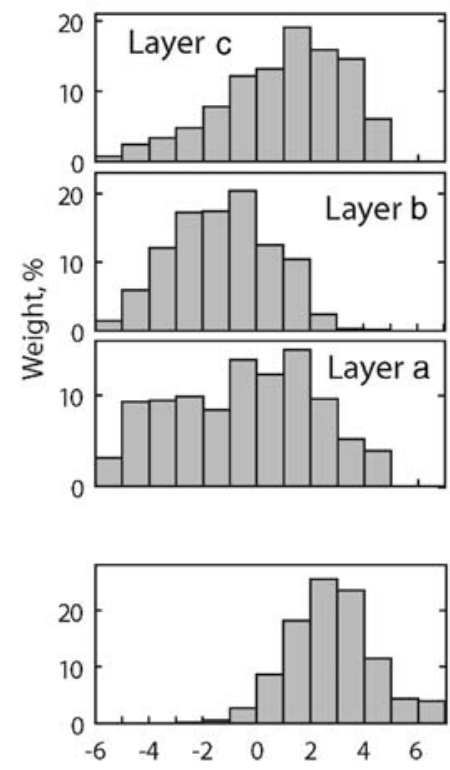

Mount St. Helens 1980

Soufriere Hills volcano 1997

Proximal zone
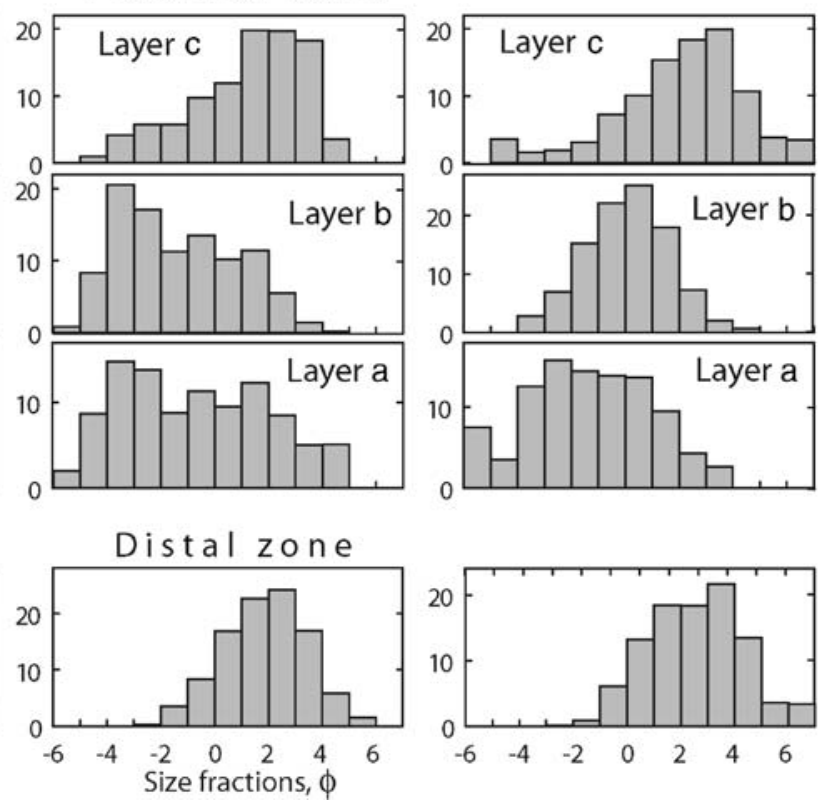

enriched by fines (positively skewed), resulting in an intermediate sorting of the layer (compared to A and B), and the finest median diameter (Fig. 14). Grain-size characteristics of the layer are consistent with rapid sedimentation under moderate-concentration, weakly tractive conditions. The upper (laminated) layer $\mathrm{Cb}$ reflects a dilute depositional regime with grain-by-grain traction deposition.

Grain-size distributions of distal facies have one welldefined mode, similar to layer B (Fig. 13) but are finer grained and better sorted. Grain-size distributions of the layer are consistent with traction sedimentation from a dilute, weakly turbulent waning current.

\section{Mechanisms of the directed blasts and blast currents}

The characteristics of the blast deposits as noted above, combined with other key data (photographic, seismic etc.) available for the three examples, enable a number of generalizations to be made concerning the mechanisms of directed blast generation.

\section{Charges of the blasts}

The strong distortion (bulging) of volcanic edifices (BZ and $\mathrm{MSH}$ ) during the pre-blast stage, as well as direct exposure of magma on the surface of the volcano (BZ and SHV), indicate clearly that before the blasts, bodies of magma had been emplaced into or onto the upper parts of the volcanic edifices (Gorshkov 1959; Lipman and Mullineaux 1981;
Sparks et al. 2002). In these three cases, the blast deposits are composed mostly of juvenile rock fragments, which are represented by moderately dense material. For instance, the densities of most blast dacite clasts at $\mathrm{BZ}$ and $\mathrm{MSH}$ are $\sim 1600-2200 \mathrm{~kg} \mathrm{~m}^{-3}$ (Fig. 7; cf. Hoblitt et al. 1981), and at least some vesiculation occurred during the decompressioninduced ( 12 MPa) explosion (Kieffer 1981) to produce bread-crusted bombs with interior density $\sim 1200 \mathrm{~kg} \mathrm{~m}^{-3}$ (Hoblitt et al. 1981). There is no evidence that water/ magma interaction played a significant role in actual explosive processes (e.g., Eichelberger and Hayes 1982; Zimanowski 1998), and thus the relatively high density of juvenile material is not of phreatomagmatic origin. The high density can be explained by the high degree of degassing and crystallinity of the exploded magmas. Although the parental magmas of these three eruptions were somewhat different chemically, the degrees of crystallization were also strongly influenced by their rates of ascent, magma permeabilities, and residence times of the magma bodies in the edifices, as well as by degrees of their proximity to the ground surface (Fig. 2). The magma of MSH had the highest ability for vesiculation to expand clasts during the blast (average vesicularity $\sim 30 \%$ and ubiquitous breadcrust bomb fragments in deposits, as at BZ), reflecting a relatively rapid magma ascent and incomplete degassing, a shallow position within the edifice, and about a two month residence time for the sealed cryptodome inside the volcanic edifice. Estimates of total energy release for the exploding cryptodome are $10^{14}-10^{15} \mathrm{~J}$. On SHV the highest degree of magma solidification was observed (average vesicularity 15\%), and this and the rarity of 


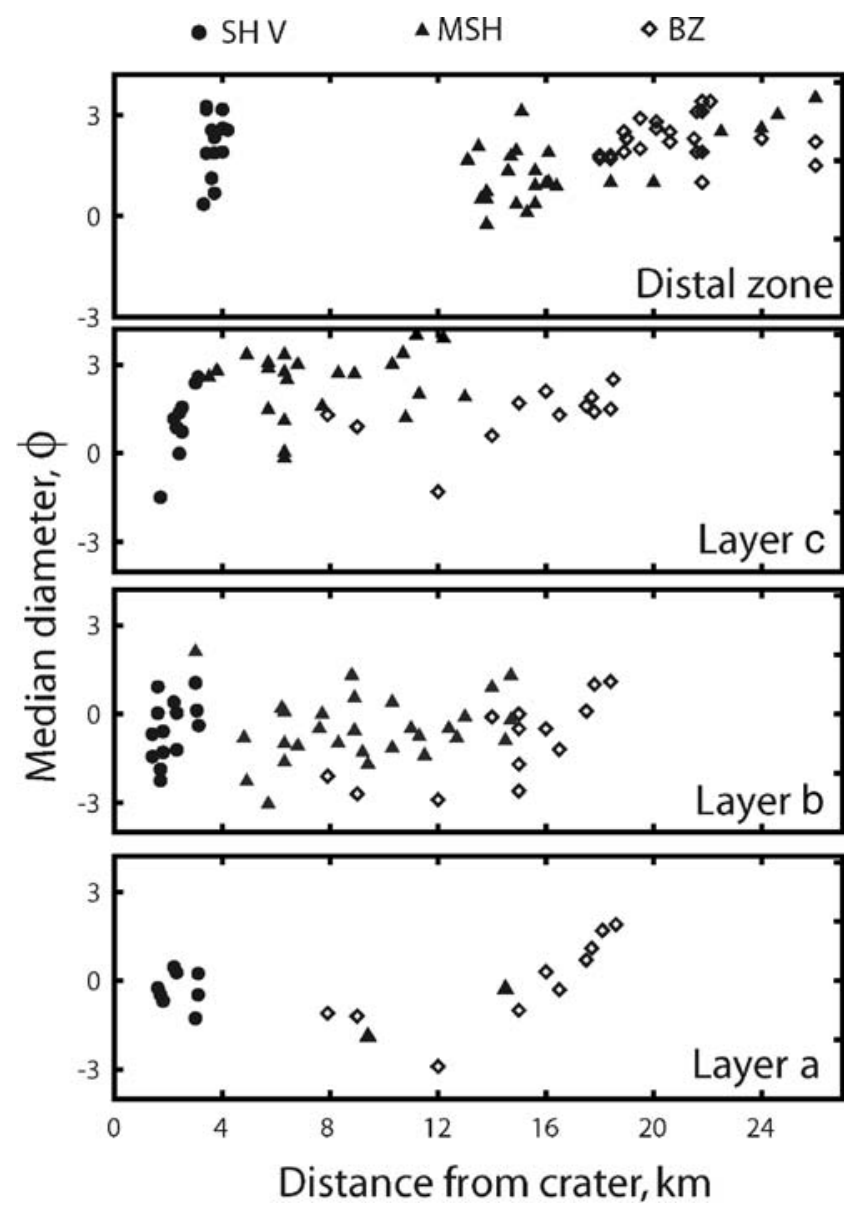

Fig. 14 Median diameters (Inman coefficient) versus distances from the craters for blast deposits of Bezymianny 1956, Mount St Helens 1980, Soufrière Hills 1997. Data from Belousov (1996), Hoblitt et al. (1981), Druitt (1992), Ritchie et al. (2002) and unpublished data of authors

breadcrust bombs in the blast deposit (while both are common for $\mathrm{BZ}$ and $\mathrm{MSH}$ ) suggest that the magma was simply more degassed. Clasts of juvenile material show chilled margins displayed across vesicle distributions, showing an effect of air cooling.

During the effusive phase at SHV, the dome built up in pulses with significantly degassed magma (Watts et al. 2002), while the exsolved volatiles separated from the magma to form bubbles or to travel through the permeable conduit and dome to the atmosphere (Eichelberger et al. 1986; Melnik and Sparks 1999; Elsworth and Voight 2001). Besides gas in pressurized bubbles, sustained gas release from rising conduit magma below can advect under pressure through vesicle and crack porosity to the upperlevel magma, adding to the mass fraction of gas, with the total gas energy available to fragment a decompressed shallow magma body. Models of the coupling between gas escape and conduit magma flow suggest that overpressures of several MPa can develop at the base of the growing dome (Sparks 1997; Melnik and Sparks 2002). The bulk volatile content of the magma was about 2 wt.\% (Barclay et al. 1998) and the rate of dome extrusion around the time of the blast in December 1997 was $\sim 8 \mathrm{~m}^{3} \mathrm{~s}^{-1}$, implying a gas flux $\sim 400 \mathrm{~kg} \mathrm{~s}^{-1}$ and pressures at the base of the dome around 5-10 MPa (Woods et al. 2002). In the compressible gas model of Woods et al. (2002) the pressure remains at relatively high values throughout the dome, except in a narrow boundary layer near the surface where it drops to atmospheric pressure. This gas pressurization is assumed to determine the gas content and energy available for explosive fragmentation (e.g., Fink and Kieffer 1993). Assuming dome porosity was $10 \mathrm{vol} \%$ leads to a net mass fraction of gas within the dome as about $10^{-4}$ to $10^{-3}$, depending on dome permeability (Woods et al. 2002). A pressurized dome can have one or two orders of magnitude less exsolved volatiles per unit mass of magma than is typically present in a plinian eruption, and this can lead to a much denser initial pyroclastic current and a different eruptive style.

Thus all the blasts considered here had a dominantly magmatic mechanism, wherein highly crystallized, shallow, intra-edifice magma bodies and their associated volatiles in permeable interconnected pore space and vesicles provided the charge for a directed blast. Subordinate amounts of hydrothermally altered, accidental material in the deposits (particularly at $\mathrm{BZ}$ and $\mathrm{MSH}$ ) and accretionary lapilli in layer $\mathrm{D}$ indicate that water- or steam-rich hydrothermal systems within the edifices participated also in the clusters of explosions, and contributed some energy for the blasts. Criswell (1987) argues for phreatomagmatic eruptions involving depressurization of hydrothermal systems. This is not disputed but the energy provided may have been of secondary importance compared to the magmatic volatile processes. Some of the water accounting for accretionary lapilli likely came from entrained snow and saturated soils at $\mathrm{BZ}$ and $\mathrm{MSH}$, and from evaporated sea water at SHV.

Triggers for the directed blasts

In all three cases the blast deposits are intimately associated with deposits of debris avalanches formed as a result of large-scale failures of the volcanic edifices (Fig. 3). At MSH the rapid transition from the edifice failure to the explosive blast was directly observed and well documented by photography, video and space imagery (Fig. 15; Voight 1981; Moore and Rice 1984; Hoblitt 2000). At BZ the explosion occurred in a remote location, and at SHV at night, so for these sites the similar successions of slope failure and explosive event were reconstructed from pyroclastic stratigraphies and various geophysical data (Belousov 1996; Sparks et al. 2002). Very irregular deformed contacts between the deposits of blasts and debris avalanches, and bent or swirled clastic dikes of blast 

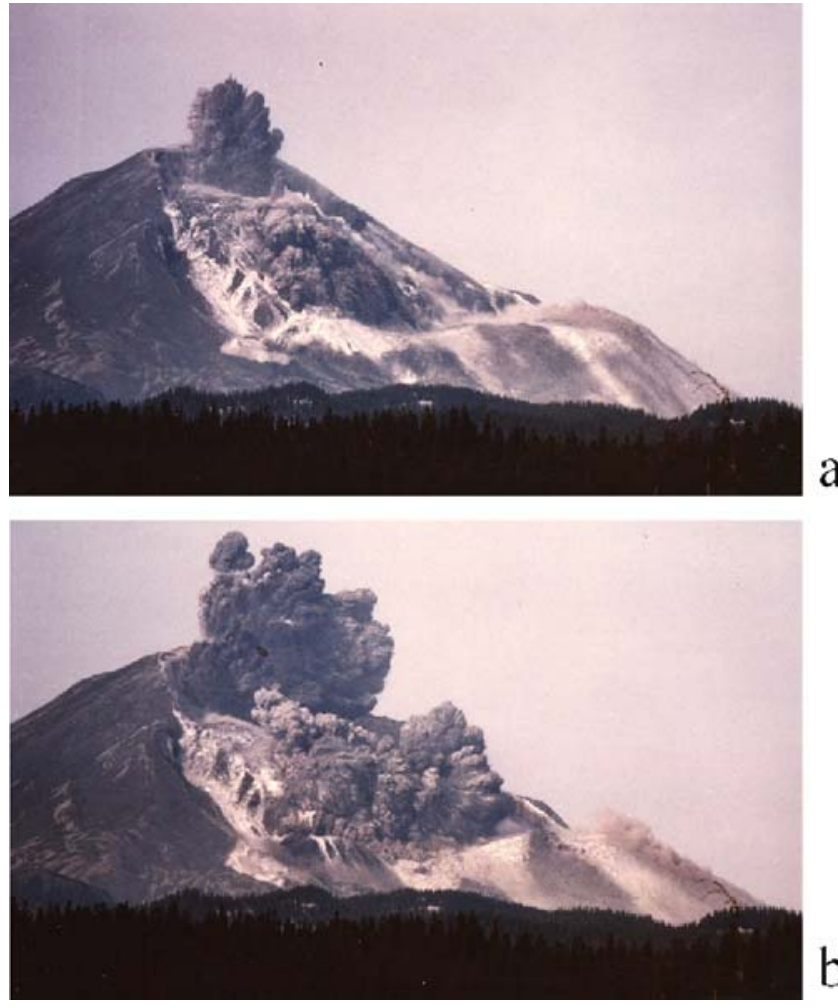

Fig. 15 Sector collapse and explosion sequence at Mount St Helens. View toward southwest. The eruption is referenced to an earthquake at 08:32.2 local time. Images $\mathbf{a}-\mathbf{d}$ represent approximate times of 08:32.9, 08:33.0, 08:33.14, 08:33.4, respectively, after Voight (1981). a Most of slide block I has moved beyond the landslide scar. Slide block II is moving behind it, with explosions occurring from its front face, and steep explosion plumes are initiated near the summit behind slide block II. b Both slide blocks continue to move, and the explosion plumes continue to evolve. c The explosions from slide block I are generating an inclined collapsing fountain whose front is moving faster

material that penetrated down into the debris avalanche deposits, indicate that the avalanches were still moving when the blast clouds started to deposit pyroclastic material on upper surfaces of the avalanches. This conclusion is supported by the photographic record for MSH (Voight 1981). Hence, the time gaps between the initiation of the collapses and the blasts, in all the studied cases, were shorter than the durations of avalanche runouts as deduced from seismic data and other evidence. At BZ, a rapid transition from edifice failure to blast is indicated by the observation that in proximal zone, the blast deposit was found only above the avalanche deposit, and in the distal zone, the blast current overran the debris avalanche - and left deposits both below as well as above the avalanche (Belousov and Belousova 1998). Similar observations were recorded at MSH (Voight et al. 1981), but at SHV, the avalanche had been partly emplaced shortly before the blast overtook it (Voight et al. 2002). Such fast transitions from landslides to explosive blasts are the principal evidence that
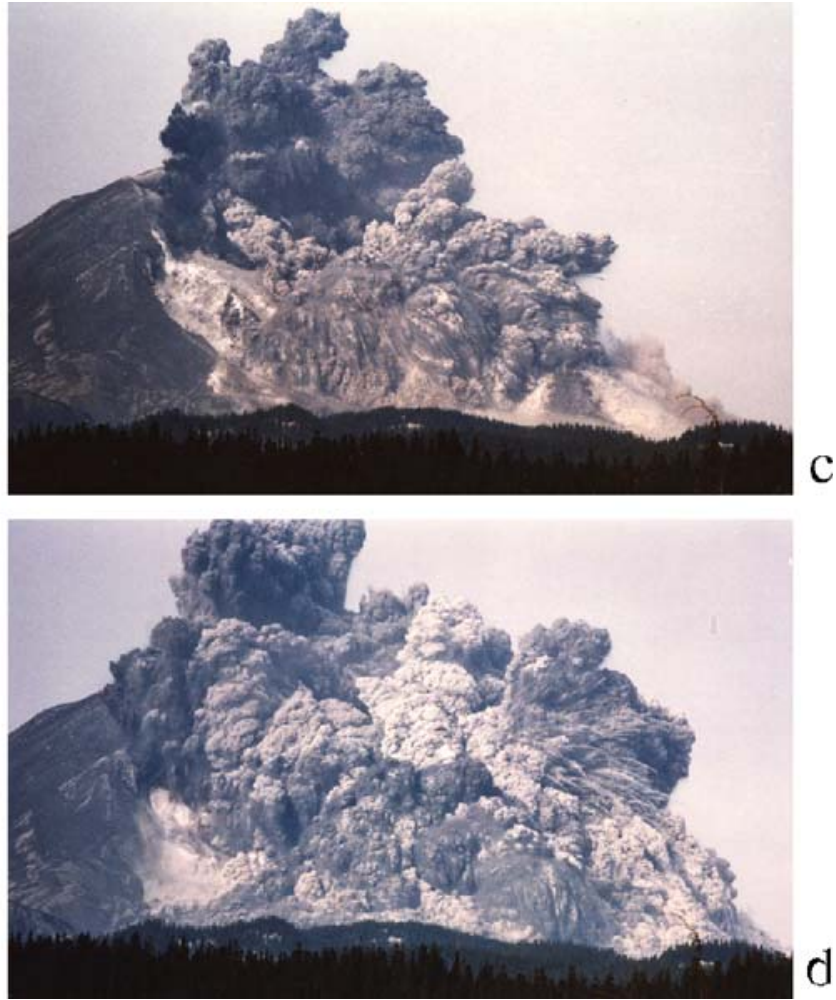

than the debris avalanche. With slide block II moving further downslope, collapse of the low fountain above the summit is deflected northward. d The individual slide blocks I and II, and further collapses, are hidden from view by the coalescing fountains from several sources, comprising the stage of fountain collapse and leading to pyroclastic density current generation. Ballistic projectiles indicate a substantial part of the plumes are directed northward with a large horizontal component. Copyrighted photographs by G Rosenquist, 1980, published with permission

the blasts were triggered by rapid and profound decompression caused by the flank collapses.

In cases when edifice failures were provoked by the onset of intrusions of magma, but no blasts followed, e.g. the multiple debris avalanches of Shiveluch (Belousov et al. 1999) and Harimkotan (Belousova and Belousov 1995), the contacts between the avalanche deposits and the cover of pyroclasts from the post-avalanche explosive activity are not deformed. This evidence suggests that the deposition of tephra and/or pyroclastic flows occurred when the avalanches had already ceased to move. Thus in these cases, the time gaps between the onsets of large-scale landslides and the following magmatic eruptions exceeded those for the cases with directed blasts. Decompression from the slope failure may have led to this succeeding eruptive activity, but the activity was delayed and associated with conduit and magma reservoir depletion, rather than explosion of a magma body already in the edifice at shallow level. The activity in these instances is comparable to the 
plinian activity at MSH that followed the debris avalanche and blast by about an hour or more (Lipman and Mullineaux 1981; Criswell 1987), and similar plinian and pumice flow activity at Bezymianny (Gorshkov 1959).

A comparison of the sequences of events for directed blast-generating eruptions, with those for eruptions where intrusions of magma triggered large-scale sector collapses without generating blasts, shows that the main difference between them is the level of magma storage inside the edifice at the moment of failure. Where intrusions had risen to high level and were stored within the edifice to be truncated by the edifice failure surface, a blast occurred; where the intrusion had just begun, perhaps destabilizing the edifice but not being truncated by the failure surface, no blast occurred (Fig. 2).

\section{Reasons why the directed blasts were 'directed'}

We distinguish between two main reasons for strong asymmetry of the blast currents. The most important is an inclined character of the parental explosion or explosions. Notable inclination of the parental explosions in all the studied cases was caused by the pre-blast slope failure (Voight 1981), which sliced across the shallow magma body at a high inclination (Fig. 15). The result was an inclined, short-lived and energetic, 'vulcanian-like' explosion, or explosions, depending on the complexity of the slope collapse.

The second reason was additional focusing of the collapsing fountain by the just-formed avalanche scar, opened only at one end. As has been observed in several eruptions, e.g. Lamington in 1951 (Taylor 1958), or Bezymianny in 1997 (Belousov et al. 2002), even quasisymmetric radial fountain collapse of vertical explosions or a violent collapse of a low fountain can be significantly focused in one direction by the horseshoe-shaped topography of a volcanic edifice. Both factors probably contributed to the asymmetric propagation of the blast currents in the cases we have considered, although we consider the first factor as likely dominant. Because not all low fountain collapses within open-sided craters have led to directed blasts (e.g., Hoblitt 1986; Belousov et al. 2002), additional factors are also involved.

Are shock waves required to explain directed blast dynamics and damage?

The shock wave hypothesis to explain damage and other features observed at MSH was developed mainly by Kieffer $(1981,1984)$, as a plan-view analog of steady-state exhaust from a rocket. This analysis involved relatively complex mathematics and has been accepted uncritically by many workers at MSH (e.g. Fisher 1990; Druitt 1992; Wohletz
1998). Kieffer proposed that the boundary between the 'direct blast zone' and the 'channelized blast zone' north of the vent corresponded to a Mach disk shock at $\sim 11 \mathrm{~km}$ from source. Although mainly focusing on the role of this shock in her analysis, she also recognized that some damage was also produced by complex multiphase flow of finite duration, such as the further deformation of splinters and root balls of toppled trees. In a further study, Kieffer and Sturtevant (1988) described furrows from ridgetops in the region $3.5-9 \mathrm{~km}$ from the blast source, and interpreted them as resulting from supersonic flow. The role of shocks was discussed further by Wohletz and Valentine (1990) and Wohletz (1998), drawing on analogies with nuclear explosions (Glasstone and Dolan 1977). Wohletz and Valentine (1990) discussed briefly some numerical results in support of Kieffer (1981), although their interpreted disc shock occurred at $3.5 \mathrm{~km}$, far shorter than Kieffer's result. Wohletz (1998) discussed how bowshocks can propagate ahead of a PDC, and multiple shock waves can migrate or stand within the flow, and noted that the magnitudes of the shock waves are the main factor that controls whether shocks can impart sufficient dynamic pressure changes to cause damage. He postulated that for blast eruptions, shock overpressure decays to $<100 \mathrm{kPa}$ within several $\mathrm{km}$. For the $1980 \mathrm{MSH}$ blast, he calculated blast overpressures of $40 \mathrm{kPa}$ and dynamic pressures $1 \mathrm{kPa}$ at $10 \mathrm{~km}$, using the full thermal energy $(7 \mathrm{Mt})$ released during lateral propagation of the blast, but assumed that the energy release time and empirical relations were similar to surges driven by a surface nuclear explosion (Glasstone and Dolan 1977). We think these overpressure values are far too large due to the variance of the assumptions from reality; mainly, the energy release at MSH was far more prolonged than assumed in analysis, and the plume front speed was less than atmospheric sound speed.

We accept that shocks can occur with overpressured jets, certainly internal shock structures related to compressibility effects, and in some cases, when explosion frontal speeds exceed atmospheric sound speed, propagating atmospheric shocks. However the question is, if such shocks are developed during the burst phase, how far from the source can the damage from these shocks be sustained? The related question is whether the damages observed at various distances at specific sites are related mainly to the burst phase, or, to the collapse or PDC phases, which are also capable of producing heavy damage. Because these issues have thus far been incompletely examined, we withhold judgment about the shock models as a primary explanation for the damage sustained at MSH as far as $13 \mathrm{~km}$ from source. The assumptions of a fixed vent position, and a sustained blast duration of 10-20 s in the Kieffer (1981) model appear at variance with observations of multiple explosions from moving slide blocks over a period of 
several minutes that created a very unsteady PDC (Fig. 15; Voight 1981; Hoblitt 2000). The analogy with a shock tube with instantly released membrane seems far from exact, as the "membrane" may be leaky, and the initial pressure release somewhat gradual. We suspect this to be the case for MSH. The Kieffer (1981) model does not consider vertical-plane issues such as boundary layer friction and stratified flow. Also, seismic data suggest unsteadiness of jet thrusts, some of which were apparently steep rather than quasi-horizontal (Brodsky et al. 1999). Thus we are skeptical about the reliability of interpretations founded on the simple 2D steady-state model approximations.

We offer the alternative hypothesis that much of the severe damage observed in these blasts might be better interpreted in light of the dynamics of collapsing fountains and stratified unsteady PDCs, including the consideration of dynamic flow pressures and the impacts of entrained, very large clasts. In the axial and proximal regions the collapsing fountains and PDCs possessed the greatest solids concentration, carried the coarsest sediment and entrained objects capable of inducing impact damage, and had the greatest lateral dynamic pressures in their basal parts. Thus impacts, erosion, and damage, observed to be most severe in the axial, proximal regions, appear consistent with these regions of high stagnation and dynamic pressures. This correlation is largely irrespective of Mach number, but in addition, $\mathrm{M}>1$ conditions could exist in both the collapse and PDC phases, and thus shocks were not necessarily restricted to the blast phase. In distal and peripheral regions, solids concentration, maximum particle size, current speed, and dynamic pressure were diminished, resulting in less intense damage by the PDCs, and enhanced influence by local topography on the lower parts of the PDC.

This hypothesis has been tested for the SHV blast by 2D and 3D multiparticle thermofluid modeling on a high-resolution DEM (Esposti Ongaro et al. 2005a,b, in press). The SHV simulations used three particle sizes representative of the range of observed size classes, and the influence of several different source volumes was tested. The 3D model runs generated a blast-affected sector that compared closely with the mapped blast area. The dynamic pressure distribution displayed $20-60 \mathrm{kPa}$ for the region of complete destruction, fitting well the estimates based on field observations (Sparks et al. 2002; Baxter et al. 2005). More peripheral areas showed $<10 \mathrm{kPa}$, and this too is compatible with observations of damage. Thus it appears from this modeling that the dynamic pressures accountable for the observed destruction from directed blasts do not require a strong shock wave in the blast phase, as had been proposed generally by Kieffer (1981, 1984) and Wohletz (1998). This conclusion does not exclude the possibility of some damage from shock waves, but the Esposti Ongaro et al. (in press) study for SHV suggests that the areas associated with such damage may be much more limited than assumed previously. Such studies remain to be done for MSH and BZ.

At SHV, modeling has shown that internal shock structures may be developed during the short-lived burst phase and collapse phase, but in a complex fashion dictated by unsteady flow. Figure 16, from Esposti Ongaro et al (in press), shows the configuration of the explosion plume at $10 \mathrm{~s}$, with contours indicating particle volume fraction. The figure also illustrates ballistic-like fluid trajectories during the blast and collapse phases of the explosion, with the end points representing the positions at $10 \mathrm{~s}$. The significant horizontal components of the trajectories are notable and imply the contribution of momentum to the PDC of the subsequent phase (compare also, Fig. 15d for MSH). The distributions of Mach numbers at several times are shown in Fig. 17. At $10 \mathrm{~s}$, for instance, the $\mathrm{M}>1$ region is separated from the source area, confined to a region of intense fountain collapse. Such effects would be limited to the proximal region. Internal shocks might also be possible at subsequent times $(t>20 \mathrm{~s})$ at distances of a few $\mathrm{km}$, within basal parts of the PDCs where $\mathrm{M}>1$ (Fig. 17). We note however that while $\mathrm{M}>1$ is a necessary condition for shock structures, it is not a sufficient condition, and the

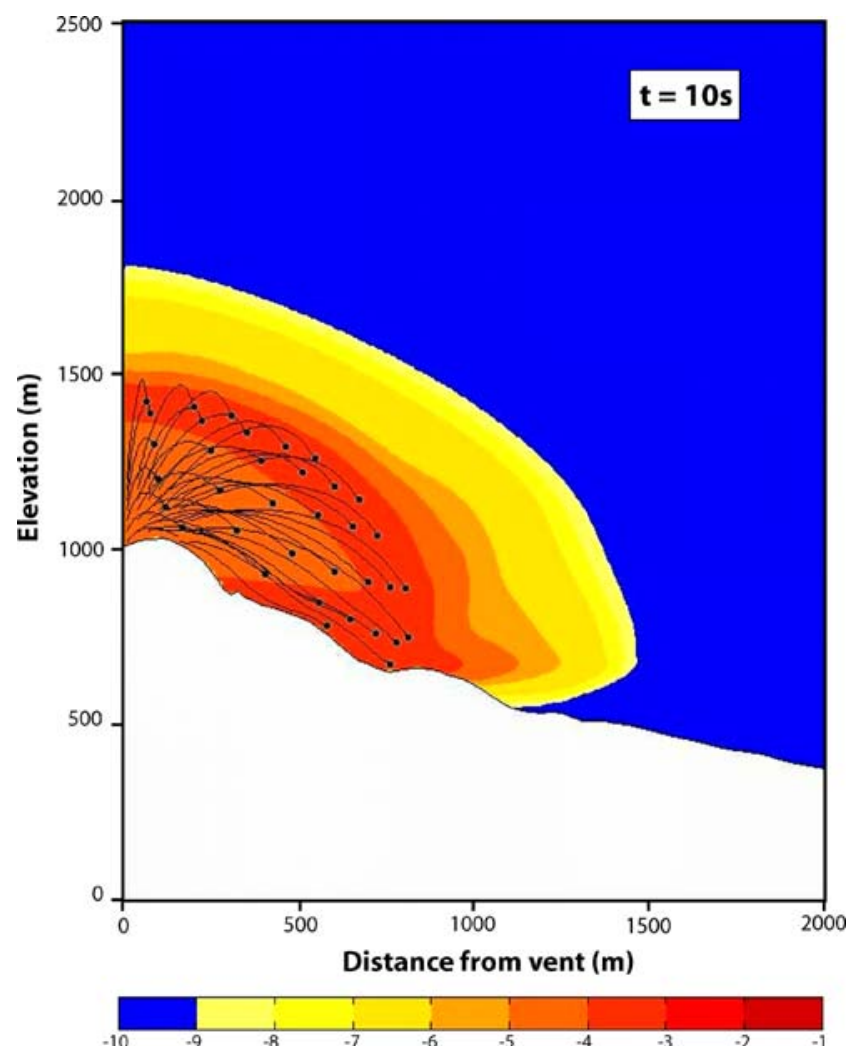

Fig. 16 Volcanic blast at Soufrière Hills volcano at $10 \mathrm{~s}$ (Esposti Ongaro et al. in press). See Fig. 17 caption for model details. Contours are $\log _{10}$ of particle volume fraction. Fluid trajectories are shown for the burst phase and collapse phase of the explosion. Note low angle of many trajectories at $t \sim 10 \mathrm{~s}$. Compare model with photographs of Mount St Helens blast, Fig. 15 

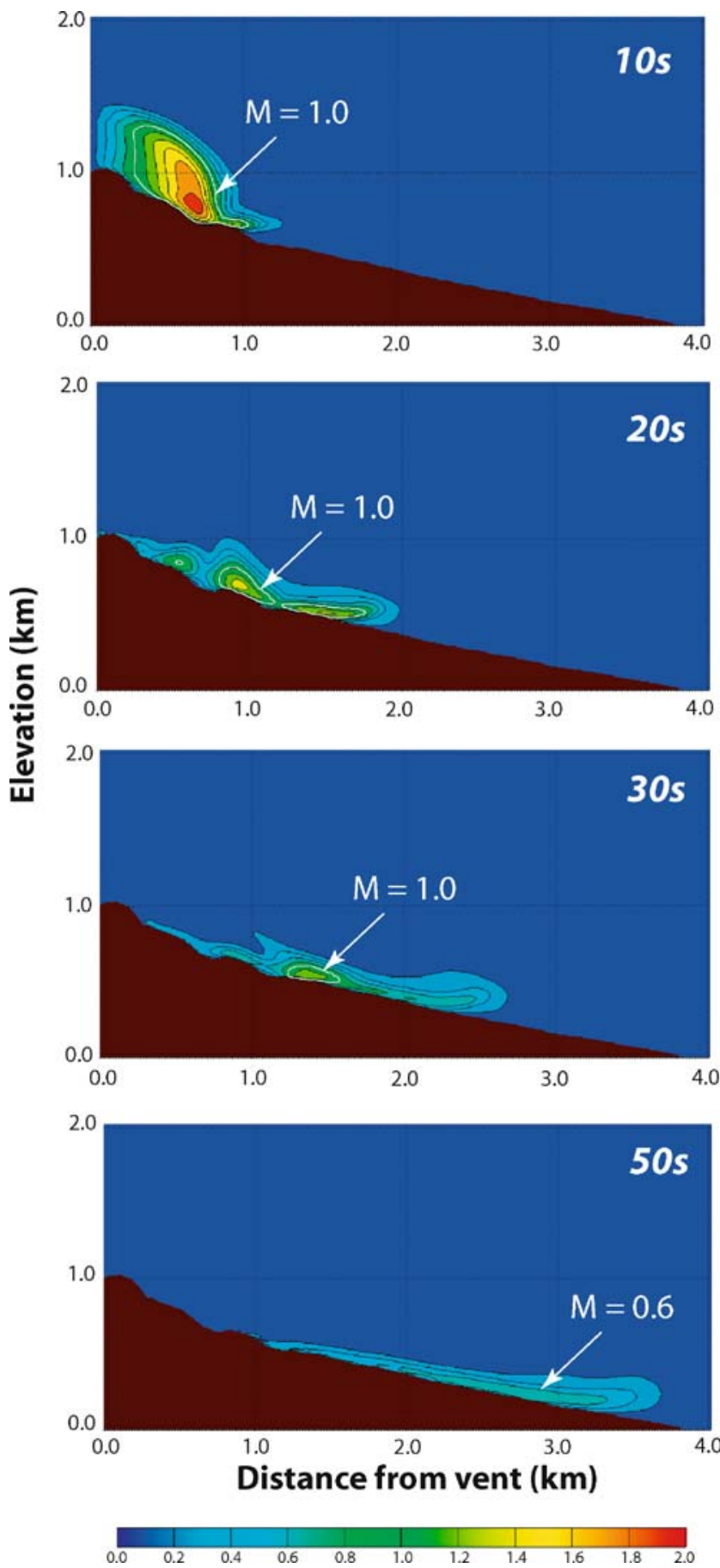

Fig. 17 Mach number distributions for volcanic blast at Soufrière Hills volcano; 2D numerical model, $5 \times 10^{6} \mathrm{~m}^{3}$ volume, high gas energy simulation (Esposti Ongaro et al. in press). Blast at $5 \mathrm{~s}$ (not shown) is quasi-hemispherical burst above source. The collapse phase is shown at $10 \mathrm{~s}$, with transformation to PDC phase nearly complete by $20 \mathrm{~s}$. Further movement shows thickening and distortion of PDC front by air drag. By $10 \mathrm{~s}$ the collapsing fountain is several hundred $\mathrm{m}$ tall with a core $M>1.4$, enveloped by regions of $M \ll 1$, both upstream and downstream. By $20 \mathrm{~s}$, isolated flattened regions of $M>1$ exist, and by $30 \mathrm{~s}$, the region for $M>1$ is limited to a thin basal patch $\sim 1.3 \mathrm{~km}$ from source. By $50 \mathrm{~s}$, with the plume front at the site of destroyed houses, the basal zone of the PDC displays $M<0.6$, but with high dynamic pressure matter is further conditioned for stratified multiphase flows for which dynamics are poorly known. The modeling demonstrates also that whereas $\mathrm{M}>1$ could occur in a thin basal zone to say $2 \mathrm{~km}$ from source, at the same time the PDC front had spread to $3.6 \mathrm{~km}$, and dynamic pressures $>15 \mathrm{MPa}$ (and rising) had already occurred at $3 \mathrm{~km}$. Thus if an interior region of $\mathrm{M}>1$ did migrate with the $\mathrm{PDC}$ downslope, it would sequentially inundate areas that already could have sustained heavy damage from high dynamic pressures and large impacting clasts within the frontal parts of the same PDC.

Particle support mechanisms in a stratified PDC

After the MSH eruption, the question was posed on how to interpret the puzzling blast deposit: was it a deposit of pyroclastic surge, or a low-aspect-ratio pyroclastic flow (Hoblitt et al. 1981; Walker and McBroome 1983, 1984; Waitt 1981, 1984; Hoblitt and Miller 1984). Some features of the deposit demonstrated either an intermediate character between the two types, or had no obvious analogues. Our comparisons of the MSH deposit with the deposits of BZ and SHV show that the blast stratigraphy, with some variations, is fundamentally similar for the three cases. Thus the interpretation issues mentioned above apply to all these cases. The deposit characteristics suggest a specific type of pyroclastic density current with a peculiar assortment of depositional regimes.

Pyroclastic surges are commonly considered as gasparticle mixtures where particle concentration is low, except in the bed-load region where particle transport may be by saltation and granular flow, and where transport is chiefly by turbulence. In contrast, pyroclastic flows are high particle concentration currents with characteristics akin to debris flows or debris avalanches, and transport is influenced by fluidization. Walker (1983) and Walker and McBroome (1984) had argued that turbulent transport could be effective only relatively near the source of a pyroclastic current, citing settling velocities from a column-collapse mixture (Sparks et al. 1978). However, field evidence shows clearly that the blast involved a highly turbulent suspension current (Hoblitt et al. 1981; Hoblitt and Miller 1984; Kieffer and Sturtevant 1988; Fisher 1990; Druitt 1992; Bursik et al. 1998). Within about $10 \mathrm{~km}$ of the vent, deposition took place largely by rapid suspension sedimentation, with traction sedimentation being limited to ridge tops and to a thin upper layer $\mathrm{Cb}$ from the waning current (Druitt 1992). At distances of 15-18 km from the vent, with layer $\mathrm{C}$ dominant, estimated flow density was $\sim 1.5 \mathrm{~kg} \mathrm{~m}^{-3}$, not much denser than normal atmosphere at $1000 \mathrm{~m}$ altitude (Bursik et al. 1998).

Valentine (1987) calculated particle Rouse numbers for particles with diameters of $0.1,1$, and $10 \mathrm{~cm}$, for 
hydraulically rough flow conditions appropriate to MSH (assumed particle density was 2,000 $\mathrm{kg} \mathrm{m}^{-3}$ ), and compared these to the critical value of Rouse number, $R_{n}=2.5$, above which turbulent suspension is ineffective. Figure 5 shows $R_{n}$ for the three clast sizes as a function of the free stream velocity. Pyroclasts with diameters of $1 \mathrm{~cm}$ or less are easily supported by turbulence, and particles approaching $10 \mathrm{~cm}$ diameter can be supported by free-stream velocities $\gg 200 \mathrm{~m} \mathrm{~s}^{-1}$. Current-front velocities calculated by us from the Christiansen-Larsen photographs from Mount Adams (Foxworthy and Hill 1982; Moore and Rice 1984) suggest maximum speeds around $130 \mathrm{~m} \mathrm{~s}^{-1}$, and Moore and Rice (1984) mentioned a maximum speed of $150 \mathrm{~m} \mathrm{~s}^{-1}$. Noting that the head of a turbulent gravity current travels at $\sim 60$ $70 \%$ of the speed of the following current (Simpson 1987), internal speeds could have been about $180-210 \mathrm{~m} \mathrm{~s}^{-1}$. Thus it is likely that large dense pyroclasts could have been transported by turbulence in the blast current. Certainly ash and lapilli could have been transported easily in lowconcentration suspension. In addition, it is believed that the addition of form drag from larger scale roughness such as avalanche hummocks, piles of fallen timber, and rough topography would lower all particle Rouse numbers (Valentine 1987; Bursik et al. 1998), and the density of blast dacite was mostly in the range $1300-1900 \mathrm{~kg} \mathrm{~m}^{-3}$ (mean $1660 \mathrm{~kg} \mathrm{~m}^{-3}$ ) (Hoblitt et al. 1981; cf. Hoblitt and Harmon 1993), less than the value of $2000 \mathrm{~kg} \mathrm{~m}^{-3}$ assumed in the calculations. Thus moderately vesiculated or lithic fragments in excess of $10 \mathrm{~cm}$ diameter could have been transported a significant distance by turbulence at MSH. Similar relations have been discussed for SHV (Woods et al. 2002; see also section, Solids concentration of the blastgenerated $P D C$, this paper).

Due to the high velocity of the exploding source discharge $\left(>100 \mathrm{~m} \mathrm{~s}^{-1}\right)$, blast eruptions can eject blocks of dense rock a meter or more (Wilson and Heslop 1990). These blocks enter the initial PDC but cannot be carried effectively by turbulence. The initial turbulent PDC is thus overloaded with much coarse material that it cannot carry. Most such material rapidly settles out to form lag breccias, but some can saltate as bed load in the flow in downsloping areas, and can cause impact damage (Sparks et al. 2002). The abundance of high-Rouse-number particles also causes the PDC to be strongly stratified near to the source (Choux and Druitt 2002; Woods et al. 2002).

We conclude that the character of the distribution of blast deposits in relation to topography, as well as a clear ability of the blast currents to sort pyroclasts according to grainsize and density, make the flow mechanism of a blastgenerated PDC much closer, over most of the depositional area, to pyroclastic surges than to pyroclastic flows. The blast-generated PDC transports sediment in a predominantly turbulent fashion, often with a thin basal non-turbulent boundary layer (Druitt 1992; Ritchie et al. 2002; Choux et al. 2004). A high-density depositional boundary layer at the base of a PDC may act as a 'selective filter' through which particles falling out of turbulent suspension must pass in order to reach the depositional surface (Branney and Kokelaar 2002). Such a boundary layer could favor deposition of heavier particles and delay sedimentation of lighter particles (Branney and Kokelaar 2002; Choux et al. 2004; Lowe 1982).

Insight into the processes of particle sedimentation and aggradation is given by the turbulent density current experiments of Choux and Druitt (2002) and Choux et al. (2004), using video that allowed particle trajectories to be traced. The aqueous currents were scaled to simulate pyroclastic density currents. A depositional isochron is defined as the surface of an aggrading deposit at any moment in time, and a superposition of isochrons on depositional layering enabled visualization of how the individual layers accumulated over time from the head and body of a moving current. In one set of experiments, the currents contained dense particles only; in the other set, both light and dense particles were used. In both sets, dense particles were normally graded, both vertically and downstream. The mass loading and grain size of the dense component decreased with distance from source and were insensitive to the initial total particle concentration. But in the two-component mixtures, the light particles were very sensitive to concentration, and with higher particle concentrations were carried farther downstream. Deposits showed reverse grading of the large light particles, and this reflected delayed sedimentation, likely from buoyancy and 'selective filtering', not flotation (Choux et al. 2004; Branney and Kokelaar 2002). In both sets of experiments, inflections in the rate of downstream decline in mass loading and maximum grain size can be attributed to two different particle settling regimes: (1) particles with Rouse numbers $>2.5$, which did not respond to turbulence and settled rapidly, and (2) particles with Rouse number $<2.5$, which followed the turbulent eddies and settled slowly. In blast deposits, well-developed inflections of maximum size versus distance have been observed (e.g. Druitt 1992, Fig. 4), and this can likely be attributed to the existence of distinct high and low Rouse number particle settling regimes that mark the transition from the overcharged state to one in which the residual particle load is transported more effectively by turbulence (Choux and Druitt 2002).

Experiments show that grading in PDC deposits does not simply reflect segregation that already existed at source, but grading generated rapidly in the PDC. While it seems clear that very-near-source segregation exists and strongly influences depositional grading (Valentine 1987; Woods et al. 2002; Ritchie et al. 2002), it is likewise true that 
differential settling of particles with different degrees of turbulent support can rapidly generate vertical particle gradients, and both effects need consideration in modeling PDC deposition (Choux et al. 2004).

Need for high flux and relatively low gas fraction

What conditions are necessary to form blast-generated PDCs? Characteristics of the blast deposits at BZ, MSH, and SHV, supported by direct observations of the MSH eruption (Voight 1981), indicate that voluminous collapses of at least partly-inclined explosive fountains of the directed blasts were associated with the generation of the violent PDCs. Probably critical are explosions at high discharge rate of voluminous relatively-dense gas-pyroclast mixtures, forming an instantly collapsing fountain, a condition that can be realized by the slope failure-induced decompression of a shallow magma body with a large exposed surface and a limited mass fraction of gas. The asymmetric slopefailure surface of a collapsing volcanic edifice can promote directed explosions from the exposed slide scarp, or series of retrogressive slide scarps (Voight 1981), but we do not preclude the possibility of generating some focused blast currents from instantly-collapsing nearlyvertical fountains within confined crater wall (amphitheatre) settings with an open end. Steep, sometimes quasi-vertical explosions (horizontal angle $>60^{\circ}$ ) were also recorded in photographs of the early moments of the 1980 eruption at $\mathrm{MSH}$, besides explosions of low inclination (Fig. 15; Voight 1981), and such steeply-inclined explosions have been interpreted also from seismic records for later stages of the collapse and blast at MSH by Brodsky et al. (1999). Such explosions might be envisaged as lowfountain collapses similar to but more intense than those described by Clarke et al. (2002a,b), and directionally focused by an open-sided crater.

In order to generate a blast PDC, we suggest that the discharge rate of magma must be enormous, larger than that usually provided by typical eruptions through conduits of ordinary dimensions, with the duration very short. At MSH, about $0.11 \mathrm{~km}^{3}$ was released in $<4$ min, giving a flux $>10^{9} \mathrm{~kg} \mathrm{~s}^{-1}$. BZ was probably similar. At SHV currents of $\sim 30 \times 10^{6} \mathrm{~m}^{3}$ were sustained over $<12 \mathrm{~min}$, yielding an average flux of order $10^{8} \mathrm{~kg} \mathrm{~s}^{-1}$; but given the pulsations in the seismic signal, higher peak fluxes are certain (Sparks et al. 2002). The appropriate conditions are provided by exposed cryptodomes or lava domes, which can be many hundreds of meters wide, noting the correspondence between vent diameter and magma discharge rate (Wilson et al. 1980; Sparks et al. 1978). The large 'effective conduit' size and discharge rate promotes instantaneous collapse of the fountain and generation of an overloaded current. This explains why magmas of the blast-generating explosions were not erupted directly through existing conduits, but were already stored in large volumes in the upper parts of edifices, ready to erupt at very high discharge rates, once the shallow storage region was decapitated by a landslide.

Likewise, domes or cryptodomes have a porosity and permeability structure that constrains the net mass fraction of pressurized gas available to drive the explosion. They have one or two orders of magnitude less exsolved volatiles per unit mass of magma than is typically present in a plinian eruption (Woods et al. 2002). The result is a substantially greater gas-pyroclast mixture density, which results in an instantly collapsing pyroclastic current.

The runout distance of suspension currents is a strong function of the mass flux, and ranges from a few kilometers at $10^{8} \mathrm{~kg} \mathrm{~s}^{-1}$ to $100 \mathrm{~km}$ at $10^{11} \mathrm{~kg} \mathrm{~s}^{-1}$ (model of Bursik and Woods 1996). This model assumes a simple geometry and uniform particle concentration, and does not account for density stratification although it is useful in exploring firstorder flow dynamics. Applied to MSH it shows that the $25 \mathrm{~km}$ maximum runout is gained with a discharge rate of $2 \times 10^{9} \mathrm{~kg} \mathrm{~s}^{-1}$, which is reasonably consistent with observations. A variation of the model applied to SHV for a discharge of $10^{8} \mathrm{~kg} \mathrm{~s}^{-1}$ on a radial $10^{\circ}$ slope was not fully consistent with field data in that the event was largely erosional on land $(<4 \mathrm{~km})$ (Sparks et al. 2002). The absence of proximal sedimentation sustains the excess density of the current longer and enables a longer runout for the same flux. Probably the White River valley wall, crossing at the upper region of the interfluve, blocked the lower, denser part of the current from rising to the interfluve, and the highly turbulent current surmounting the interfluve was mainly erosive to the sea. Modeling in 3D can capture such complications.

\section{Discussion}

The blast eruptions of BZ, MSH, and SHV show remarkable similarities involving eruptive sequences, effects, and deposits. This is clear evidence that in these cases we are dealing with the same special type of eruptive scenario. The key elements involve a major slope failure of an edifice bearing shallow magma, and an associated directed blast. Plinian eruptions from magma at deeper levels may or may not follow the blast. More than three cases of this type occurred in the 20th century (we include Pelée in 1902), indicating that blast eruptions should be considered not as exotic but as a fairly common natural phenomenon.

While a large number of deposits of ancient debris avalanches have been found in the past two decades (Siebert 1984, 1996), this is not the case for deposits of 
ancient directed blasts. First of all, not each large-scale failure of a volcano is accompanied by a directed blast, even when the slope failure is associated with a magmatic component. As shown by the three studied cases, directed blasts occur only if, at the moment of slope failure, a shallow magma body that can serve as a blast charge exists either within, or in close proximity to, the slope failureaffected volume of the volcanic edifice. In the 20th century this condition took place in the cases we have described, while for two other major volcanic slope failures, at Harimkotan (Kuriles) in 1933 and Shiveluch (Kamchatka) in 1964, magma was present inside the conduit but not present substantially at a shallow level inside the edifice, and no directed blasts followed.

For realization of a Bezymianny-type scenario (Gorshkov 1962; Siebert et al. 1987), some intermediate degree of preeruption structural instability seems necessary. If the volcanic edifice is initially too unstable, the first weak deformations involving the vanguard of rising magma can provoke a collapse too early for a blast to follow, i.e., when much of the magma is still situated very deep within, or even under, the edifice. In this case, slope collapse will not cause a directed blast because:

(1) The failure surface (or retrogressive failure surfaces) of the landslide does not cross the magma body, but is at a higher level, above the magma body (Fig. 2). Thus, pressurized magma will be not be exposed directly to atmospheric pressure, and decompression will be less extreme, of smaller scale (a roof of edifice rocks will exist above magma lower in the edifice or in the conduit), and its response delayed.

(2) Magma at deeper levels will be less degassed and less crystallized by microlites. Slope failure-induced decompression of deeper magma bodies, instead of producing immediate fragmentation, will at first promote vesiculation in the conduit - a condition that can promote subsequently a plinian-type eruption, and a delay of eruption onset.

Such a situation occurred on numerous different occasions for edifice or lava dome failures of Shiveluch and Harimkotan volcanoes. In these cases, the major collapses initially caused only weak phreatic explosions of small superficial hydrothermal systems within the volcanoes, without the generation of blast PDCs. Following these phreatic explosions, decompressed magma at deeper level required some time to arrive at the surface. Thus, plinian eruptions started after some delay ( $\sim 13 \mathrm{~min}$ ) for the 1964 eruption of Shiveluch, and were associated with fountain-collapse pumiceous pyroclastic flows (Belousov and Belousova 1996; Belousov et al. 1999). We suggest this scenario might be termed Shiveluchtype. It was repeated at least seven times in the Holocene history of this volcano (Belousov 1995; Belousov et al. 1999).

A similar situation involved the 1888 Bandai eruption (Sekiya and Kikuchi 1889). The edifice of this volcano had been structurally very unstable for centuries, mostly due to fumarolic alteration of rocks, and numerous major edifice failures have been documented (Moriya 1980; Yamamoto and Suto 1996). We suspect that flank failure in 1888 may have been triggered by incipient deformations or gas pressurization induced by co-seismic magma ascent, when it was still deeply under the edifice (Voight and Elsworth 1997, Fig. 15). This could explain why this edifice failure provoked only a relatively weak (but nevertheless lethal) phreatic explosion, caused by decompression of the hydrothermal system. The explosion generated small phreatic PDCs which deposited old, hydrothermally altered rock material (Sekiya and Kikuchi 1889; Glicken and Nakamura 1988). Contrary to the cases at Shiveluch and Harimkotan, the rising batch of magma may have been small and deep, and decompression was unable to provoke a magmatic eruption since no magmatic activity followed the Bandai failure. However, the hydrothermal system could have been additionally pressurized by magmatic gas. This type of scenario, with phreatic rather than magmatic activity observed after major slope failure, is termed Bandai-type (Moriya 1980; Siebert et al. 1987).

If the edifice of a volcano is structurally very stable, deformations caused by rising magma may still be unable to cause gravitational instability. In this case magma will probably erupt without a blast, extruding lava while degassing, as occurs during ordinary dome-forming or lava-effusing eruptions on many volcanoes worldwide, or erupting by periodic vulcanian or plinian explosions unrelated to slope collapse.

A second obvious reason for the few genuine ancient directed blast deposits that have been recognized is that they are difficult to find and identify. Debris avalanche deposits have characteristics that allow them to be mapped on aerial and space images (Francis and Wells 1988), as well as easily recognized in the field. Old blast deposits are not detectable with remote sensing, are easily eroded, and in the field, even an experienced researcher can easily misinterpret them as conventional flow, fall, or weak pyroclastic surge deposits, depending on the specific layer and facies of the deposit observed; or, vice versa. We hope that the present paper, with its summary of common features of directed blast deposits, may assist others with field identifications. Volcanic edifices with morphologies, structures, and types of erupting silicic magmas similar to those of BZ, MSH, and SHV, and favoring the possibility of directed blasts, are common in volcanic arcs. We foresee that specially focused detailed studies will be able to discover deposits of directed blasts elsewhere. 


\section{Conclusions}

This comparative study has made it possible to provide answers to some key questions posed about nature of directed blasts:

What explodes? The explosion involves a partly crystallized magma body situated in the upper part of a volcanic edifice. Blast-generating magmas can exhibit a large range of degassing or cooling histories, and strongly meltdegassed and highly crystallized magma can contain pressurized gas in vesicles and pore space. Sustained gas release from rising conduit magma below can advect under pressure through connected porosity, including permeable vesicle structure, to the upper-level magma, adding to the mass fraction of gas, with the total gas energy sufficient to fragment a rapidly-depressurized shallow magma body. This gas fraction is, however, much less than that necessary to create, directly and primarily, a vertically rising plume from a buoyant ash-gas mixture. The result is the rapid collapse of an inclined fountain, and generation of an energetic, relatively dense, density-stratified and grain-sizestratified PDC. A vertically rising plume can develop subsequently from convective lofting of the fines-rich mixture within the PDC, once sedimentation and air mixing have rendered it buoyant.

Why do blasts occur? The shallow, gas-pressurized magma body becomes highly and very rapidly decompressed as a result of major edifice or lava dome failure.

What focuses the directed blasts? The pre-blast slope failure asymmetrically exposes the shallow magma body to cause a directed explosion or series of explosions. The axis of the blast coincides generally with the direction of slope movement, and much of the explosion occurs at an inclination roughly normal to the steep rear part of the slip surface. Following collapse of the inclined fountain, travel of the blast-generated PDC is shaped by momentum and topography (slope variations in the direction of PDC motion, channeling, confinement or lack of confinement). In cases where initial explosions or explosion clusters are steeply inclined, fountain collapse and a horseshoe-shaped crater geometry can lead to asymmetric travel of a focused PDC.

What dynamic processes cause damage? We separate the transient directed blast phenomenon into three main parts, the burst phase, the collapse phase, and the PDC phase. A major unresolved question is whether the preponderance of strong damage observed in the several volcanic blasts should be attributed to shock waves within an overpressured jet in the burst phase (Kieffer 1981), or to dynamic pressures and possibly shocks within energetic collapse and PDC phases (Esposti Ongaro et al. in press). We note that internal shock structures related to unsteady flow and compressibility effects can occur in each of these phases, so that the issue of shock damage appears less unique and more complicated than previously considered. We withhold judgment about published shock models as a primary explanation for the damage sustained at MSH until modern 3D numerical modeling is accomplished, but we argue that the severe damage observed in blasts can be reasonably interpreted to have been caused by high dynamic pressures and clast impact loading within the inclined collapsing fountain and/or the stratified PDC. This view is reinforced by recent modeling cited for SHV. In distal and peripheral regions, solids concentration in the PDC, maximum particle size, current speed, and dynamic pressure were diminished, resulting in specific but lesser damage, and enhanced influence by local topography on PDC movement.

What was deposited and how? In the proximal zones, following a phase of severe erosion, a three-layered stratigraphy plus a capping fallout layer, with rapid local fluctuations of thickness and grain-size, was produced by stratified PDCs with an initially high concentration of particles. The blast-generated PDC transports sediment mainly in a turbulent fashion, with a thin basal non-turbulent boundary layer. Particle sizes supported by turbulence can exceed $10 \mathrm{~cm}$, as mixture density is high and internal blast-generated PDC speeds can exceed $100 \mathrm{~m} \mathrm{~s}^{-1}$. A high-density depositional boundary layer exists at the base of a PDC and may act as a 'selective filter' through which particles falling out of turbulent suspension must pass in order to reach the depositional surface, delaying sedimentation of lighter particles (Branney and Kokelaar 2002; Choux et al. 2004). The lowermost parts of the PDCs were high in particle concentration in proximal regions, and the PDCs became more dilute with distance (Druitt 1992, Esposti Ongaro et al. in press).

The basal layer A reflects intense turbulent boundary shear between the basal part of the energetic head of the PDC, and the substrate. Deposition of the fines-depleted second layer B occurred by rapid suspension sedimentation in rapidly waning, high-concentration conditions. The upper layer $\mathrm{C}$ mainly involved rapid sedimentation under moderate-concentration, weakly tractive conditions, with the uppermost laminated part reflecting a dilute depositional regime with grain-by-grain traction deposition. By analogy to laboratory experiments, mixing at the flow head of the PDC creates a turbulent and dilute wake above the body of a gravity current (Kneller et al. 1999; Ritchie et al. 2002; Choux and Druitt 2002; Choux et al. 2004), with layer B deposited by the flow body, and layer $\mathrm{C}$ by the wake. In a blast-generated PDC the division between these 
flow regions could be accentuated by heating entrained air, producing a thicker expanded wake with segregated fines, and by stratification initially generated by source dynamics but accentuated further by differential settling of particles with different degrees of turbulent support.

\section{Which criteria enable recognition of old directed blasts?} Blasts may be identified using a combination of criteria, including an association with collapsed volcanoes (horseshoe craters, debris avalanche deposits), evidence of PDC deposits in close temporal relation to the avalanche deposit (distal avalanche overtaken by blast PDC, with blast deposits both under and over the avalanche deposit), evidence of severe erosion under blast deposits, substantial PDC-induced damage and tree blow-down, similarities of stratigraphy to the classic sites and especially the finesdepleted layer B, evidence of high-energy particle support mechanisms, secondary blast pyroclastic flows in valleys isolated from the explosion source, abundance in PDC deposits of clasts of silicic magma and commonly breadcrust bombs, distinctive thermal effects in relation to layer stratigraphy. We hope that the present paper, with its summary of the special features of directed blast deposits, may assist others with identifications.

Which volcanoes are potentially blast-dangerous? Volcanoes erupting viscous, partly-crystalline silicic (mainly andesite and dacite) magmas and volcanoes with domes, especially those demonstrating signs of gravitational instability and having high level injections of gas-pressurized magma, are susceptible to blasts.

Acknowledgements We thank Tim Druitt for his thorough constructive review, an anonymous reviewer, and John Stix for remarks and careful editorial work. We likewise acknowledge support and insights from colleagues at Mount St. Helens, particularly CD Miller, RP Hoblitt, R Waitt, HX Glicken, S Kieffer, R Christiansen, D Peterson, and RV Fisher, among others mostly represented as the authors of USGS PP 1250; colleagues at the Institute of Volcanology and Seismology in Kamchatka, particularly A Petukhin and $M$ Alidibirov; and co-workers and staff at Montserrat Volcano Observatory as represented by RSJ Sparks, SR Young, and the authors of Geological Society Memoir 21. We salute the pioneers of directed blast studies, GS Gorshkov at Kamchatka and the Kuriles, DR Crandell and D Mullineaux in the Cascade Range, and A LaCroix in the Caribbean region. Rocky Crandell is responsible for inviting BV's hazards and research participation at St Helens, and BV is grateful for this. The research of $\mathrm{K}$ Wohletz and $\mathrm{G}$ Valentine provided important insights on blast dynamics. BV is indebted especially to colleagues A Neri, T Esposti Ongaro, A Clarke, and C Widiwijayanti for the privilege and pleasure of our continued collaborative modeling research. C. Widiwijayanti also aided the submission of the manuscript. This research was financed chiefly by grants from the US Civilian Research \& Development Foundation, and the PetrologyGeochemistry Program of NSF, with additional support by the volcano observatory organizations noted above.

\section{References}

Alidibirov M (1994) A model for viscous magma fragmentation during volcanic blasts. Bull Volcanol 56:459-465

Alidibirov M, Dingwell DB (1996) Magma fragmentation by rapid decompression. Nature 380:146-148

Aspinall WP, Miller AD, Lynch LL, Latchman JL, Stewart RC, White RA, Power JA (1998) Soufrière Hills eruption, Montserrat, 1995-1997: volcanic earthquake locations and fault plane solutions. Geophys Res Lett 25:3397-3400

Banks NG, Hoblitt RP (1981) Summary of temperature studies of 1980 deposits. In: Lipman PV, Mullineaux DR (eds) The 1980 eruptions of Mount St. Helens, Washington. US Geol Surv Prof Pap 1250:295-315

Banks NG, Hoblitt RP (1996) Direct temperature measurements of deposits, Mount St. Helens, Washington, 1980-1981. US Geol Surv Prof Pap 1387:1-76

Barclay J, Carroll MR, Rutherford MJ, Murphy MD, Devine JD, Gardner J, Sparks RSJ (1998) Experimental phase equilibria constraints on pre-eruptive storage conditions of the Soufrière Hills magma. Geophys Res Lett 25:3437-3440

Baxter PJ, Boyle R, Cole F, Neri A, Spence R, Zuccaro G (2005) The impacts of pyroclastic surges on buildings at the eruption of the Soufriere Hills Volcanol, Montserrat Bull Volcano 67:292-313

Beget J, Kienle J (1992) Cyclic formation of debris avalanches at Mount St Augustine volcano. Nature 356:701-704

Belousov A (1995) The Shiveluch volcanic eruption of 12 November 1964: explosive eruption provoked by failure of the edifice. J Volcanol Geotherm Res 66:357-365

Belousov A (1996) Pyroclastic deposits of March 30, 1956 directed blast at Bezymianny volcano. Bull Volcanol 57:649-662

Belousov A, Belousova M (1996) Large scale landslides on active volcanoes in the 20th century-Examples from the KurileKamchatka region (Russia). In: Senneset K (ed) Landslides. Balkema, Rotterdam, pp 953-957

Belousov A, Belousova M (1998) Bezymyannyi eruption on March 30, 1956 (Kamchatka): sequence of events and debris avalanche deposits. Volcanol Seismol 20:29-47

Belousov AB, Bogoyavlenskaya GE (1988) Debris avalanche of the 1956 Bezymianny eruption. Proc. Kagoshima Int Conf on Volcanoes: $460-462$

Belousov A, Belousova M, Voight B (1999) Multiple edifice failures, debris avalanches and associated eruptions in the Holocene history of Shiveluch volcano, Kamchatka, Russia. Bull Volcanol 61:324-342

Belousov A, Voight B, Belousova M, Petukhin A (2002) Powerful pyroclastic surge in the May 8-10, 1997 explosive eruption of Bezymianny volcano, Kamchatka, Russia. Bull Volcanol 64:455-471

Belousova M, Belousov A (1995) Prehistoric and 1933 debris avalanches and associated eruptions of Harimkotan Volcano (Kurile islands) Periodico di Mineralogia 64:99-101

Bogoyavlenskaya GE (1962) Agglomerate flow Bezymianny Volcano. Bull Volcanol 24:203-210

Bogoyavlenskaya GE, Kirsanov IT (1981) Twenty five years of volcanic activity of Bezymianny (in Russian). Volcanol Seismol 2:3-13

Bogoyavlenskaya GE, Braitseva OA, Melekestsev IV, Maximov AP, Ivanov BV (1991) Bezymianny volcano. In: Fedotov SA (ed) Active volcanoes of Kamchatka. V 1. Nauka, Moscow, pp 166-197

Boudon G, Lajoie J (1989) The 1902 Peléean deposits in the Fort Cemetery of St Pierre, Martinique: a model for the accumulation of turbulent nuées ardentes. J Volcanol Geotherm Res 38:113-129

Boudon G, Semet M, Vincent P (1984) Flank failure - directed blast eruption at Soufrière, Guadeloupe, French West Indies: a 3,000yr-old Mt St Helens? Geology 12:350-353 
Bourdier JL, Boudon G, Gourgaud A (1989) Stratigraphy of the 1902 and 1929 nuée-ardente deposits, Mt Pelée, Martinique. J Volcanol Geotherm Res 38:77-96

Braitseva OA, Melekestsev IV, Bogoyavlenskaya GE, Maximov AP (1991) Bezymianny: eruptive history and dynamics. Volcanol Seismol 12:165-195

Branney MJ, Kokelaar P (2002) Pyroclastic density currents and the sedimentaion of ignimbrites. Geol Soc Mem, London 27:1-152

Brantley SR, Waitt RB (1988) Interrelations among pyroclastic surge, pyroclastic flow, and lahars in the Smith Creek valley during the first minutes of 18 May 1980 eruption of Mount St. Helens, USA. Bull Volcanol 50:304-326

Brodsky EE, Kanamori H, Sturtevant B (1999) A seismically constrained mass discharge rate for the initiation of the May 18, 1980 Mount St. Helens eruption. J Geophys Res 104:29, 389-29, 400

Bursik MI, Woods AW (1996) The dynamics and thermodynamics of large ash flows. Bull Volcanol 58:175-193

Bursik MI, Kurbatov A, Sheridan M, Woods AW (1998) Transport and deposition in the May 181980 Mount St Helens blast. Geology 28:155-158

Cantagrel J, Arnaud N, Ancochea E, Fuster J, Huertas M (1999) Repeated debris avalanches on Tenerife and genesis of Las Canadas caldera wall (Canary Islands). Geology 27:739-742

Carey S, Sigurdsson H, Gardner JE, Criswell W (1990) Variations in column height and magma discharge during the May 18, 1980 eruption of Mount St Helens. J Volcanol Geotherm Res 43:99112

Carey S, Gardner J, Sigurdsson H (1995) The intensity and magnitude of Holocene plinian eruptions from Mount St Helens volcano. J Volcanol Geotherm Res 66:185-202

Cashman KV (1992) Groundmass crystallization of Mount St. Helens dacite, 1980-1986: a tool for interpreting shallow magmatic processes. Contrib Mineral Petrol 109:431-449

Cashman KV, Blundy J (2000) Degassing and crystallization of ascending andesite. Phil Trans Royal Soc London 358:14871513

Cashman KV, Hoblitt RP (2004) Magmatic precursors to the 18 May 1980 eruption of Mount St Helens. Geology 32:141-144

Choux C, Druitt T (2002) Analogue study of particle segregation in pyroclastic density currents, with implications for the emplacement mechanisms of large ignimbrites. Sedimentology 49:907928

Choux C, Druitt T, Thomas N (2004) Stratification and particle segregation in flowing polydisperse suspensions, with applications to the transport and deposition of pyroclastic density currents. J Volcanol Geotherm Res 138:223-241

Clarke AB, Voight B (2000) Pyroclastic current dynamic pressures from aerodynamics of tree or pole blow-down. J Volcanol Geotherm Res 100:395-412

Clarke AB, Hidayat D, Voight B (1997) Pyroclastic current speedometer/densitometer from dynamics of tree or pole blow-down. In: IAVCEI General Assembly: Volcanic Activity and the Environment, $\mathrm{p} 8$

Clarke AB, Neri A, Macedonio G, Voight B (2002a) Transient dynamics of Vulcanian explosions and column collapse. Nature 415:897-901

Clarke AB, Neri A, Voight B, Macedonio G, Druitt T (2002b) Computational modeling of the transient dynamics of August 1997 Vulcanian exposions at Soufrière Hills Volcano, Montserrat. In: Druitt TH, Kokelaar BP (eds) The eruption of Soufrière Hills volcano, Montserrat, from 1995 to 1999. Mem Geol Soc London 21:319-348

Clavero JE, Sparks RSJ, Huppert HE, Dade WB (2002) Geological constraints on the emplacement mechanism of the Parinacota debris avalanche, northern Chile. Bull Volcanol 64:40-54
Crandell DR (1987) Deposits of pre-1980 pyroclastic flows and lahars from Mount St Helens volcano, Washington. US Geol Surv Prof Paper 1444:1-91

Crandell DR, Hoblitt R (1986) Lateral blasts at Mount St. Helens and hazard zonation. Bull Volcanol 48:27-37

Criswell CW (1987) Chronology and pyroclastic stratigraphy of the May 18, 1980, eruption of Mount St Helens, Washington. J Geophys Res 92:10,237-10,266

Deplus C, Le Friant A, Boudon G, Komorowski J-C, Villemant B, Harford C, Segoufin J, Cheminee J-L (2001) Submarine evidence for large-scale debris avalanches in the Lesser Antilles Arc. Earth Planet Sci Lett 192:145-157

Donnadieu F, Merle O (1998) Experiments in the indentation process during cryptodome intrusions: new insights into Mount St. Helens deformation. Geology 26:79-82

Donnadieu F, Merle O (2001) Geometrical constraints of the 1980 Mount St. Helens intrusion from analogue models. Geophys Res Lett 28:639-642

Druitt TH (1992) Emplacement of the 18 May 1980 lateral blast deposit ENE of Mount St. Helens, Washington. Bull Volcanol 54:554-573

Druitt TH (1998) Pyroclastic density currents. In: Gilbert JS, Sparks RSJ (eds). The physics of explosive volcanic eruptions. Geological Society Special Publications no. 145. Geological Society, London, 21, pp. 145-182

Druitt TH, Kokelaar BP (eds) (2002) The eruption of Soufrière Hills volcano, Montserrat, from 1995 to 1999. Geol Soc London Memoir 21:1-845

Druitt TH, Young S, Baptie B, Calder E, Clarke A, Cole P, Harford C, Herd R, Luckett R, Ryan G, Sparks S, Voight B (2002a) Episodes of cyclic Vulcanian explosive activity with fountain collapse at Soufrière Hills volcano, Montserrat. In: Druitt TH, Kokelaar BP (eds) The eruption of Soufrière Hills volcano, Montserrat, from 1995 to 1999. Mem Geol Soc London 21:281-306

Druitt TH, Calder ES, Cole PD, Hoblitt RP, Loughlin SC, Norton GE, Ritchie LJ, Sparks RS, Voight B (2002b) Small-volume, highly mobile pyroclastic flows formed by rapid sedimentation from pyroclastic surges at Soufrière Hills volcano, Montserrat: an important volcanic hazard. In: Druitt TH, Kokelaar BP (eds) The eruption of Soufrière Hills volcano, Montserrat, from 1995 to 1999. Mem Geol Soc London 21:263-280

Dzurisin D, Vallance JW, Gerlach TM, Moran SC, Malone SC (2005) Mount St Helens reawakens. EOS Trans AGU 86(3):25-36

Eichelberger JC, Hayes DB (1982) Magmatic model of the Mount St Helens blast of May 18, 1980. J Geophys Res 87:7727-7738

Eichelberger JC, Carrigan CR, Westrich HR, Price RH (1986) Nonexplosive silicic volcanism. Nature 323:598-602

Elsworth D, Voight B (2001) The mechanics of harmonic gas pressurization and failure of lava domes. Geophys J Int 145:187-198

Esposti Ongaro T, Clarke AB, Neri A, Voight B, Widiwidjayanti C (1995a) A high-performance 3D multiphase flow code to simulate directed blasts and their pyroclastic density currents: example from the Boxing Day event, Montserrat. Programme and Abstracts, Soufriere Hills Volcano - Ten Years On,... Scientific Conference, Montserrat

Esposti Ongaro T, Clarke AB, Neri A, Voight B, Widiwidjayanti C (1995b) A new high-performance 3D multiphase flow code to simulate directed blasts and their pyroclastic density currents: example from the Boxing Day event, Montserrat. EOS Trans AGU 86(52), Fall Meet Suppl, Abs V3D-0645

Esposti Ongaro T, Neri A, Clarke AB, Voight B, Widiwidjayanti C (2007) Fluid dynamics of the 1997 Boxing Day volcanic blast on Montserrat, W.I. J Geophys Res (in press)

Fink JH, Kieffer SW (1993) Estimate of pyroclastic flow velocities resulting from explosive decompression of lava domes. Nature 363:612-615 
Fisher RV (1990) Transport and deposition of a pyroclastic surge across an area of high relief: the 18 May 1980 eruption of Mount St. Helens, Washington. Geol Soc Am Bull 102:1038-1054

Fisher RV, Glicken HX, Hoblitt RP (1987) May 18, 1980, Mount St. Helens deposits in South Coldwater Creek, Washington. J Geophys Res 92:10267-10283

Formenti Y, Druitt T (2003) Vesicle connections in pyroclastics and implications for the fluidization of fountain-collapse pyroclastic flows, Montserrat (West Indies). Earth Plan Sci Lett 214:561-574

Foxworthy BL, Hill M (1982) Volcanic eruptions of 1980 at Mount St Helens - the first 100 days. US Geol Surv Prof Pap 1249:1-125

Francis PW, Wells GL (1988) Landsat Thematic Mapper observations of debris avalanche deposits in the Central Andes. Bull Volcanol $50: 258-278$

Glasstone S, Dolan PJ (1977) The effects of nuclear weapons. US Dept Defense and US Energy Res Develop Admin, third edn. US Gov Printing Office, Washington DC, pp 1-653

Glicken H (1998) Rockslide-debris avalanche of May 18, 1980 , Mount St. Helens volcano, Washington. Bull Geol Soc Japan 49:55-106

Glicken G, Nakamura Y (1988) Restudy of the 1888 eruption of Bandai volcano, Japan. In: Proc Kagoshima Int Conf Volcanoes, Japan, pp 392-395

Gorshkov GS (1959) Gigantic eruption of the Bezymianny volcano. Bull Volcanol 20:77-109

Gorshkov GS (1962) On the classification and terminology of Pelee and Katmai type eruptions. Bull Volcanol 24:155-165

Gorshkov GS (1963) Directed volcanic blasts. Bull Volcanol 26:83-88

Gorshkov GS, Bogoyavlenskaya GE (1965) Bezymianny volcano and peculiarities of its last eruption (1955-1963). Nauka, Moscow, pp 1-171, (in Russian)

Hart K, Carey S, Sigurdsson H, Sparks RSJ (2004) Discharge of pyroclastic flows into the sea during the 1996-1998 eruptions of Soufriere Hills Volcano, Montserrat. Bull Volcanol 66:599-614

Hausback BP, Swanson DA (1990) Record of prehistoric debris avalanches on the north flank of Mount St. Helens volcano, Washington. Geosci Can 17:142-145

Hoblitt RP (1986) Observations of the eruptions of July 22 and August 7, 1980, at Mount St Helens, Washington. US Geol Surv Prof Pap 1335:1-44

Hoblitt RP (2000) Was the 18 May 1980 lateral blast at Mt St Helens the product of two explosions? Phil Trans Royal Soc London 358:1639-1661

Hoblitt RP, Harmon R (1993) Bimodal density distribution of cryptodome dacite from the 1980 eruption of Mount St Helens, Washington. Bull Volcanol 55:421-438

Hoblitt RP, Miller CD (1984) Comments and reply on "Mount St. Helens 1980 and Mount Pelée 1902-flow or surge?" Geology 12:692-693

Hoblitt RP, Crandell D, Mullineaux D (1980) Mount St Helens eruptive behavior during the past 1.500 yr. Geology 8:555559

Hoblitt RP, Miller CD, Vallance JW (1981) Origin and stratigraphy of the deposit produced by the May 18 directed blast. In: Lipman P W, Mullineaux DR (eds) The 1980 eruptions of Mount St. Helens, Washington. US Geol Surv Prof Pap 1250:401-419

JANNAF [Joint Army, Navy, NASA, Air Force] (1975) Handbook of rocket exhaust plume technology

Kadik AA, Maksimov AP, Ivanov BV (1986) Physico-chemical conditions of crystallisation and origin of andesites (on examples of Kluchevskaya Group of volcanoes). Nauka, Moscow, pp 1158 , (in Russian)

Kieffer SW (1981) Fluid dynamics of the May 18 blast at Mount St. Helens. In: Lipman PW, Mullineaux DR (eds) The 1980 eruptions of Mount St. Helens, Washington. US Geol Surv Prof Pap 1250:379-401
Kieffer SW (1984) Factors governing the structure of volcanic jets. In: Explosive volcanism: inception, evolution, and hazards. National Academy, Washington, pp 143-157

Kieffer SW, Sturtevant B (1984) Laboratory studies of volcanic jets. J Geophys Res 89:8253-8268

Kieffer SW, Sturtevant B (1988) Erosional furrows formed during the lateral blast at Mount St Helens, May 18 1980. J Geophys Res 93:14793-14816

Kneller BC, Bennett SJ, McCaffrey WD (1999) Velocity structure, turbulence and fluid stresses in experimental gravity currents. J Geophys Res 104:5381-5391

Lacroix A (1904) La Montagne Pelée et ses eruptions. Masson, Paris, pp $1-650$

Lipman PW, Mullineaux DR (eds) (1981) The 1980 eruptions of Mount St. Helens, Washington. US Geol Surv Prof Pap 1250:1-844

Lipman PW, Moore JG, Swanson DA (1981) Bulging of the north flank before the May 18 eruption-geodetic data. In: Lipman PW, Mullineaux DR (eds) The 1980 eruptions of Mount St. Helens, Washington. US Geol Surv Prof Pap 1250:143-156

Lowe DR (1982) Sediment gravity flows: II. Depositional models with special reference to the deposits of high-density turbidity currents. J Sediment Petrol 52:279-297

Mayberry GC, Rose WI, Bluth GJS (2002) Dynamics of volcanic and meteorological clouds produced on 26 December (Boxing Day) 1997 at Soufriere Hills Volcano, Montserrat. In: Druitt TH, Kokelaar BP (eds) The eruption of Soufrière Hills volcano, Montserrat, from 1995 to 1999. Mem Geol Soc London 21:539-556

Melnik O, Sparks RSJ (1999) Non-linear dynamics of lava dome extrusion. Nature 402:37-41

Melnik O, Sparks RSJ (2002) Dynamics of magma ascent and lava extrusion at the Soufrière Hills volcano, Montserrat. In: Druitt TH, Kokelaar BP (eds) The eruption of Soufrière Hills volcano, Montserrat, from 1995 to 1999. Mem Geol Soc London 21:153-171

Merzbacher C, Eggler DH (1984) A magmatic geohygrometer: application to Mount St. Helens and other dacitic magmas. Geology 12:587-590

Middleton GV, Neal WJ (1990) Experiments on the thickness of beds deposited by turbidity currents. J Sediment Petrol 59:297-307

Moore JG, Albee WC (1981) Topographic and structural changes, March-July 1980 - photogrammetric data. In: Lipman PW, Mullineaux DR (eds) The 1980 eruptions of Mount St. Helens, Washington. US Geol Surv Prof Pap 1250:123-134

Moore JG, Rice CJ (1984) Chronology and character of the May 18, 1980, explosive eruptions of Mount St Helens. In: explosive volcanism: inception, evolution, and hazards. National Academy, Washington, pp 133-142

Moore JG, Sisson TW (1981) Deposits and effects of the May 18 pyroclastic surge. In: Lipman PW, Mullineaux DR (eds) The 1980 eruptions of Mount St. Helens, Washington. US Geol Surv Prof Pap 1250:421-438

Moriya I (1980) "Bandaian eruption" and landforms associated with it. In: collection of articles in memory of retirement of Prof. K. Nishimura from Tohoku University. Fac Sci Tohoku Univ, Sendai: 214-219 (in Japanese with English abstract)

Mullineaux DR (1986) Summary of pre-1980 tephra-fall deposits erupted from Mount St. Helens, Washington State, USA. Bull Volcanol 48:17-26

Mullineaux DR, Crandell DR (1981) The eruptive history of Mount St. Helens. In: Lipman PW, Mullineaux DR (eds) The 1980 eruptions of Mount St. Helens, Washington. US Geol Surv Prof. Pap 1250:3-16

Murphy MD, Sparks RSJ, Barclay J, Carroll MR, Brewer TS (2000) Remobilisation origin for andesite magma by intrusion of mafic magma at the Soufrière Hills volcano, Montserrat, WI: a trigger for renewed eruption. J Petrol 41:21-42 
Palmer B, Alloway B, Neall V (1991) Volcanic debris-avalanche deposits in New Zealand-lithofacies organization in unconfined, wet-avalanche flows. In: Fisher RV, Smith GA (eds) Sedimentation in volcanic settings. SEPM Spec Publ 45:89-98

Ritchie L, Cole P, Sparks PSJ (2002) Sedimentology of pyroclastic density current deposits generated by the December 26, 1997 eruption at the Soufrière Hills volcano, Montserrat. In: Druitt T, Kokelaar BP (eds) The eruption of Soufrière Hills volcano, Montserrat, from 1995-1999. Mem Geol Soc London 21:435-456

Robertson R, Cole P, Sparks RSJ, Harford C, Lejeune AM, McGuire WJ, Miller AD, Murphy MD, Norton G, Stevens NF, Young SR (1998) The explosive eruption of Soufrière Hills volcano, Montserrat, West Indies, September 17, 1996. Geophys Res Lett 25:3429-3433

Robertson RA, Aspinall WR, Herd RA, Norton GE, Sparks RSJ, Young R (2000) The 1995-1998 eruption of the Soufrière Hills volcano, Montserrat, WI. Phil Trans Royal Soc London 358:1619-1637

Roobol M, Smith A (1998) Pyroclastic stratigraphy of the Soufrière Hills volcano, Montserrat-implications for the present eruption. Geophys Res Lett 25:3393-3396

Rutherford MJ, Devine JD (1988) The May 18, 1980 eruption of Mount St Helens. Stability and chemistry of amphibole in the magma chamber. J Geophys Res 93:11,949-11,959

Rutherford MJ, Sigurdsson H, Carey S, Davis AN (1985) The May 18, 1980 eruption of Mount St Helens. Melt composition and experimental phase equilibria. J Geophys Res 90:2929-2947

Scandone R, Malone SD (1985) Magma supply, magma discharge and readjustment of the feeding system of Mount St. Helens during 1980. J Volcanol Geotherm Res 23:239-262

Sekiya S, Kikuchi Y (1889) The eruption of Bandai-san. Tokyo Imp Univ Coll Sci J 3:91-172

Siebe C, Komorowski J-C, Sheridan MF (1992) Morphology and emplacement of an unusual debris-avalanche deposit at Jocotitlan volcano, Central Mexico. Bull Volcanol 54:573-589

Siebe C, Macias JL, Abrams M, Rodriguez S, Castro R, Delgado H (1995) Quaternary explosive volcanism and pyroclastic deposits in East Central Mexico: implications for future hazards. Field trip guide book 1 for Geol Soc Am Ann Mtg: 1-47

Siebert L (1984) Large volcanic debris avalanches: characteristics of source areas, deposits and associated eruptions. J Volcanol Geotherm Res 22:163-197

Siebert L (1996) Hazards of large volcanic debris avalanches and associated eruptive phenomena. In: Scarpa R, Tilling R (eds) Monitoring and mitigation of volcano hazards. Springer, Berlin Heidelberg New York, pp 541-572

Siebert L, Glicken H, Ui T (1987) Volcanic hazards from Bezymianny- and Bandai-type eruptions. Bull Volcanol 49:435-459

Siebert L, Beget J, Glicken H (1995) The 1883 and late-prehistoric eruptions of Augustine volcano, Alaska. J Volcanol Geotherm Res 66:367-395

Simpson JE (1987) Gravity currents in the environment and in the laboratory. Halstead, New York, pp 1-244

Sisson TW (1995) Blast ashfall deposit of May 18, 1980 Mount St Helens, Washington. J Volcanol Geotherm Res 66:203-216

Sousa J, Voight B (1995) Multiple-pulsed debris avalanche emplacement at Mount St Helens in 1980. Evidence from numerical continuum flow simulations. J Volcanol Geotherm Res 66:227-250

Sparks RSJ (1983) Discussion on "Mt. Pelée, Martinique; May 8 and 20, 1902 pyroclastic flows and surges". J Volcanol Geotherm Res 19:175-180

Sparks RSJ (1997) Causes and consequences of pressurization in lava dome eruptions. Earth Planet Sci Lett 150:177-189

Sparks RSJ, Wilson L, Hulme G (1978) Theoretical modeling of the generation, movement and emplacement of pyroclastic flows by column collapse. J Geophys Res 83:1727-1739
Sparks RSJ, Moore JG, Rice CJ (1986) The initial giant umbrella cloud of the May 18th, 1980, explosive eruption of Mount St Helens. J Volcanol Geotherm Res 28:257-274

Sparks RSJ, Bursik ME, Carey SN, Gilbert JS, Glaze LS, Sigurdsson H, Woods AW (1997) Volcanic plumes. Wiley, New York, pp 1574

Sparks RSJ, Murphy MD, Lejeune AM, Watts RB, Barclay J, Young S (2000) Control on the emplacement of the andesite lava dome of the Soufrière Hills volcano, Montserrat by degassing-induced crystallization. Terra Nova 12:1-20

Sparks RSJ, Barclay J, Calder ES, Herd RA, Luckett R, Norton GE, Pollard L, Robertson RA, Ritchie L, Voight B, Young SR, Woods AW (2002) Generation of a debris avalanche and violent pyroclastic density current: the Boxing Day eruption of 26 December 1997 at the Soufrière Hills volcano, Montserrat. In: Druitt T, Kokelaar BP (eds) The eruption of Soufrière Hills volcano, Montserrat, from 1995-1999. Mem Geol Soc London 21:409-434

Taylor GA (1958) The 1951 eruption of Mount Lamington, Papua. Bur Min Res Geol Geophys Bull 38:1-112

Valentine GA (1987) Stratified flow in pyroclastic surges. Bull Volcanol 49:616-630

Valentine GA (1998a) Damage to structures by pyroclastic flows and surges, inferred from nuclear weapons effects. J Volcanol Geotherm Res 87:117-140

Valentine GA (1998b) Eruption column physics. In: Freund A, Rosi M (eds) From magma to tephra. Elsevier, Amsterdam, pp 91-138

Valentine GA, Wohletz KH (1989) Numerical models of Plinian eruption columns and pyroclastic flows. J Geophys Res 94:18671887

Voight B (1981) Time scale for the first movements of the May 18 eruption. In: Lipman PW, Mullineaux DR (eds) The 1980 eruptions of Mount St. Helens, Washington. US Geol Surv Prof Pap 1250:69-86

Voight B (2000) Structural stability of andesite volcanoes and lava domes. Phil Trans Royal Soc London 358:1663-1703

Voight B, Elsworth D (1997) Failure of volcano slopes. Geotechnique 47:1-31

Voight B, Elsworth D (2000) Stability and collapse of hazardous gaspressurized lava domes. Geophys Res Lett 48:1-4

Voight B, Glicken H, Janda RJ, Douglass PM (1981) Catastrophic rockslide avalanche of May 18. In: Lipman PW, Mullineaux DR (eds) The 1980 eruptions of Mount St. Helens, Washington. US Geol Surv Prof Pap 1250:347-377

Voight B, Glicken H, Janda RJ, Douglass PM (1983) Nature and mechanics of the Mount St Helens rockslide-avalanche of 18 May 1980. Geotechnique 33:243-273

Voight B, Komorowski J-C, Norton G, Belousov A, Belousova M, Boudon G, Francis P, Franz W, Sparks S, Young S (2002) The 1997 Boxing Day sector collapse and debris avalanche, Soufrière Hills Volcano, Montserrat, B.W.I. In: Druitt T, Kokelaar BP (eds) The eruption of Soufrière Hills volcano, Montserrat, from 19951999. Mem Geol Soc Lond 21:363-407

Wadge G, Isaacs MC (1988) Mapping the volcanic hazards from Soufrière Hills Volcano, Montserrat, West Indies using an image processor. J Geol Soc Lond 145:541-551

Waitt RBJ (1981) Devastating pyroclastic density flow and attendant air fall of May 18 - stratigraphy and sedimentology of deposits. In: Lipman, PW, Mullineaux DR (eds) The 1980 eruptions of Mount St. Helens, Washington. US Geol Surv Prof Pap 1250:439-458

Waitt RBJ (1984) Comments and reply on "Mount St. Helens 1980 and Mount Pelée 1902-flow or surge?" Geology 12:693

Wallis GB (1969) One-dimensional two-phase flow. McGraw Hill, New York

Walker GPL (1983) Ignimbrite types and ignimbrite problems. J Volcanol Geotherm Res 17:65-88 
Walker GPL, McBroome LA (1983) Mount St. Helens 1980 and Mount Pelée 1902-flow or surge? Geology 11:571-574

Walker GPL, McBroome LA (1984) Comments and reply on "Mount St. Helens 1980 and Mount Pelée 1902-flow or surge? Geology 12:693-694

Watts R, Sparks RSJ, Herd RA, Young SR (2002) Growth patterns and emplacement of the andesitic lava dome at Soufrière Hills volcano, Montserrat. In: Druitt T, Kokelaar BP (eds) The eruption of Soufrière Hills volcano, Montserrat, from 19951999. Mem Geol Soc London 21:115-152

Wilson L, Heslop SE (1990) Clast sizes in terrestrial and Martian ignimbrite lag deposits. J Geophys Res 95:17309-17314

Wilson L, Sparks RSJ, Walker JPL (1980) Explosive volcanic eruptions, IV. The control of magma properties and conduit geometry on eruption column behavior. Geophys J Royal Astron Soc 63:117-148

Winner WE, Casadevall TJ (1981) Fir leaves as thermometers during the May 18 eruption. In: Lipman PW, Mullineaux DR (eds) The 1980 eruptions of Mount St. Helens, Washington. US Geol Surv Prof Pap 1250:315-320

Wohletz KH (1998) Pyroclastic surges and compressible two-phase flow. In: Freund A, Rosi M (eds) From magma to tephra. Elsevier, Amsterdam, pp 247-312

Wohletz KH, Sheridan MF (1979) A model of pyroclastic surge. Geol Soc Am Spec Pap 180:177-194
Wohletz KH, Valentine GA (1990) Computer simulations of explosive volcanic eruptions. In: Ryan MP (ed) Magma transport and storage. Wiley, New York, pp 113-135

Wohletz KH, McGetchin TR, Sandford MT, Jones EM (1984) Hydrodynamic aspects of caldera-forming eruptions: numerical models. J Geophys Res 89:8269-8285

Woods A (2000) Dynamics of hazardous volcanic flows. Phil Trans Royal Soc London 358:1705-1724

Woods AW, Sparks RSJ, Batey J, Gladstone C, Ritchie LJ, Bursik M (2002) The generation of vertically stratified pyroclastic density currents by rapid decompression of a pressurised volcanic dome on 26 December (Boxing Day) 1997 at Soufrière Hills volcano, Montserrat. In: Druitt T, Kokelaar BP (eds) The eruption of Soufrière Hills volcano, Montserrat, from 1995-1999. Mem Geol Soc London 21:457-465

Yamamoto T, Suto S (1996) Eruptive history of Bandai volcano, NE Japan, based on tephrostratigraphy. Bull Geol Surv Japan 47:335-359

Young SR, Voight B, Barclay J, Herd R, Komorowski JC, Miller AD, Sparks RSJ, Stewart RC (2002) Hazards implications of small-scale edifice instability and sector collapse: a case-history from Soufrière Hills Volcano, Montserrat. In: Druitt T, Kokelaar BP (eds) The eruption of Soufrière Hills volcano, Montserrat, from 1995-1999. Mem Geol Soc London 21:349-363

Zimanowski B (1998) Phreatomagmatic explosions. In: Freundt A, Rosi M (eds) From magma to tephra. Elsevier, Amsterdam, pp 25-54 